NBER WORKING PAPER SERIES

\title{
HUMAN CAPITAL POLICY
}

\author{
Pedro Carneiro
}

James Heckman

Working Paper 9495

http://www.nber.org/papers/w9495

\author{
NATIONAL BUREAU OF ECONOMIC RESEARCH \\ 1050 Massachusetts Avenue \\ Cambridge, MA 02138 \\ February 2003
}

James Heckman is Henry Schultz Distinguished Service Professor at the University of Chicago and Senior Fellow of the American Bar Foundation. Pedro Carneiro is a graduate student at the University of Chicago. The research reported here was supported by the National Science Foundation grants SES-93-21-048, 97-30657, and 00-99-195; NICHD grant R01-34598-03; NIH grant R01-HD32058-03, and the American Bar Foundation. Carneiro was funded by Fundacao Ciencia e Tecnologia and Fundacao Calouste Gulbenkian. We have benefited from comments received from David Bravo, Mark Duggan, Lars Hansen, Robert LaLonde, Steve Levitt, Dayanand Manoli, Dimitriy Masterov, Casey Mulligan, Derek Neal, Flavio Rezende-Cunha and Je. Smith on various aspects of this paper. We have benefited from comments on the first draft received from George Borjas, Eric Hanushek, Larry Katz, Lance Lochner, Lisa Lynch and Larry Summers. Dayanand Manoli and Dimitriy Masterov provided valuable research assistance for which we are grateful. This work draws on and substantially extends Heckman (2000) and Heckman and Lochner (2000). Correspondence to: James J. Heckman, Department of Economics, University of Chicago, 1126 E. 59th Street, Chicago IL 60637 USA. The views expressed herein are those of the authors and not necessarily those of the National Bureau of Economic Research.

(C)2003 by James Heckman and Pedro Carneiro. All rights reserved. Short sections of text not to exceed two paragraphs, may be quoted without explicit permission provided that full credit including notice, is given to the source. 
Human Capital Policy

James Heckman and Pedro Carneiro

NBER Working Paper No. 9495

February 2003

JEL No. I2, I28

\section{$\underline{\text { ABSTRACT }}$}

This paper considers alternative policies for promoting skill formation that are targetted to different stages of the life cycle. We demonstrate the importance of both cognitive and noncognitive skills that are formed early in the life cycle in accounting for racial, ethnic and family background gaps in schooling and other dimensions of socioeconomic success. Most of the gaps in college attendance and delay are determined by early family factors. Children from better families and with high ability earn higher returns to schooling. We find only a limited role for tuition policy or family income supplements in eliminating schooling and college attendance gaps. At most $8 \%$ of American youth are credit constrained in the traditional usage of that term. The evidence points to a high return to early interventions and a low return to remedial or compensatory interventions later in the life cycle. Skill and ability beget future skill and ability. At current levels of funding, traditional policies like tuition subsidies, improvements in school quality, job training and tax rebates are unlikely to be effective in closing gaps.

Pedro Carneiro

Department of Economics

The University of Chicago

1126 E. 59th Street

Chicago, IL 60637

pmcarnei@midway.uchicago.edu
James J. Heckman

Department of Economics

The University of Chicago

1126 East 59th Street

Chicago, IL 60637

and The American Bar Foundation

and NBER

jjh@uchicago.edu 


\section{Introduction and Motivation}

\subsection{Introduction}

The aphorism that the source of a nation's wealth is the skill of its people has special meaning for contemporary American society. Growth in the quality of the workforce has been a major source of productivity growth and economic mobility over the past century. By many measures, since 1980 the quality of the workforce has stagnated or its growth has dramatically slowed down (see Ellwood, 2001; Jorgenson and Ho, 1999; DeLong, Goldin and Katz, 2002). ${ }^{1}$ Figure 1 shows that after a half century of progress, cohorts born after 1950 did not improve much, or at all, on the educational attainment of their predecessors. This is true for Americans of all racial and ethnic backgrounds. Moreover, the stagnation in educational attainment in the aggregate is not due solely to migration. While immigrants are more unskilled, and contribute to growth in the pool of unskilled labor, stagnation in aggregate college participation is also found among native born Americans although immigrants contribute to the growing pool of high school dropouts (Figure 2).

Unpleasant as these numbers are, the official statistics paint an overly optimistic picture because they count exam-certified high school equivalents (GEDs) as high school graduates. According to these statistics the high school graduation rate is increasing and the high school dropout rate decreasing (see Figure 3A). Recent studies (Cameron and Heckman, 1993; Boesel, Alsalam and Smith, 1998; and Heckman, Hsee and Rubinstein, 2001) show that GEDs perform the same in the labor market as high school dropouts with comparable schooling levels. The percentage of measured high school graduates who achieve the degree by route of the GED is growing and is as high as $25 \%$ in some states (see Figure 3B). As a result, the quality of measured high school graduates is declining. When GEDs are classified as dropouts, the U.S. high school dropout rate is increasing (see Figure 3C).

The slowdown in the growth of the quality of the labor force comes in a period of rising wage

\footnotetext{
${ }^{1}$ The slowdown in the growth of labor force quality reduced productivity growth after 1980 by $0.13 \%$ per year. This reduces productivity growth by $8 \%$ (DeLong, Goldin and Katz, 2002).
} 
differentials between skilled and unskilled workers and contributes to the growth in those differentials and to overall wage inequality. The measured wage premium for higher skilled workers began to increase substantially around 1980 (see Autor and Katz, 1999). In response to these economic incentives, children from certain socioeconomic groups increased their college attendance. However, the response has not been uniform across racial, ethnic or family income groups even though the return to schooling has increased for all groups. Adolescent white male high school graduates from the top half of the family income distribution began to increase their college going rate in 1980 (see Figure 4). Those from the third quartile of the family income distribution were less likely to attend college and delayed their response to the rising wage premium for skill. The response was even more delayed for white male high school graduates at the bottom of the family income distribution. The already substantial gaps in college-going widened. Racial and ethnic gaps in attendance differentials also widened (see Figure 5$).{ }^{2}$ Because education is a primary determinant of earnings, these responses to the new market for skills will widen racial, ethnic and family origin wage differentials in the next generation, making the America of tomorrow more unequal.

In the face of declining real wages for low skilled persons and rising real returns to college graduation, the United States is now producing a greater fraction of low skill, dropout youth than it was thirty years ago. College enrollment responses to the rising return to schooling are weak. This is in spite of the growth in per pupil expenditure in public schools over the past 30 years. Together with the decline in high school graduation has come a decline in the performance of American students (Hanushek, 2000). America has an underclass of unskilled and illiterate persons with no counterpart in Northern Europe (see Blau and Khan, 2001).

The problem is clear. The supply of skilled workers is not keeping pace with demand. How to increase the supply in an economically efficient way is not so clear, and there are many advocates of fundamentally different policies that are difficult to compare because their costs and benefits

\footnotetext{
${ }^{2}$ For women, the substantial ethnic, racial and family income gaps did not widen but they did not shrink either. Secular trends dominate the female time series.
} 
are not tabulated. Many recent discussions seize upon the gaps in schooling attainment by family income, evident in Figure 4, as a major causal factor. The growth in tuition costs over the past twenty years and the decline in the earnings of families headed by low skill workers are often cited to explain college attendance patterns (see Carnevale and Fry, 2000 and Hauser, 1993). Policies are proposed to reduce tuition or supplement family resources of children in the college-going years. Yet the evidence presented in this paper suggests that longer term factors such as parental environments and family income available to children over their entire life cycle are far more decisive in promoting college readiness and social attachment than family income in the adolescent years. This evidence suggests that factors operating during the early childhood years and culminating in adolescence in the form of crystallized cognitive abilities, attitudes, and social skills play far more important roles than tuition or family credit constraints during the college-going years in explaining minority-majority gaps in socioeconomic attainment. It suggests that tuition policy may be much less effective than policies that foster cognitive abilities.

In this paper we critically examine the claim that liquidity constraints in the college going years play a fundamental role in explaining the gaps evident in Figure 4. We present evidence that a small group of people is credit-constrained in this short run sense, and that policies that relieve such constraints may be cost effective. Nonetheless, relieving all short-term credit constraints is unlikely to substantially reduce gaps in schooling participation.

We also suggest a variety of other policies to improve the quality of skills in the American economy. Policies to improve the quality of secondary schools are often put forward, and debates over such policies are intense. We argue that they are unlikely to have any substantial effect unless more fundamental reforms in incentives in schools are made. Second chance remediation programs such as publicly provided job training or exam certification as an alternative to conventional high school graduation (GED programs) are sometimes suggested as low cost, effective strategies to overcome early disadvantage. We show that the economic return to such programs is low. Tax and subsidy policies are also advocated. We find that they are likely to have only modest effects 
on skill formation. Policies to limit the immigration of the unskilled are proposed to alleviate the downward pressure on wages and to reduce inequality (Borjas, 1999). We argue that such policies are likely to be ineffective.

There is no shortage of policy proposals. There is, however, a shortage of empirical evidence on the efficacy of these policies. No common framework has been used to evaluate them. The goal of this paper is to provide evidence on the effectiveness of alternative polices within a common cost-benefit framework.

This paper analyzes policies that are designed to foster skill formation in the American economy. A central premise of this paper is that effective policy is based on empirically grounded studies of the sources of the problems that the proposed policies address. While it is possible through trial and error to stumble onto effective policies without understanding the sources of the problems that motivate them, a more promising approach to policy formulation is to understand the mechanisms and institutions that produce skill, and to understand how they are related and where they have gone wrong.

These considerations are especially important in the study of skill formation. Human capital accumulation is a dynamic process. The skills acquired in one stage of the life cycle affect both the initial conditions and the technology of learning at the next stage. Human capital is produced over the life cycle by families, schools and firms, although most discussions of skill formation focus on schools as the major producer of skills, despite a substantial body of evidence that families and firms are major producers of abilities and skills. A major determinant of successful schools is successful families. Schools work with what parents bring them. They operate more effectively if parents reinforce them by encouraging and motivating children. Job training programs, whether public or private, work with what families and schools supply them, and cannot remedy 20 years of neglect.

Recent studies in child development (Shonkoff and Phillips, 2000) emphasize that different stages of the life cycle are critical to the formation of different types of abilities. When the op- 
portunities for formation of these abilities are missed, remediation is costly and full remediation is often prohibitively costly. These findings highlight the need to take a comprehensive view of skill formation over the life cycle that is grounded in the best science and economics in order to devise effective policies.

A study of human capital policy grounded in economic and scientific fundamentals improves on a purely empirical approach to policy evaluation that relies on evaluations of programs and policies in place or previously experienced. While any trustworthy study of economic policy must be grounded in data, it is also important to recognize that the policies that can be evaluated empirically are only a small subset of the policies that might be tried. If we base speculation about economic policies on economic fundamentals, rather than solely on estimated "treatment effects" that are only weakly related to economic fundamentals, we are in a better position to think beyond what has been tried to propose more innovative solutions to human capital problems. This paper investigates the study of human capital policy by placing it in the context of economic models of life cycle learning and skill accumulation rather than focusing exclusively on what policies have "worked" in the past.

We use the rate of return, in cases where it is justified, to place different policies on a common footing. Our justification for using the marginal rate of return to human capital compared to the market return on physical capital in evaluating human capital projects is presented in Appendix A. For many, but not all, human capital policies it is an accurate guide to determining where the next dollar should be spent. We also compute present values of alternative policies where possible. Present values are not subject to the criticisms that plague the use of rates of return.

Figure 6 summarizes the major theme of this paper. It plots the rate of return to human capital at different stages of the life cycle for a person of given abilities. The horizontal axis represents age, which is surrogate for the agent's position in the life cycle. The vertical axis represents the rate of return to investment assuming the same investment is made at each age. Ceteris paribus the rate of return to a dollar of investment made while a person is young is higher than the rate 
of return to the same dollar made at a later age. Early investments are harvested over a longer horizon. In addition, because early investments raise the productivity (lower the costs) of later investments, human capital is synergistic. This dynamic complementarity in human investment was ignored in the early work on human capital (Becker, 1964). ${ }^{3}$ Learning begets learning, skills (both cognitive and non-cognitive) acquired early on facilitate later learning. For an externally specified opportunity cost of funds $r$ (represented by the horizontal line with intercept $r$ in Figure 6-1), an optimal investment strategy is to invest less in the old and more in the young. Figure 6-2 presents the optimal investment quantity counterpart of Figure 6-1.

A second interpretation of Figure 6-1 that we develop in this paper is that it is an empirical description of the economic returns to investment at current levels of spending in the American economy: the return to investment in the young is apparently quite high; the return to investments in the old and less able is quite low. A socially optimal investment strategy would equate returns across all investment levels. A central empirical conclusion of this paper is that at current investment levels, efficiency in public spending would be enhanced if human capital investment were directed more toward the young and away from old, unskilled and illiterate persons for whom human capital is a poor investment.

Our analysis challenges the conventional point of view that equates skill with intelligence, and draws on a body of research that demonstrates the importance of both cognitive and non-cognitive skills in determining socioeconomic success. Both are affected by families and schools but they differ in their malleability over the life cycle with non-cognitive skills being more malleable than cognitive skills at later ages. Cognitive and non-cognitive differences by family income and family background emerge early and persist. If anything, schooling widens these early differences.

Current educational policy and economic analysis focuses on tested academic achievement as

\footnotetext{
${ }^{3}$ Write $H(a)$ as the stock of human capital at age $a$ and $\dot{H}(a)$ as the rate of increase in the human capital stock. Generalizing the celebrated Ben-Porath model (1967) we obtain that human capital production is governed by $\dot{H}(a)=F(H(a), I(s), a)$, where $I(a)$ is the rate of investment for each age and where the stock of human capital and the production function depend on the stage of the life cycle. Dynamic complementarity arises if $\frac{\partial^{2} F}{\partial H(a) \partial I(a)^{\prime}}$ is a positive matrix (all elements are positive).
} 
the major output of schools. Proposed performance evaluation systems are often premised on that idea. Economic models of signalling and screening assume that predetermined cognitive ability is an important determinant if not the important determinant of academic and economic success. Recent evidence challenges these views. No doubt, cognitive ability is an important factor in schooling and labor market outcomes. At the same time, non-cognitive abilities, while harder to measure, also play an important role.

Non-cognitive abilities matter both for success in the labor market and in schooling. These findings are supported by studies of early childhood interventions that primarily improve noncognitive skills, with substantial effects on schooling and labor market outcomes, but only weakly affect cognitive ability. Mentoring programs in the early teenage years can also affect these traits. Current analyses of skill formation focus too much on cognitive ability and too little on non-cognitive ability in evaluating human capital interventions.

We also depart from the conventional human capital literature in another respect. The early literature stressed that human capital theory was an alternative to ability-based models of earnings. In our analysis, cognitive ability is affected by schooling and family background. Schooling does not equalize differences in cognitive ability. Cognitive ability is a form of human capital and not a rival to it.

This paper also stresses the need for clear analytical frameworks for comparing alternative policies. Good economic policy evaluation accounts for the limited size of the government budget and the opportunity costs of public funds. Saying that an educational project earns a $10 \%$ rate of return and should be supported is a meaningless statement unless the opportunities forgone, including the other projects and the costs of tax revenues, are properly accounted for. We emphasize the importance of cost-benefit analyses that properly account for the full costs of policies, including the social opportunity costs of funds for public projects. Many analyses of human capital programs ignore direct costs and the costs of taxation in presenting cost-benefit calculations. When they are counted properly, many apparently successful policies are shown to be economically unprofitable. 
It is important to account for the policies in place when evaluating new policies that are introduced to supplement existing efforts. One should distinguish statements about a world in which there is no human capital policy from the world in which we live. The relevant question for this paper is whether we should increase current subsidies to education and job training, and not whether there should be any subsidies at all. At a very low level of expenditure, increasing schooling quality is known to improve schooling outcomes. Increasing the level of schooling undoubtedly produces externalities when schooling is at a low level. However, the current subsidy of direct costs to students at major public universities in the U.S. is around $80 \%$ and the rate is even higher for secondary and primary schools.

One topic we do not discuss is the case for subsidies due to human capital externalities. While such externalities have received prominent play in the recent revival of growth theory, no evidence for them at the current level of spending has been found. An accumulating body of evidence (Acemoglu and Angrist, 2001; Heckman, Layne-Farrar and Todd, 1996; Heckman and Klenow, 1998 and others) suggests that these theoretical possibilities are empirically irrelevant.

This paper is organized into three parts. Part 2 lays the foundation for our policy analysis by examining the sources of skill disparities. A major premise of our paper is that good policy is based on a clear understanding of the problems that the policies are intended to address. We seek to elevate the discussion of skill formation policy above the level of the standard treatment effect approach which discusses what "works" and what does not. In Section 2.1, we present evidence on the relative importance of short term credit constraints and cognitive ability in accounting for disparities in educational attainment (Evidence on job training is presented in Part 3). In Section 2.2 , we present evidence on the early origin of cognitive ability differentials and their determinants. In Section 2.3, we present a similar analysis of non-cognitive skills.

Part 3 draws on the analysis of Part 2 and discusses specific policies. Section 3.1 discusses policies designed to improve primary and secondary schooling. We demonstrate the ineffectiveness of policies designed to improve schooling quality at existing levels of expenditure without reforms 
in incentives and choices in schools. They are ineffective in a cost benefit sense. Section 3.2 discusses the evidence on early childhood policies. The greatest effect of early childhood programs is on non-cognitive skills, motivation and achievement, not on I.Q. Section 3.3 discusses adolescent mentoring policies. What we know about them is that they are effective and operate primarily through motivation of participants. Section 3.4 discusses the evidence on the effectiveness of both public and private job training programs. While some public programs are successful, most are not. Private training is much more successful. We present evidence that private training reinforces early differentials in ability and schooling but compensates for early disadvantages in access to funds. This latter feature of private training tends to offset the dynamic complementarity of the former feature. On net, job training is neutral with respect to family background. Section 3.5 discusses tax and subsidy policy. Tax policy is an unlikely vehicle for eliminating skill differentials. Section 3.6 discusses the problem of the transition and the likely effectiveness of wage subsidies. Section 3.7 briefly discusses migration policy. The separation of Parts 2 and 3 is far from exact. Some of the evidence on the skill formation process is obtained from analyzing specific policies. Part 4 concludes. We present an appendix on rates of return and discount rates.

\section{Sources of Skill Differences}

\subsection{The Evidence on Credit Constraints}

There is a strong relationship between family income and college attendance. Figure 4 displays aggregate time series college participation rates for 18-24 year-old American males classified by their parental income. Parental income is measured in the child's late adolescent years. There are substantial differences in college participation rates across family income classes in each year. This pattern is found in many other countries (see the essays in Blossfeld and Shavit, 1993). In the late 1970s or early 1980s, college participation rates start to increase in response to rising returns to schooling, but only for youth from the top family income groups. This differential educational 
response by income class promises to perpetuate or widen income inequality across generations and among race and ethnic groups.

There are two, not necessarily mutually exclusive, interpretations of this evidence. The common interpretation of the evidence and the one that guides current policy is the obvious one. Credit constraints facing families in a child's adolescent years affect the resources required to finance a college education. A second interpretation emphasizes more long-run factors associated with higher family income. It notes that family income is strongly correlated over the life cycle. Families with high income in the adolescent years are more likely to have high income throughout the child's life at home. Better family resources in a child's formative years are associated with higher quality of education and better environments that foster cognitive and non-cognitive skills.

Both interpretations of the evidence are consistent with a form of credit constraint. The first, more common, interpretation is clearly consistent with this point of view. But the second interpretation is consistent with another type of credit constraint: the inability of the child to buy the parental environment and genes that form the cognitive and non-cognitive abilities required for success in school. This interpretation renders a market failure as a type of credit constraint. ${ }^{4}$

This paper argues on quantitative grounds that the second interpretation of Figure 4 is by far the more important one. Controlling for ability formed by the early teenage years, parental income plays only a minor role. The evidence from the US presented in this paper suggests that at most $8 \%$ of American youth are subject to short-term liquidity constraints that affect their post-secondary schooling. Most of the family income gap in enrollment is due to long-term factors that produce the abilities needed to benefit from participation in college.

In this section, we first summarize the evidence against an influential argument advanced by Card $(1999,2001)$ and others. That argument claims that the evidence that instrumental variables (IV) estimates of the wage returns to schooling (the Mincer coefficient) exceed least squares esti-

\footnotetext{
${ }^{4}$ The suggested market failure is somewhat whimsical since the preferences of the child are formed, in part, by the family into which he/she is born. Ex post, the child may not wish a different family, no matter how poor the family.
} 
mates (OLS) is evidence of the importance of short-term credit constraints. We discuss why this argument is uninformative about the presence or absence of short term credit constraints.

We also consider other arguments advanced in the literature in support of the empirical importance of short-term credit constraints: (1) Kane (1994) claims that the sensitivity of college enrollment to tuition is greater for people from poorer families. Greater tuition sensitivity of the poor, even if empirically true, does not prove that they are constrained. Kane's empirical evidence has been challenged by Cameron and Heckman (1999, 2001). Conditioning on ability, responses to tuition are uniform across income groups. (2) Cameron and Heckman also show that adjusting for long-term family factors (measured by ability or parental background) mostly eliminates ethnic-racial gaps in schooling. We extend their analysis to eliminate most of the family income gaps in enrollment by conditioning on long-term factors. (3) We also examine a recent qualification of the Cameron-Heckman analysis by Ellwood and Kane (2000), who claim to produce evidence of substantial credit constraints. For several dimensions of college attendance adjusting for long-term factors eliminates any role for short-term credit constraints associated with family income. (4) We also scrutinize the arguments advanced in support of short-term credit constraints that (a) the rate of return to human capital is higher than that of physical capital and (b) rates of return to education are higher for individuals from low-income families. We also review some of the main findings in the empirical literature.

The evidence assembled in this section suggests that the first order explanation for gaps in enrollment in college by family income is long run family factors that are crystallized in ability. Short-run income constraints play a role, albeit a quantitatively minor one. There is scope for intervention to alleviate these short-term constraints, but one should not expect to substantially eliminate the enrollment gaps in Figure 4 by eliminating such constraints. 


\subsubsection{Family Income and Enrollment in College}

The argument that short-term family credit constraints are the most plausible explanation for the relationship depicted in Figure 4 starts by noting that human capital is different from physical capital. With the abolition of slavery and indentured servitude, there is no asset market for human capital. People cannot sell rights to their future labor earnings to potential lenders in order to secure financing for their human capital investments. Even if they could, there would be substantial problems in enforcing performance of contracts on future earnings given that persons control their own labor supply and the effort and quality of their work. The lack of collateral and the inability to monitor effort are widely cited reasons for current large-scale government interventions to finance education.

If people had to rely on their own resources to finance all of their schooling costs, undoubtedly the level of educational attainment in society would decline. To the extent that subsidies do not cover the full costs of tuition, persons are forced to raise tuition through private loans, through work while in college or through foregone consumption. This may affect the choice of college quality, the content of the educational experience, the decision of when to enter college, the length of time it takes to complete schooling, and even graduation from college. Children from families with higher incomes have access to resources that are not available to children from low income families, although children from higher-income families still depend on the good will of their parents to gain access to those funds. Limited access to credit markets means that the costs of funds are higher for the children of the poor, and this limits their enrollment in college. ${ }^{5}$ This story apparently explains the evidence that shows that the enrollment response to the rising educational premium that began in the late 1970s or early 1980s was concentrated in the top half of the family income distribution.

\footnotetext{
${ }^{5}$ Evidence on educational responses to tuition subsidies is sometimes mistakenly interpreted as evidence on credit constraints. The purchase of education is governed by the same principles that govern the purchase of other goods. The lower the price, the more likely are people to buy the good. Dynarski (2000) presents recent evidence about the strength of these tuition effects that is consistent with a long line of research. In addition, there is, undoubtedly, a consumption component to education. Families with higher incomes may buy more of the good for their children and buy higher quality education as well. This will contribute to the relationship displayed in Figure 4.
} 
Low-income whites and minorities began to respond to the rise in the return to college education only in the 1990s. The reduction in the real incomes of families in the bottom half of the family income distribution coupled with a growth in real tuition costs apparently contributes to growing disparity between the college attendance of the children of the rich and of the poor.

An alternative interpretation of the same evidence is that long-run family and environmental factors play a decisive role in shaping the ability and expectations of children. Families with higher levels of resources produce higher-quality children who are better able to perform in school and take advantage of the new market for skills.

Children whose parents have higher income have access to better quality primary and secondary schools. Children's tastes for education and their expectations about their life chances are shaped by those of their parents. Educated parents are better able to develop scholastic aptitude in their children by assisting and directing their studies. What is known about cognitive ability is that it is formed relatively early in life and becomes less malleable as children age. By age 14, intelligence as measured by I.Q. tests seems to be fairly well set (see the evidence summarized in Heckman, 1995). Non-cognitive skills appear to be more malleable until the late adolescent years (Heckman, 2000). The influences of family factors present from birth through adolescence accumulate to produce ability and college readiness. By the time individuals finish high school and scholastic ability is determined, the scope of tuition policy for promoting college attendance through boosting cognitive and non-cognitive skills is greatly diminished.

The interpretation that stresses the role of family and the environment does not necessarily rule out short-term borrowing constraints as a partial explanation for Figure 4. However, if the finances of poor but motivated families hinder them from providing decent elementary and secondary schooling for their children, and produce a low level of college readiness, government policy aimed at reducing the short-term borrowing constraints for the college expenses of those children during their college-going years is unlikely to be effective in substantially closing the gaps in Figure 4. Policy that improves the environments that shape ability will be a more effective avenue for 
increasing college enrollment in the long run. The issue can be settled empirically. Surprisingly, little data has been brought to bear on this question until recently.

The following experiment captures the essence of the distinction we are making. Suppose families participate in lotteries that are adjusted to have the same expected present value (at age zero of the child) but have different award dates. Credit markets are assumed to be imperfect, at least in part, so the timing of receipts matters. A family that wins in the child's adolescent years is compared to a family that wins in the child's early formative years. The child from the family that wins late would lack all of the benefits of investment in the early years of the child that the child from the family that wins early would receive. The child from the late-winning family would be likely to have lower level of cognitive and non-cognitive abilities than the child from the early-winning family. While none of the data we possess are as clean as the data generated by this hypothetical experiment, taken as a whole they point in the same general direction.

In this subsection, we critically examine the evidence in the literature and present new arguments and evidence of our own. There is evidence for both short-run and long-run credit constraints. Long-run family influence factors produce both cognitive and non-cognitive ability that vitally affect schooling. Differences emerge early and, if anything, are strengthened in school. Conditioning on long-term factors eliminates most of the effect of family income in the adolescent years on college enrollment decisions for most people, except for a small fraction of young people. We reach similar conclusions about other dimensions of college participation - delay of entry, final graduation, length of time to complete school and college quality. For some of those dimensions, adjusting for long-run factors eliminates or even over-adjusts the family income gaps. At most, $8 \%$ of American youth are constrained. Credit constraints in the late adolescent years play a role for a small group of youth who can be targeted.

Before turning to our main evidence, we briefly review and criticize the argument that comparisons between IV and OLS estimates of the returns to schooling are informative about the importance of credit constraints. 


\subsubsection{OLS, IV and Evidence On Credit-Constrained Schooling}

A large body of literature devoted to the estimation of "causal" effects of schooling has found that in many applications instrumental variable estimates of the return to schooling exceed ordinary least squares estimates (see Griliches, 1977; Card, 1999, 2001). Researchers have used compulsory schooling laws, distance to the nearest college or tuition as their instruments to estimate the return to schooling.

Since IV can be interpreted as estimating the return to schooling for those induced to change their schooling status by the selected instrument, finding higher returns for changers suggests that they are credit-constrained persons who face higher marginal costs of schooling. This argument has become very popular in recent research in the economics of education (see e.g. Kane, 2001, and DeLong, Goldin and Katz, 2002).

For three reasons, this evidence is not convincing on the issue of the existence of credit constraints. First, the validity of the instruments used in this literature is questionable (Carneiro and Heckman, 2002). These instruments systematically bias upward the estimated return to schooling. Second, even granting the validity of the instruments, the IV-OLS evidence is consistent with empirically well established models of self-selection or comparative advantage in the labor market even in the absence of credit constraints (Carneiro, Heckman and Vytlacil, 2001 and Carneiro and Heckman, 2002). Third, the argument ignores the quality margin. One manifestation of credit constraints is lower-quality schooling. Students will attend two-year schools instead of four-year schools, or will attend lower-quality schools at any level of attained years of schooling. This leads to a lower Mincer return to credit constrained people induced to attend schooling. For further elaboration of these arguments see Carneiro and Heckman (2002).

An additional criticism of this literature is that, in general, IV does not identify the creditconstrained people for whom it would be useful to target an intervention. Using a direct method like the one described next we can identify a group of high-ability people who are not going to 
college and we can target policy interventions towards them.

\subsubsection{Adjusting Family Income Gaps by Ability or Other Long-Term Family Factors}

A more direct approach to testing the relative importance of long-run factors vs. short-run credit constraints in accounting for the evidence in Figure 4 is to condition on long-run factors and examine if there is any additional role for short-run credit constraints. Conditioning on observables also offers the promise of identifying specific subgroups of persons who might be constrained and who might be targeted by policies.

Cameron and Heckman $(1998,1999,2001)$ compare the estimated effects of family background and family income on college attendance, controlling for scholastic ability (AFQT). Measured scholastic ability is influenced by long-term family and environmental factors, which are in turn produced by the long-term permanent income of families. To the extent that the influence of family income on college attendance is diminished by the inclusion of scholastic ability in an analysis of college attendance, one would conclude that long-run family factors crystallized in AFQT scores are the driving force behind schooling attainment, and not short-term credit constraints. Fitting a life cycle model of schooling to a subsample of the NLSY data on youth with AFQT measured before high school graduation, Cameron and Heckman examine what portion of the gap in school attendance at various levels between minority youth and whites is due to family income, to tuition costs, and to family background. ${ }^{6}$ They find that when they do not control for ability measured at an early age, about half ( 5 points) of the 11 point gap between black and white college attendance rates is due to family income; more than half (4 points) of the 7 point difference between Hispanics and whites is due to family income. When scholastic ability is accounted for, only one half of one point of the 11 point black-white gap is explained for family income. For Hispanics, the gap actually widens when family income is included in the empirical model. Equalizing ability more than accounts for minority-majority college attendance gaps. Comparable results are obtained when

\footnotetext{
${ }^{6}$ See BLS (2001) for a description of the NLSY data.
} 
they adjust for parental education and family structure. ${ }^{7}$ The effects of tuition on college entry are also greatly weakened when measures of ability are included. Ability and not financial resources in the teenage years accounts for pronounced minority-majority differences in schooling attainment. The disincentive effects of college tuition on college attendance are dramatically weakened when ability is included in the analysis of college attendance. This analysis suggests that it is long-run factors that determine college attendance, not short-term borrowing constraints, that explain the evidence in Figure 4.

It is sometimes claimed that the enrollment responses to tuition should be larger for constrained (low-income) persons (see Kane, 1994, and the survey in Ellwood and Kane, 2000). This does not follow from any rigorous argument. ${ }^{8}$ Table 1, taken from Cameron and Heckman (1999), explicitly addresses this issue empirically. It reports estimates of tuition responses by family income in the adolescent years of the child not adjusting and adjusting for AFQT (see panels B and C, respectively). ${ }^{9}$ Even without adjusting for AFQT, there is no pattern in the estimated tuition response by family income level. When the authors condition on ability, tuition effects become smaller (in absolute value) and no pattern by family income is apparent. Even if the argument had theoretical validity, there is no empirical support for it.

\footnotetext{
${ }^{7}$ The authors condition on an early measure of ability not contaminated by the feedback from schooling to test scores that is documented in Hansen, Heckman and Mullen (2002).

${ }^{8}$ Mulligan (1997) shows that, in the context of a Becker-Tomes model, tuition elasticities for human capital accumulation are greater (in absolute value) for unconstrained people. His proof easily generalizes to more general preferences (results are available on request from the authors). By a standard argument in discrete choice, Kane's claim cannot be rigorously established. Let $S=1$ if $I(t, X) \geq \varepsilon$ where $I$ is an index of net benefit from college, $t$ is tuition, $\frac{\partial I}{\partial t}<0$ and $X$ are other variables, including income. $\varepsilon$ is an unobservable psychic cost component. Then assuming that $\varepsilon$ is independent of $t, X$,

$$
\operatorname{Pr}(S=1 \mid t, X)=\int_{-\infty}^{I(t, X)} f(\varepsilon) d \varepsilon
$$

where $f(\varepsilon)$ is the density of psychic costs. Then

$$
\frac{\partial \operatorname{Pr}(S=1 \mid t, X)}{\partial t}=\left[\frac{\partial I(t, X)}{\partial t}\right] f(I(t, X)) .
$$

For constrained persons with very low income, $I(t, X)$ is small. Depending on the density of $\varepsilon$, the location of $I(t, X)$ in the support of the density, and the value of $\frac{\partial I(t, X)}{\partial t}$, constrained persons may have larger or smaller tuition responses than unconstrained persons. Thus if $\varepsilon$ is normal, and $I(t, X) \longrightarrow-\infty$ for constrained people, if the derivative is bounded, the tuition response is zero for constrained people.

${ }^{9}$ Standard errors are not presented in their paper but test statistics for hypothesis of equality are presented.
} 
Ellwood and Kane (2000) accept the main point of Cameron and Heckman that academic ability is a major determinant of college entry. At the same time, they argue that family income operates as an additional constraint, not as powerful as academic ability, but more easily addressed by policy than ability. Figure 7 presents our version of their case using data from the National Longitudinal Survey of Youth for 1979. Classifying people by ability there is a clear ordering that more able people are more likely to go to college. Classifying white males by their test score terciles, we further display college enrollment rates by family income. There is a clear ordering in the highability group and in other ability groups as well. Persons from families with higher income are more likely to enroll in college. This ordering occurs in other data sets, even for low-ability groups.

These plots indicate a subsidiary, but still quantitatively important role for family income in accounting for schooling enrollment. Does this mean that short-run credit constraints are operative in the college-going years? Not necessarily. Family income in the adolescent years is strongly correlated with family income throughout the life cycle. In addition, long-run family resources are likely to produce many skills that are not fully captured by a single test score.

When we control for early family background factors (parental education, family structure and place of residence) we greatly weaken this relationship. Tables 2-A and 2-B report overall adjusted gaps for the five dimensions of college participation listed in the first column. For each measure, within each AFQT tercile and income quartile we adjust the raw rates for the background variables listed at the base of the table. Plots of the adjusted rates for three of these measures are presented in Figures 7-1B, 7-1D and 7-1F corresponding to Figures 7-1A, 7-1C and 7-1E respectively. The estimates in Table 2 report weighted averages of the differences in adjusted rates between the highest income quartiles within each ability tercile averaged over all three ability terciles and over income quartiles within each ability tercile. The weights are the population proportion in each cell. They are measures of the adjusted discrepancy in participation rates by income controlling for long-term factors and are an estimate for the importance of short-term credit constraints. Focusing on enrollment (first row), we find that only $5.2 \%$ of all white males are constrained relative to 
the top income group. Figure 7-1B plots the adjusted family income gaps by the three different ability terciles for college enrollment using the regressors reported in Table 2-A Table 2-B reports the results for the statistically significant gaps alone ${ }^{10}$. They are generally much smaller.

Most of the analysis in the literature focuses on college enrollment and much less on other dimensions of college attendance such as completion, quality of school and delay of entry into college. ${ }^{11}$ In part, this emphasis is due to reliance on CPS data which are much more reliable for studying enrollment-family income relationships than completion-family income relationships.

Using the NLSY79 data we look at four other dimensions of college participation. The remaining panels of Tables 2-A and 2-B report estimates of the credit-constrained for these dimensions. When we perform a parallel analysis for completion of four-year college, we find no evidence of constraints for white males and in fact over-adjust college enrollment. Figures 7-1C and 7-1D present the raw and adjusted gaps for completion of four-year college. Figures $7-1 \mathrm{E}$ and $7-1 \mathrm{~F}$ are the raw and adjusted gaps for delay of entry into college ${ }^{12}$. There is no evidence of short-run credit constraints in these dimensions. In results available from the authors on request, there is evidence of short-run credit constraints for the "dumb poor" in completing two years of college, but not for the "bright poor". There is weak evidence in certain cells for short-term credit constraints in years of delay of entry and for choice of two-year vs. four-year colleges, which is a measure of quality. Depending on the measure of college participation selected, the estimated percent of white males constrained ranges from 0 to $9 \%$. Setting statistically insignificant gaps to zero we obtain a much smaller range of values (0-7\%). We obtain comparable results for other demographic groups.

Overall, the estimated percent constrained ranges from $8 \%$ (for completion of two year college) to zero percent for completion of four year college. The strongest evidence for short-term credit constraints is for Hispanic males. For this group, illegality of many Hispanics may make them

\footnotetext{
${ }^{10}$ These tables are constructed using the coefficients of the regressions in Table B-1. These regressions are described at the base of Table 2 .

${ }^{11}$ Work in school is studied in Keane and Wolpin (2001). Delay in entry is studied in Kane (1996).

${ }^{12}$ These graphs are constructed using the coefficients of the regressions in Table B-3. These regressions are described at the base of figure $7-1$.
} 
appear to be constrained because they do not have the same eligibility for schooling aid as legals. The weakest evidence for credit constraints is for black males. On many dimensions for this group, the effective constraint is zero. There is little evidence that short term credit constraints explain much of the gap in college participation.

The analysis just presented is strongly suggestive but is not definitive. Many of the variables that we condition on to control for long term family factors also predict family income in the adolescent years. There is still independent variation in family income controlling for these variables but much of it may be captured by the long run factors.

We present two additional pieces of evidence to bolster the point made in Tables 2-A and 2-B. First, in Tables 2-C and 2-D, we reverse the roles of family income in the adolescent years and family background. We create an index of family background, defined precisely at the base of those tables (and in appendix Table B-4), and classify persons on the basis of quartiles of this index. The index includes a child's ability, parental education and location. This index strongly predicts the various college participation decisions. When we condition further on family income in the adolescent years (Table 2-C) a strong family background effect remains. This is true even if we report only statistically significant estimates (Table $2-\mathrm{D})^{13}$. Figure $7-2$ graphically records the results of this analysis. The gaps by family status are not substantially affected by adjusting for family income in the adolescent years.

Further evidence on the unimportance of short-run credit constraints on college attendance is reported in Table 3. It reports estimates of child enrollment in college on family per capita permanent income and on family per capita income flows received at other stages of the life cycle. Permanent income is formed as an average discounted income flow to the family over the life of the child at home (ages 0-18). ${ }^{14}$

Two features are clear from this table: (a) permanent income matters a lot and (b) given

\footnotetext{
${ }^{13}$ These tables are constructed using the coefficients of the regressions in Table B-2. These regressions are described at the base of Table 2 .

${ }^{14}$ We obtain the same empirical patterns reported in the text whether or not we use per capita income measures.
} 
permanent income, transitory income flows matter little. Early income and late income have positive but small and statistically insignificant effects (see column 4) but late income has, if anything, a slight negative effect. The evidence in Table 3 suggests that short term income constraints are not binding. ${ }^{15}$

Policies that improve the financing of the education of identified constrained subgroups will increase their human capital and may well be justified on objective cost-benefit criteria. The potential economic loss from delay can be substantial. If $V$ is the economic value of attending school, and schooling is delayed one year, then the costs of delay of schooling by one year are $\frac{r}{1+r} V$ where $r$ is the rate of return. For $r=.10$, which is not out of line with estimates in the literature, this delay is $9 \%$ of the value of lifetime schooling (roughly $\$ 20,000$ ). For these groups, the benefits to reducing delay, and promoting earlier college completion, higher college quality and graduation, are likely to be substantial.

In designing policies to harvest this benefit, it is important to target the interventions toward the constrained. Broad-based policies generate dead weight. For example, Dynarski (2001) and Cameron and Heckman (1999) estimate that 93\% of President Clinton's Hope Scholarship Funds, which were directed towards middle-class families, were given to children who would attend school even without the program.

While targeting the identified constrained may be good policy, it is important not to lose sight of the main factors accounting for the gaps in Figure 4. Family background factors crystallized in ability are the first order factors explaining college attendance and completion gaps.

These differences in average ability appear at early ages and persist. We discuss the sources

\footnotetext{
${ }^{15}$ The evidence in Table 3 apparently runs counter to widely cited evidence reported by Duncan and Brooks-Gunn (1997, Table 18.3). They show that family income at an early age has a stronger effect on child completed schooling than family income at later ages. They do not control for total family income (permanent income). Their evidence does not contradict our evidence. Permanent income is $P=\sum_{t=0}^{18} \frac{1}{(1+r)^{t}} Y_{t}$. In a model in which only permanent income mattered: $S=\gamma_{0}+\gamma_{1} P$ the coefficient on early income entered as a separate regressor would necessarily be larger than the coefficient on later income unless $r=0$. Controlling for permanent income $P$ (as they do not), there would be no effect of income receipts at any age. This is what we find. When we exclude permanent income from the regression in Table 3 we find strong effects of average income at ages 0 through 5 and weak effects of average income at ages 16 through 18 . These results are available on request from the authors.
} 
of these differences in the next section. A major conclusion of this paper is that the ability that is decisive in producing schooling differentials is shaped early in life. If we are to substantially eliminate ethnic and income differentials in schooling, we must start early, and we cannot rely on tuition policy applied in the child's adolescent years to compensate for neglect of the early years.

At the same time, policies to foster early abilities are known to be costly. The mechanisms generating ability remain to be fully explored. Policies that efficiently target the short-run constrained are likely to pass a rigorous cost-benefit test. Policies that foster skill may not be cost effective, although the evidence presented in Section 3 suggests that they are. We next consider other arguments used to support the claim of pervasive short-term credit constraints.

\subsubsection{High Rate of Return to Schooling Compared to the Return on Physical Capital}

Estimates of the rate of return to schooling, based on the Mincer earnings function, are often above $10 \%$ and sometimes are as high as $17 \%$ - 20\%. Estimates based on instrumental variables are especially high. See, for example, the evidence surveyed by Card $(1999,2001)$ and the discussion of the quality of the instruments used in this literature presented in Carneiro and Heckman (2002). It is sometimes claimed that these returns are very high and therefore people are credit-constrained or some other market failure is present.

The cross-section Mincerian rate of return to schooling does not, in general, estimate the marginal internal rate of return to schooling. See Heckman, Lochner and Taber (1998a) for an example where cross-section rates of return are uninformative about the return to schooling that any person faces. Willis (1986) and Heckman, Lochner and Todd (2001) state the conditions under which the Mincerian rate of return will be equal to the marginal internal rate of return to schooling. Even if these conditions are satisfied, implicit comparisons are usually made against a risk-free interest rate. However this is not the relevant comparison for evaluating schooling decisions. Carneiro, Hansen and Heckman $(2001,2002)$ estimate considerable uncertainty in the returns to schooling. We discuss this evidence in Part 3. Illiquidity and irreversibility of human capital investments drive 
the premium on human capital far above the safe interest rate (see Judd, 2000). Comparisons of Mincer returns and returns to capital are intrinsically uninformative about the existence of credit constraints or the need for intervention in human capital markets.

\subsubsection{Are Rates of Return to Schooling Higher for Persons from Low-Income Fami- lies?}

Assuming the same technology of educational investment across families, and no comparative advantage in the labor market, if low-income families are credit-constrained, then at the margin the returns to schooling for constrained children should be higher since they are investing less than the efficient amount. Carneiro and Heckman (2002) establish that if choices are made at the quality margin, the estimated Mincer return may be lower for constrained persons, unless adjustments for quality are made. The empirical literature, which does not adjust for quality, finds that returns to schooling are higher for high-ability people than for low-ability people. See for example Meghir and Palme (1999), Cawley et al.(2000), Taber (2001) or the evidence presented in Section 3.1 below. Family income and child ability are positively correlated so one would expect higher returns to schooling for children of high-income families for just this reason. Altonji and Dunn (1996) find in their preferred empirical specification that the returns to schooling are higher for children of more educated families than for children of less educated families. There is no evidence that rates of return to schooling are higher for children from low-income families than for children from high-income families. ${ }^{16}$

\footnotetext{
${ }^{16}$ The take-up rate on Pell Grants and Perkins Loans targeted towards students from low-income families is low (Orfield, 1992). Many more people are eligible for support than those who claim it. Binding borrowing constraints are not a plausible explanation for the lack of utilization of these potential resources. Kane (1999) suggests that nonmonetary costs of applying for financial aid may be high especially for low income people because the application process is complex. He argues that decreasing these costs may be a more promising avenue for relaxing financing constraints for low income people than expanding existing programs. He provides no evidence on this conjecture. An alternative explanation consistent with our evidence is that many eligible persons perceive that even with a substantial tuition subsidy, the returns to college education for them are too low to pay for the foregone earnings required to attend school. Risk aversion due to the uncertainty of income flows may also reduce the returns relative to the benefits.
} 


\subsubsection{Additional Evidence from the Literature}

Cameron and Heckman (1998) analyze the determinants of grade by grade schooling attainment for cohorts of American males born between 1908 and 1964. Consistent with the notion that family income and family background factors reflect long-run and not short-term influences on schooling attainment, they find that ability and family background factors are powerful determinants of schooling completion from elementary school through graduate school. An appeal to borrowing constraints operating in the college years is not required to explain the relationship between family income and college attendance decisions and the stability of the relationship over long periods of time.

Cameron and Taber (2000) examine the empirical importance of borrowing constraints in a model that incorporates the insight that both schooling choices and returns to schooling will be influenced by borrowing constraints. Using a variety of methods, they find no evidence that borrowing constraints play a role in explaining the years of schooling attained of recent cohorts of American youth. Keane and Wolpin (2001) estimate a more explicit sequential dynamic model and reach the same conclusion. Students are estimated to be short-run constrained but alleviate the constraints through working. Relaxing the budget constraint barely budges schooling decisions but affects work while in school. Neither study looks at delay or quality effects that have been found to be quantitatively important.

Stanley (1999) studies the impact of the G.I. Bill on the college-going decisions of Korean War Veterans. Consistent with our story, he finds that most college subsidies were used by veterans from families in the top half of the socioeconomic distribution. When she studies the effects of the HOPE program in Georgia, Dynarski (2000) finds that it benefits mostly middle and higherincome students. However, the elasticity of enrollment to tuition subsidies in her sample is as high as anywhere else in the literature: middle and higher-income people do not seem to respond less elastically to education subsidies than lower-income people. This is consistent with the evidence 
from Cameron and Heckman (1999) previously discussed. Shea (2000) estimates the effect of a measure of parental income on schooling using the Panel Survey of Income Dynamics (see Hill, 1992, for a description of this data set). Controlling for parental background variables, he finds an effect of his measure of family income on schooling, controlling for ability. However, using instrumental variables he estimates no effect of his measure of family income on schooling attainment and he interprets this result as evidence of no credit constraints. ${ }^{17}$

\subsubsection{Summary of Section 2.1}

In this section we have examined arguments about the strength of credit constraints in schooling that are made in the literature. We evaluate the available evidence and present new evidence using American data.

Some of the evidence in the literature is uninformative on this question. The leading example is the IV-OLS evidence discussed in detail in Carneiro and Heckman (2002). The literature on price effects and tuition subsidies generally is also not very informative on this question since it does not separate price effects from borrowing constraints.

The observed correlation between family income and college attendance can be interpreted as arising in two different ways: from short-run credit constraints or from long-run family effects. The latter are quantitatively more important, even though we identify a group of people (at most $8 \%$ of the population) who seem to be facing short-run credit constraints. The first order factors accounting for the gaps in Figure 4 are long-term factors that cannot easily be offset by tuition policy or supplements to family income in the adolescent years of prospective students.

It is important to stress that all of the empirical analysis reported in this section is for contemporary American society where a substantial edifice of financial aid to support post-secondary

\footnotetext{
${ }^{17}$ Shea splits his sample into children of educated and uneducated parents. He finds an effect of his measure of income on the schooling attainment of the children of the latter. Many interpret this as evidence for short term credit constraints. However Shea's measure of income is an average income over every year the family is sampled irrespective of the age of the child. It is a long run measure of permanent income for some families for which data are available over the life cycle of the family and the child and a short run measure when the sampling process starts in the child's adolescent years. Thus Shea's estimated income effect combines short-run and long-run effects in an uninterpretable fashion and is thus uninformative on the issue of the empirical importance of short run credit constraints.
} 
education is in place. Our assessment of the limited role of short-run credit constraints in explaining contemporary American educational gaps is, no doubt, in part due to the successful operation of policies that were designed to eliminate such constraints. Substantial reductions in the generosity of educational benefits would undoubtedly affect participation in college although they would operate primarily through price effects. However, the evidence in Blossfeld and Shavit (1993), Cameron and Heckman (1998) and Cossa (2000) suggests the universal first order importance of long-term family influences on educational attainment. Gaps in educational attainment related to family background arise in many different environments including those with free tuition and no restrictions on college entry. This evidence points to the powerful role of the long-term factors that we have emphasized in this section of our paper. We next turn to evidence on the sources of these long-term ability differentials.

\subsection{Early Test Score Differentials}

Important differences in ability across family types appear at early ages and persist. Figure 8-A presents plots of average percentile rank in PIAT- Math scores by age and family income quartile. ${ }^{18}$ For all race and ethnic groups, there are important differences by family income quartile in how children rank in cognitive test scores as early as age 6 . These gaps in ranks across income quartile remain stable as children grow and for some test scores they widen. At the same time, just as racial differences in schooling participation rates are evident, similar patterns emerge in early test scores. Figure 8C presents evidence of the emergence of racial gaps in ranks of test scores as measured by PIAT-Math test scores.

The ability that drives schooling participation is shaped early in life. The available evidence

\footnotetext{
${ }^{18}$ The Peabody Individual Achievement Test - Math (PIAT-M) is administered to children ages 5 and older. Results for other test scores such as the Peabody Picture Vocabulary Test, and PIAT-Reading Recognition, PIAT-Reading Comprehension, and Memory for Location are also available upon request. The Memory for Location test is given to children ages 0 to 3 ; by age 1 , test score gaps similar to those presented in this section emerge.

In making this graph, for each person we compute the percentile rank in the distribution of test scores at each age. Then we group individuals in different quartiles of family income and compute the average percentile rank within each group at each age the test is taken. We use ranks because the absolute values of test scores or their growth have no meaning. Any monotonic transformation of a test score is also a valid test score. Use of ranks avoids this difficulty.
} 
indicates that cognitive ability is relatively more malleable early in the life cycle (see Heckman, 1995). Having access to more and higher quality resources that contribute to improving cognitive ability early in life affects skill acquisition later in life.

Figure 9 presents ranks of adjusted test scores gaps in Figure 8 controlling for the long-term family factors listed at the top of the table. The gaps in rank across racial and income groups are significantly reduced when we control for mother's education, mother's ability, and family structure in the test score equation ${ }^{19}$. However, the gaps at age 12 do not disappear when we compare the highest and lowest income quartiles or whites with blacks. Measured long-term family factors play a powerful role but do not fully eliminate the gaps.

Other analysts have also focused their attention on these differences in cognitive ability and have attempted to eliminate the gaps by controlling for more factors. Using data from the Early Childhood Longitudinal Survey (ECLS), Fryer and Levitt (2002) eliminate the black-white test score gap in math and reading scores in early kindergarten by controlling for measures of family background, birth-weight and number of books a child has. ${ }^{20}$ They also find that both the raw and the residualized test score gaps widen with age. If anything, schooling widens this gap, a point emphasized in their paper. They cannot account for this increase using available measures of school quality. Their evidence indicates that socioeconomic background at early ages is a very important determinant of a child's test score. Using data on the Children of the NLSY, Phillips, et al. (1998) also study the black-white test score gap. ${ }^{21}$ They analyze only the PIAT-Math and the Peabody Picture Vocabulary Tests at ages 3-4. They cannot fully eliminate the test score gap using family background, mother's AFQT, and rich measures of family environment, although controlling for these factors substantially reduces these gaps.

\footnotetext{
${ }^{19}$ We first regress the test score on mother's education, mother's AFQT and broken home at the same age the test is taken. We then rank individuals on the residuals of this regression and construct percentiles. The pictures we present show the average percentile by income group at different ages. Figure 9C presents gaps by race. We further include family income at the age of the test in the regression as well as the other variables mentioned above before taking the residuals and constructing the ranks.

${ }^{20}$ Conditioning on a family choice variable is problematic in producing causal relationships. In addition, they analyze one of many cardinalizations of the test score and discuss growth in levels as if they had meaning.

${ }^{21}$ Again, they choose a particular cardinalization.
} 
The emergence of early test score differentials is not only limited to cognitive measures. At early ages, differences in children's behaviors and attitudes across income and racial groups are also evident. Figure 10A illustrates this point. It presents differences in ranks of Anti-Social test scores across different income and racial groups. ${ }^{22}$ It is common knowledge that motivation, trustworthiness and other behavioral skills are important traits for success in life. We consider evidence on the importance of non-cognitive skills in the next section. Hence, understanding these gaps in behavioral skills and how to eliminate them is also important for understanding the determinants of socioeconomic success. Figure 11 presents adjusted ranks of test scores for behavioral measures for mother's ability, mother's AFQT and broken home ${ }^{23}$. Adjusting for early family background factors substantially reduces gaps in ranks in non-cognitive skills. Comparing adjusted cognitive and non-cognitive test scores reveals the importance of long-term factors in reducing the gaps in behavioral scores across income and racial groups. While cognitive ability gaps cannot completely be eliminated at later ages, controlling for mother's ability, family income and family structure and location significantly reduces the gaps in ranks both at early and later ages. $^{24}$

This evidence, like that of the entire literature, is very crude. Good families promote cognitive, social and behavioral skills. Bad families do not. The relevant policy issue is to determine what interventions in bad families are successful. We present evidence on this question after presenting further evidence on the importance of non-cognitive skills. We show in Part 3 that manipulating non-cognitive skills is more feasible (less costly) than manipulating cognitive skills. In addition,

\footnotetext{
${ }^{22}$ The Anti-Social score is calculated on the basis of frequency of dishonest, cruel, non-cooperative, violent or disobedient behaviors (BLS, 2001). We first rank individuals by their Anti-Social scores and then we construct percentiles. The figures plot average percentiles by income and race groups.

${ }^{23}$ We first regress the Anti-Social score on mother's education, mother's AFQT and broken home at the same age the test is taken. We then rank individuals on the residuals of this regression and construct percentiles. The pictures we present show the average percentile by income group at different ages. Figure 11C presents gaps by race. We further include family income at the age the score is measured in the regression as well as the other variables mentioned above before taking the residuals and constructing the ranks.

${ }^{24}$ No meaning can be attached to the absolute levels or growth rates in levels of the test scores since any monotonic transformation of a test score is still a valid test score. However, statements can be made about relative ranks within an overall distribution and how they change.
} 
remediation efforts for non-cognitive skills are effective at later ages. But first we discuss the evidence on the importance of non-cognitive skills for socioeconomic success.

\subsection{The Evidence on the Importance of Non-Cognitive Skills}

Numerous instances can be cited of high I.Q. people who fail to achieve success in life because they lacked self discipline and of low I.Q. people who succeeded by virtue of persistence, reliability and self-discipline. It is thus surprising that academic discussions of skill and skill formation focus almost exclusively on measures of cognitive ability and ignore non-cognitive skills. The early literature on human capital (Becker, 1964) contrasted cognitive ability models of earnings with human capital models, ignoring non-cognitive traits entirely. The signalling literature (Spence, 1974) emphasized that education was a signal of a one-dimensional ability, usually interpreted as a cognitive skill. Most discussions of ability bias in the estimated return to education treat omitted ability as cognitive ability and attempt to proxy the missing ability by cognitive tests. Most assessments of school reforms stress the gain from reforms as measured by the ability of students to perform on a standardized achievement test. Widespread use of standardized achievement and ability tests for admissions and educational evaluation are premised on the belief that the skills that can be tested are essential for success in schooling and in the workplace, a central premise of the educational testing movement since its inception.

Much of the neglect of non-cognitive skills in analyses of earnings, schooling and other lifetime outcomes is due to the lack of any reliable measure of them. Many different personality and motivational traits are lumped into the category of non-cognitive skills. Psychologists have developed batteries of tests to measure non-cognitive skills (Sternberg, 1985). These tests are used by companies to screen workers but are not yet used to ascertain college readiness or to evaluate the effectiveness of schools or reforms of schools. The literature on cognitive tests ascertains that one dominant factor (" $g$ ") summarizes cognitive tests and their effects on outcomes. No single factor has emerged in the literature on non-cognitive skills and it is unlikely that one will ever be found 
given the diversity of traits subsumed under the category of non-cognitive skills.

Studies by Bowles and Gintis (1976), Edwards (1976) and Klein et al. (1991) demonstrate that job stability and dependability are traits most valued by employers as ascertained by supervisor ratings and questions of employers although they present no direct evidence on wages and educational attainment. Perseverance, dependability and consistency are the most important predictors of grades in school (Bowles and Gintis, 1976).

Self-reported measures of persistence, self esteem, optimism, time preference and the like are now being collected and some recent papers discuss estimates of the effects of these measures on earnings and schooling outcomes (see Bowles, Gintis and Osborne, 2001). These studies shed new light on the importance of non-cognitive skills. Yet they are not without controversy. For example, ex post assessments of self-esteem may be as much the consequence as the cause of the measures being investigated.

Heckman and Rubinstein (2001) avoid these problems by using evidence from the GED testing program in the United States to demonstrate the quantitative importance of non-cognitive skills in determining earnings and educational attainment. The GED program is a second-chance program that administers a battery of cognitive tests to self-selected high school dropouts to determine whether or not they are the academic equivalents of high school graduates. Study of the GED program is of interest in its own right. It is a major output of government training programs, including the Job Corps program, as we note in Part 3. GED-certified persons constitute 15\% of all persons certified with new high school credentials.

In this section of the paper we summarize findings reported in Heckman, Hsee and Rubinstein (2001), and Heckman and Rubinstein (2001). The GED exam is successful in psychometrically equating GED test takers with ordinary high school graduates who do not go on to college. Recipients are as smart as ordinary high school graduates who do not go on to college, where cognitive ability is measured by an average of cognitive components of the Armed Forces Qualifying Test (AFQT) or by the first principle component (" $g$ "). By these same measures, GED recipients are 
smarter than other high school dropouts who do not obtain a GED (see Figure 12 which plots AFQT). The pattern is the same for other groups. GED recipients earn more than other high school dropouts, have higher hourly wages and finish more years of high school before they drop out. This is entirely consistent with the literature that emphasizes the importance of cognitive skills in determining labor market outcomes.

Controlling for measured ability, however, GED recipients earn less, have lower hourly wages and obtain lower levels of schooling than other high school dropouts. Some unmeasured factor accounts for their relatively poor performance compared to other dropouts. Heckman and Rubinstein identify this factor as non-cognitive skill recognizing that a subsequent analysis should parcel out which specific non-cognitive factors are the most important.

The GED is a mixed signal. Dropouts who take the GED are smarter (have higher cognitive skills) than other high school dropouts and yet at the same time have lower levels of non-cognitive skills. Both types of skill are valued in the market and affect schooling choices. The findings of Heckman and Rubinstein (2001) challenges the conventional signalling literature which assumes a single skill. It also demonstrates the folly of a psychometrically oriented educational evaluation policy that assumes that cognitive skills are all that matter. Inadvertently, a test has been created that separates out bright but nonpersistent and undisciplined dropouts from other dropouts. It is, then, no surprise that GED recipients are the ones who drop out of school, fail to complete college (Cameron and Heckman, 1993) and who fail to persist in the military (Laurence, 2000). GEDs are "wiseguys" who lack the ability to think ahead, persist in tasks or to adapt to their environments. The performance of the GED recipients compared to both high school dropouts of the same ability and high-school graduates demonstrates the importance of non-cognitive skills in economic life. The study of GEDs is of interest in its own right because they represent a growing proportion of all new high school graduates. 


\subsubsection{Evidence from the GED Program}

The performance of the GED recipients compared to both high school dropouts of the same ability and high-school graduates demonstrates the importance of non-cognitive skills in economic life. GEDs are high school dropouts who obtain high school equivalency certificates through exam certification. The study of GEDs is of interest in its own right because they represent a growing proportion of all new high school graduates and are a principle output of the Job Corps which trumpets its success by its rate of GED production (see our discussion in Section 3).

Boesel et al. (1998) present a comprehensive review of evidence on the GED program. Currently one in two high school dropouts and one in five high school graduates, as classified by the US Census, is a GED recipient. ${ }^{25}$ In a series of papers using National Longitudinal Survey of Youth (NLSY) data (Cameron and Heckman, 1993; Heckman, Hsee and Rubinstein, 2001), the following facts have been established for white males: (i) in unadjusted cross-sectional comparisons, GED recipients earn hourly wage rates and annual earnings substantially less than those of high school graduates and earn slightly more than other high school dropouts. GED recipients also have slightly more years of schooling than other dropouts. Accounting for their higher years of schooling, and for their higher AFQT scores, GED recipients earn less than other high school dropouts, and have lower hourly wages. Similar results for other demographic groups are reported in Heckman (2002). These results are statistically significant. (ii) Controlling for individual fixed effects (person specific unobservables), longitudinal studies reveal that there is no evidence of a permanent effect of GED certification on wages, employment, or job turnover for persons who take the GED after age 17. GED recipients are more likely to change jobs, both before and after taking the exam. (iii) Both cognitive and non-cognitive skills promote educational attainment. (iv) Persons with higher AFQT scores take the GED earlier. This accounts for a larger initial positive effect of GED certification on earnings for younger recipients that disappears with age. (v) In a model that explicitly accounts

\footnotetext{
${ }^{25}$ When GEDs are counted as dropouts, the U.S. high school dropout rate has increased between 1975 and 1998. See Figure 3.
} 
for both unmeasured (or badly measured) cognitive and non-cognitive skills, in the short run GED certification appears to have an effect of boosting wages for persons who take the GED at young ages (younger than 20), holding constant non-cognitive skills, by signalling greater cognitive ability of workers. This effect fades quickly as employers rapidly learn about non-cognitive ability. In the long run, holding ability constant, GED recipients earn lower wages as their adverse non-cognitive characteristics are revealed. (vi) The story for white females is slightly different. Girls who drop out of school because of pregnancy typically do so with fewer years of schooling attained than other girls who drop out. Girls who drop out for reasons other than pregnancy are like teenage boys who drop out (i.e., they earn less than other dropouts conditioning on AFQT or schooling). As for teenage mothers, GED recipients earn the same as other high school dropouts once AFQT scores and years of schooling are accounted for. (vii) There is some suggestion that white male GED recipients show the highest level of participation in (almost) every category of participation in illegal activity, compared to other high-school dropouts. This is true even when the outcomes are not adjusted for differences in AFQT and educational attainment.

It is also true when we drop persons who acquire the GED in prison, or all persons who have been in prison, to avoid a spurious causal relationship arising from prisoners, and hence people with a greater participation in crime, acquiring the GED. The same applies for white females, except for teenage mothers, who are much less likely to get the GED in prison. GED recipients are more likely to participate in illegal drug use, drug selling, fighting in school, vandalism, shoplifting, theft, robberies, and school absenteeism than are other dropouts. ${ }^{26}$ (viii) The labor-force participation and employment rates of GED recipients are lower than those of other dropouts. ${ }^{27}$ Their turnover rates are higher. These rates do not change with the acquisition of the GED. Hence GED recipients accumulate less work experience over the life cycle. (ix) The correlation between AFQT scores and an index of participation in illicit activity defined in Heckman, Hsee and Rubinstein (2001) is

\footnotetext{
${ }^{26}$ Excluding GED recipients, the rate of illegal and delinquent behavior decreases monotonically as education levels rise.

${ }^{27}$ Conditional on AFQT scores and years of schooling completed.
} 
statistically significantly negative in the population at large. Individuals with higher AFQT scores are less likely to participate in illicit behavior. Yet this relationship does not hold within education groups. The correlation between AFQT scores and an index among all high school dropouts and among high school graduates (with 12 years of schooling) is positive and statistically significant. It is especially strong for all dropouts, suggesting that among high school dropouts, the higher the AFQT score, the more likely is participation in illicit activity. Such a trade-off is consistent with the view that both cognitive and non-cognitive traits play important roles in determining graduation from high school.

\subsubsection{Implications for Policy}

There are two main conclusions that we draw from this analysis apart from the conclusion that the GED is a mixed signal that characterizes its recipients as smart but unreliable. (i) Current systems of evaluating educational reforms are based on changes in scores on cognitive tests. These tests capture only one of the many skills required for a successful life (see Heckman, 1999). A more comprehensive evaluation of educational systems would account for their effects on producing the non-cognitive traits that are also valued in the market. There is substantial evidence that mentoring and motivational programs oriented toward disadvantaged teenagers are effective. We discuss this evidence in Part 3. Much of the effectiveness of early childhood interventions comes in boosting non-cognitive skills and in fostering motivation (see Heckman, 2000, for a comprehensive review of the literature). It has long been conjectured that the greater effectiveness of Catholic schools comes in producing more motivated and self-disciplined students (Coleman and Hoffer, 1983). It has also been conjectured that the decline in discipline in inner-city public schools is a major source of their failure. It would be valuable to gather more systematic information on noncognitive effects of alternative education systems. (ii) I.Q. is fairly well set by age eight. Motivation and self-discipline are more malleable at later ages (Heckman, 2000). Given the evidence on the quantitative importance of non-cognitive traits, social policy should be more active in attempting 
to alter them, especially for children from disadvantaged environments who receive poor discipline and encouragement at home. This would include mentoring programs and stricter enforcement of discipline in the schools. We present evidence on the value of such interventions in Part 3. Such interventions will benefit the child and the larger society but at the same time may conflict with the liberal value of the sanctity of families that undervalue self-discipline and motivation and resent the imposition of middle-class values on their children.

\subsection{Summary of Part 2}

The evidence presented in this part of the paper demonstrates that long-term environmental factors crystallized in cognitive and non-cognitive abilities play the major role in accounting for gaps in schooling attainment across socioeconomic groups, while the short term credit constraints and tuition factors that receive prominent attention in current policy discussions do not. However, short-term credit constraints affect a small group of persons and targeted subsidy policies appear to be cost effective for them. We cannot expect tuition reduction policies to eliminate the substantial gaps in schooling attainment by socioeconomic background. Gaps in cognitive and non-cognitive skills open up early and are linked to family environments at early ages, not parental income in the adolescent years. Non-cognitive skills substantially determine socioeconomic success.

In the next section, we apply these lessons and add to them in our analyses of specific policies designed to foster skills.

\section{Analyses of Specific Policies}

In this section of the paper, we analyze the returns to schooling and schooling quality and the returns to job training, early childhood interventions and mentoring programs. We also consider tax and subsidy policy, immigration policy and problems of the transition. 


\subsection{The Returns to Schooling and Schooling Quality}

Few topics in empirical economics have received more attention from empirical economists than the economic return to schooling. By now there is a firmly established consensus that the mean rate of return to a year of schooling in the 1990's exceeds 10 percent, and may be as high as 1720\% (Carneiro, Heckman and Vytlacil, 2001). This return is higher for more able people (Taber, 2001) and for children from better backgrounds (Altonji and Dunn, 1996). Persons from better backgrounds and with higher ability are more likely to attend college and earn a higher rate of return from it. This evidence is robust to alternative choices of instrumental variables and to the use of alternative methods for controlling for self selection. The synergy or complementarity suggested in Figure 6-1 is confirmed in estimates of ability and background on earnings. Both cognitive and non-cognitive skills raise earnings through promoting schooling and through their direct effects on earnings (see the evidence in Taber 2001; Heckman, Hsee, and Rubinstein, 2001 and in Carneiro, Hansen, and Heckman, 2001, 2002). Table 4 presents our summary of the mean rate of return to schooling for different ability groups. The annual return to college is higher for persons with greater ability.

Means mask a lot of important information about the distribution of returns. Even if the mean returns to participants in schooling are high, marginal entrants attracted into schooling may have low returns. Economic analysis is all about persons at the margin. Although Mincer (1974) emphasized heterogeneity in the returns to education in his pioneering research on earnings functions and reports estimates of the dispersion of these returns, it is only recently that full distributions of returns and the returns to marginal entrants attracted into schooling have been estimated (Carneiro, Hansen and Heckman, 2001, 2002). We summarize the main findings of this body of work.

The heterogeneity in rates of return can arise from cross sectional differences known to agents but not observing economists or from genuine uncertainty that agents face in making their schooling 
decisions. Both heterogeneity in returns and the components of genuine uncertainty unknown to agents when they make their schooling decisions are estimated in recent research by Carneiro, Hansen and Heckman $(2001,2002)$ who distinguish ex ante components of gains to schooling known to agents at the time they make their decisions from ex post realizations. ${ }^{28}$

Their research extends the pioneering analysis of Willis and Rosen (1979) to consider multiple schooling levels and to identify distributions of outcomes of schooling. In different schooling markets, they estimate that both cognitive and non-cognitive abilities affect earnings. Self selection is relatively more important in college choice decisions than in schooling decisions at the secondary level.

Figure 13 plots the ex post (realized) counterfactual distribution of the returns to college graduation (compared to high school graduation) for both college graduates and high school graduates who go on to college. Even among college graduates, there is a substantial fraction (37\%) who earn ex post negative returns. For them, going to college turns out to be a financial mistake. ${ }^{29}$ It would be a mistake for an even greater proportion of those who stay in high school and do not go on to college.

Carneiro, Hansen and Heckman (2002) estimate that only $9 \%$ of the variance in the discounted present value of the returns to schooling is forecastable at the time college attendance decisions are made. One way to summarize their findings is presented in Figure 14. It shows the reduction in the ex ante dispersion of the distribution of returns to college versus high school under a no-information assumption (no predictors) and a rich information set using all the information that agents act on in making schooling choices. Even under a rich information set, which they argue is implausibly rich, there is a great deal of intrinsic uncertainty about future returns at the time schooling decisions are made. This intrinsic uncertainty coupled with the risk aversion that is estimated in their model

\footnotetext{
${ }^{28}$ These authors identify counterfactuals by postulating low dimensional factor models that generate the potential outcomes. They produce evidence that the low dimensional models fit the data on wages and employment. To extract estimates of uncertainty they estimate schooling decision rules and ascertain which factors that explain future outcomes agents act on when they make their schooling decisions.

${ }^{29}$ This is also true when we compute present values.
} 
helps to explain the apparent puzzle discussed by Ellwood and Kane (2000), among others, that students react more strongly to costs than to returns. Direct costs (such as tuition) are known with near certainty. Future returns are uncertain. Risk aversion leads agents to discount returns relative to costs.

This evidence suggests that there are great potential benefits to gathering the information to reduce uncertainty about future payoffs. Greater dispersion in ex ante returns among minorities and low income majority groups than among majority groups partially explains the sluggish response of minorities and low income majority whites to changes in the returns to schooling over time.

The marginal entrants attracted into college by changes in tuition are below those of the average participant. Figure 15, taken from the work of Carneiro, Hansen and Heckman (2001, 2002) show that returns to schooling are lower for people less likely to attend college. Currently the average index of the average marginal participant in college in the U.S. is slightly below "0" in the x-axis of that figure. The falloff in the return to college in the relevant range is mild. Small increases in college enrollment at current levels would only mildly reduce the returns to the marginal entrant. However, if college attendance became universal, the marginal student would earn a negative return. ${ }^{30}$

\subsubsection{The Effects of Schooling on Measured Test Scores and the Effects of Test Scores on Wages.}

In recent work, Hansen, Heckman and Mullen (2002), estimate the effect of schooling on test scores accounting for the joint determination of schooling and tests. ${ }^{31}$ It is well known that test scores predict schooling. It is more controversial that schooling raises measured test scores. Herrnstein and Murray (1994) claim that such effects are weak. Winship and Korenman (1997) survey this literature. Hansen, Heckman and Mullen (2002) estimate the effect of additional years of schooling on standardized test scores for persons 14 and over at different levels of latent ability. ${ }^{32}$ Schooling

\footnotetext{
${ }^{30}$ This is a partial equilibrium statement. The return to high school would rise as more people went to college. This would flatten the slope of Figure 16 as college-going increased.

${ }^{31}$ They also account for ceiling effects of tests. In this work they cardinalize the test score.

${ }^{32}$ In their paper, latent ability is equated with IQ, which cannot be manipulated after ages 8-10.
} 
raises measured achievement (AFQT) by two tenths of a standard deviation per year. This effect is uniform across latent ability levels. There are substantial gains in test scores in the early high school years. But due to parallelism across ability levels of schooling on achievement test scores, schooling does not eliminate initial disadvantages in test scores across latent ability levels. Because the relationship between log wages and test scores is nonlinear (see Heckman and Vytlacil, 2001), schooling tends to equalize wages for those at the bottom of the latent test score distribution.

This research shows that schooling has an additional effect on earnings through raising ability above and beyond its direct effect on earnings. Estimates of returns to schooling that condition on measured test scores that are reported in the literature lead to downward biased estimates of the return to schooling.

\subsubsection{Raising Schooling Quality}

The most commonly suggested reforms to schools are class size reductions, summer school programs and increases in teacher salaries and per-student expenditures. Krueger (1999) suggests that these interventions are likely to be effective. Some of the evidence on the success of such initiatives is based on experimental evidence, such as the Tennessee Student-Teacher Achievement Ratio (TNSTAR). Evidence on this program has been mixed; kindergarten students initially have higher test scores than those in larger class sizes, but in later grades, treated and untreated students' test scores become virtually indistinguishable (see Hanushek, 2000; for an opposing view, see Krueger, 1999). There is no evidence that class size reductions of the sort reported in the Tennessee STAR experiment will substantially affect earnings or reduce the substantial skill gaps across socioeconomic groups in American society. A further point is that even if the test score gains are persistent, test scores are only weakly linked to later outcomes (Cawley, Heckman and Vytlacil, 1999 and Heckman and Vytacil, 2001).

Recent studies linking measures of schooling quality to lifetime earnings and occupational achievement have appeared, thereby avoiding reliance on inherently arbitrarily scaled test scores. 
From this literature, there is a growing consensus indicating that within current ranges in most developed economies, changes in measured inputs such as class size and spending per pupil have little, if any, effect on the future earnings of students (see Heckman, Layne-Farrar, and Todd, 1996, and Hanushek, 1998, 2002). Even if one takes the most favorable estimates from the literature and combines them with the best case scenario for the costs of raising schooling quality, decreasing the pupil-teacher ratio by 5 on a national level is not a wise investment. Such a reduction in class size, while keeping the number of students enrolled the same would require the addition of new teachers, not to mention the addition of new classroom and school facilities. Accounting only for the costs of adding new teachers, we estimate that decreasing the pupil-teacher ratio by 5 would require a cost of about $\$ 790^{33}$ per student. Table 5 presents estimates of the net returns for such a pupil-teacher ratio reduction under different assumptions about productivity growth, discount rates, and the social opportunity costs of funds. ${ }^{34}$ Taking a high estimate (relative to the estimates reported in the literature) of a $4 \%$ increase in future earnings resulting from a decrease in the pupil-teacher ratio by 5 yields a loss of lifetime earnings of between $\$ 2,600$ to $\$ 5,500$ per 1990 high school graduate at standard discount rates $(5-7 \%)$.

Card and Krueger (1997) argue that productivity growth in wages should be included in such calculations. Using a $1 \%$ productivity growth rate-which is consistent with historical experiencedoes not reverse this conclusion. Even using a 3\% productivity growth rate in wages (calculations not shown), which is a high estimate outside of historical experience, does not offset the costs unless one uses a $3 \%$ discount rate. ${ }^{35}$ Estimates of the net returns are even more negative after accounting for the social costs of taxation. Only if we take the very high end estimates of the effect of schooling quality on earnings and discount costs by a very low rate (3\%) do we find any sizeable positive effect of schooling quality on future earnings.

\footnotetext{
${ }^{33}$ All dollar values here are in 1990 dollars.

${ }^{34}$ This calculation was suggested to us by Sam Peltzman. Similar calculations for increasing teacher salaries by $30 \%$ lead to the same conclusions. They first appear in Heckman and Lochner (2000). Dayanand Manoli updated these estimates under our guidance.

${ }^{35}$ Computations available on request from the authors. We thank Dayanand Manoli for his help with these computations.
} 
This evidence indicates that the U.S. may be spending too much on students given current organization of educational production. Pouring more funds into schools to lower class sizes by one or two pupils or to raise spending per pupil by a few hundred dollars will not solve the problems of the American primary and secondary school system, nor will it stimulate the college going of minorities and the poor. This is not to say that school quality does not matter. Hanushek (1971), Murnane (1975), Hanushek (1997), and Hanushek and Luque (2000) all show that individual teachers matter in the sense of raising the test scores of students. However, conventional measures of teacher quality do not predict who are the good teachers. Giving principals more discretion in rewarding and punishing teachers would be an effective way to use local knowledge. Bureaucratization hinders the use of this knowledge.

While the effects of quality vary across environments and additional funding for some schools may be justified, marginal improvements in school quality are likely to be ineffective and more fundamental changes are required if we hope to see a significant improvement in our educational system.

\subsubsection{Improving School Quality Through Choice in Schooling}

It is commonly perceived that despite the high estimated returns to schooling, American primary and secondary schools as a whole are failing. The evidence for this failure is both the dismal ranking of American high school students on standardized achievement tests compared to the performance of students from other nations and stagnant test scores over time (see the evidence presented in Blau and Khan, 2001; OECD and Statistics Canada, 1995; and Hanushek, 2000). Fixing this problem requires an understanding of how American schools are organized. By and large, public school systems in the U.S. are local monopolies with few competitors. The incentives of many principals and teachers to produce knowledge are weak, although there are many dedicated professionals. Educational bureaucracies are often unresponsive to the changing demand for skills or to the market realities that will confront their students when they leave schools. They are not 
accountable to anyone because it is not easy to monitor them. One valuable source of information - parental and student perception of the qualities of teachers and schools - is rarely used to punish poor teaching.

School choice has been advocated as a reform to improve the quality of educational services for students. Proponents of school choice argue that competition among schools to attract students will force schools to decrease costs and increase the quality of services provided. Additionally, by having parents actively choose the schools attended by their children, school choice systems would likely increase the degree of parental participation involved in children's schooling. On the other hand, opponents of school choice argue that increased competition among schools will lead to increased stratification and inequality among students as well as a dilution of basic schooling standards and that poor parents lack the information and the ability to make informed decisions for their children. Hence, school choice systems would be most beneficial to those already able to exercise choice in the current system, the richer families.

Most of the research on this topic has been theoretical. Although there is some degree of choice within the current U.S. schooling system that can be explored to understand the mechanisms of school choice, the data are often lacking and when available are inadequate.

Voucher experiments provide experimental data for empirical studies concerning school choice. Experiments that give tuition vouchers to public school students so that they may attend private schools have been conducted in several U. S. cities including Milwaukee, Cleveland, Minneapolis and New York. ${ }^{36}$ These studies have been controversial. Researchers do not agree on whether vouchers have any impact on students' educational achievement. Recent research (see Peterson and Hassel 1998) shows important differences in educational outcomes and parental satisfaction: relative to parents not allowed to exercise choice, parents under school choice systems are more likely to report satisfaction with their children's school. These voucher experiments are often limited in their scale and it is difficult to generalize any findings to the national level. Any national voucher program will

\footnotetext{
${ }^{36}$ Prominent studies include Witte (2000), Peterson and Hassel (1998) and Rouse (1997).
} 
most likely have large general equilibrium effects that cannot be estimated from these small-scale experiments (see Urquiola and Hsieh, 2002).

Other researchers have studied the effect of introducing competition among public schools into the monopolistic setting of the U.S. public school system. Evidence from these studies indicates that increased school competition and student and parental choice improves the quality of schools as measured by test scores and by parental and student satisfaction with learning. Contrary to the view that competition siphons resources away from the public sector, to its detriment, Caroline Hoxby's (2000) research suggests that when public schools are subject to greater competition both from parochial and other private schools, the performance of all schools increases. Higher levels of achievement are produced at lower cost.

Cullen, et al. (2000) present evidence on competition among schools in the Chicago Public School system. They find that those students who move schools given the choice have higher high school graduation rates than observationally identical students who remain at their assigned schools. They explain their results through student sorting. School choice allows higher ability students to sort to higher quality schools and increase their likelihood of high school graduation. Even though choice helps high-quality students, it does not seem to hurt low ability students.

A study by Derek Neal (1997) demonstrates that the higher schooling attainment of Catholic school students compared to public school students is largely a consequence of gains registered by inner city students who choose Catholic schools over inferior inner city public schools. In the suburbs, where districts are smaller and competition among school districts is more intense, the Catholic schools have little advantage over the public schools and the performance of both school systems is higher than in the centralized inner city schools. Grogger and Neal (2000) present substantial confirmatory evidence on the original Neal study using a broader set of outcome measures, including measured achievement and attainment.

It is remarkable that in a society as committed to consumer sovereignty and choice as the American society, there is so much resistance to permitting choice and instituting incentives in 
education. The conventional argument of the educational planners is that parents and students are not able to make wise choices. The available evidence points to better outcomes from increased school competition. Such policies are much more likely to raise schooling performance than policies that increase schooling quality and do not change the organization of schools. However, exact quantitative trade-offs are not available (see Hanushek, 2000, 2002).

\subsection{Early Childhood Investments}

The evidence presented in Part 2 suggests that both cognitive and non-cognitive abilities affect schooling and economic success and that socioeconomic differences in cognitive and non-cognitive skills appear early, and, if anything, widen over the life cycle of the child. We demonstrate there that parental inputs are important determinants of these skills. Yet the indicated policy intervention is far from obvious because the exact mechanisms by which good families produce good children are not yet well understood. Perhaps for this reason, American society has been reluctant to intervene in family life, especially in the early years.

There is a profound asymmetry in popular views about family life and schooling. On the one hand, there is a widespread belief that parents cannot make wise choices about their children's schooling. If that is true, then how can parents be trusted to make correct decisions in the preschool years which recent research has demonstrated to be so important for lifetime success? The logical extension of the paternalistic argument that denies the wisdom of parental sovereignty in choosing schools would suggest that the state should play a far more active role in the preschool life of the child. That is a position that few would accept.

For certain dysfunctional families paternalistic interventions may be appropriate. If we are to violate the principle of consumer sovereignty anywhere in the life cycle process of learning, the case for doing so is strongest at the preschool stage for some groups and not at later stages of formal schooling where the argument for paternalism is most often made. Dysfunctional families and environments are major sources of social problems. Paternalistic interventions into the family life 
may be warranted on efficiency grounds although such interventions raise serious questions about the need to protect the sanctity of family life.

Recent small-scale studies of early childhood investments on children from disadvantaged environments have shown remarkable success and indicate that interventions in the early years can effectively promote learning and can be enriched through external channels. They demonstrate the value of good families by showing that interventions can remedy the failings of bad families. Early childhood interventions of high quality have lasting effects on learning and motivation. They raise achievement and noncognitive skills but not I.Q. Disadvantaged subnormal I.Q. children in Ypsilanti, Michigan were randomly assigned to the Perry Preschool program and administered intensive treatment at ages $4-5 .{ }^{37}$ Their parents were also subject to interventions. Treatment was then discontinued and the persons were followed over their life cycle. The treatment group is now about 35 years old. Evidence on them indicates that those enrolled in the program have higher earnings and lower levels of criminal behavior in their late 20s than do comparable children randomized out of the program. Reported cost-benefit ratios for the program are substantial. Measured through age 27 , the program returns $\$ 5.70$ for every dollar spent. When returns are projected for the remainder of the lives of program participants, the return on the dollar rises to $\$ 8.70$. A substantial fraction $(65 \%)$ of the return to the program has been attributed to reductions in crime (Schweinhart, Barnes and Weikart, 1993). The Syracuse Preschool program provided family development support for disadvantaged children from prenatal care through age five. Reductions in problems with probation and criminal offenses ten years later were as large as $70 \%$ among children randomly assigned to the program. Girls who participated in the program also showed greater school achievement (Lally, et al. 1988). Studies of early intervention programs have found short-term increases in test scores, less grade retention, and higher high school graduation rates among enrolled children. Of those studies that examine pre-delinquent or criminal behavior, most have found lower rates of deviant behavior among program participants. See Table 6 for a summary of the effects of selected early

\footnotetext{
${ }^{37}$ These children had an average IQ of approximately 80.
} 
intervention programs on student test scores, schooling, earnings, and delinquency. See Table 7 for a summary of the Perry Preschool findings, and a cost benefit analysis of that program. The benefit cost ratio is substantially greater than one. Recent estimates of the rate of return to this program are $13 \%$ (Barnett, 2002, private communication). This number looks low relative to the return for schooling. It should be compared to the return for low ability students. We conjecture that the returns to maternal inputs at early ages are very high for normal children and that $13 \%$ is a lower bound on the return to normal children, although there is no direct evidence on this question. At the same time, the gap between schooling and preschooling returns might widen if there are substantial noncognitive returns to schooling that we have not enumerated.

Evidence on the more universal Head Start program is less clear, but the program is quite heterogeneous and is much less well funded than the Perry preschool program. Currie and Thomas (1995) find short-term gains in test scores for all participating children; however, most of those gains decayed quickly for African-American children. They conclude that either differences in local program administration or in subsequent schooling quality are at the root of the differences between the outcomes for black and white children. Ramey et al. (1988) note that the schools attended by the Perry preschool children were of substantially higher quality than those attended by the typical Head Start child. In addition, the Perry Program also taught parenting skills and arguably put in place better long term environments for the children. The failure to maintain the initial positive stimulus of Head Start may account for the decline in its impact over time, and may account for its comparative ineffectiveness.

In light of our discussion in Part 2, an emphasis on cognitive test scores appears to be misplaced. It appears that early childhood programs are most effective in changing non-cognitive skills, although they do raise achievement test scores (as opposed to I.Q.). We also note that declines in test scores like those found in the Head Start program were found for programs like Perry Preschool, but their long-term evaluations are quite favorable in terms of success in school and society at large. The psychometric test score literature is not clear about the relationship between early test scores 
and success in school, graduation rates, socialization, and labor market outcomes. The fade-out effects in test scores found for this program do not imply that long-term beneficial effects of Head Start are not present. Head Start may improve the lifetime prospects of its participants, despite yielding only short-term gains in test scores that may not measure many relevant dimensions of social and emotional skills.

The Perry intervention affected both children and parents. Parents improve their education and labor force activity and reduce their participation in welfare. The successful enriched programs like Perry Preschool foster long-term improvements in the home environment that carry over to the child long after the program has terminated. Head Start offers a much lower quality (and lower paid) staff, part-time classes for children, and limited parental involvement. The program terminates without any substantial intervention into or improvement in the home environments of the disadvantaged children. Improvements in Head Start, proponents argue, are likely to produce effects closer to those observed in more successful small-scale programs. Given the potential for success (as exhibited by the Perry Preschool experiment), more studies of the long-term impacts of various types of small-scale and broad-based early intervention programs are certainly warranted.

Provocative calculations by John Donohue and Peter Siegelman (1998) indicate that if enriched early intervention programs were targeted toward high risk disadvantaged minority male youth, the substantial costs of these enriched programs evident in Table 6 would be more than repaid by the expected savings in incarceration costs alone.

An important lesson to draw from the Perry Preschool program, and, indeed the entire literature on successful early interventions, is that it is the social skills and motivation of the child that are more easily altered - not I.Q. These social and emotional skills affect performance in school and in the workplace. Academics have a bias toward believing that cognitive skills are of fundamental importance to success in life. Because of this, the relatively low malleability of I.Q.s after early ages has led many to proclaim a variety of interventions to be ineffective.

Yet the evidence from the Perry Preschool program and the evidence in Table 8 reveals that these 
programs are highly effective in reducing criminal activity, promoting social skills and integrating disadvantaged people into the mainstream society. The greatest benefits of these programs are on socialization and not I.Q. Social skills and motivation have large payoffs in the labor market so these programs have the potential for a large payoff.

At the same time, it is important to be cautious about the evidence from these programs. The ability to replicate them on a large scale is an issue. As in the Tennessee STAR program, teachers may have been motivated more than would be possible in a permanent large-scale program. Proper treatment of future benefits is required before strong conclusions can be drawn. The substantial gap in time between the payment in terms of costs and the harvest of benefits remains requires substantial benefits to justify these programs. Prima facie the benefits are there, but a stronger case would be desirable.

We next turn to the evidence on the effectiveness of interventions for older children. These programs attempt to redress the damage of bad childhoods. While these programs do not raise I.Q., there is some evidence that they can affect social skills (non-cognitive abilities) because the prefrontal cortex of adolescents which controls emotion and behavior is malleable until the late teenage years (Shonkoff and Phillips, 2000).

\subsection{Interventions in the Adolescent Years}

How effective are interventions in the adolescent years? Is it possible to remedy the consequences of neglect in the early years? This question is relevant because cognitive abilities are fairly well determined and stable by age 8-9 in the sense that I.Q. is highly correlated at successive ages beyond that age range. Just as the early intervention programs have a high payoff primarily due to the social skills and motivation imparted to the child, and the improved home environment, so do interventions that operate during the adolescent years, and for many of the same reasons.

Table 10 summarizes evidence on the effects of adolescent interventions on education, earnings, and crime rates. There are few estimates of rates of return for these programs. Both school-based 
and training-based programs are compared. We briefly discuss what is known about school-based interventions during the adolescent years. A few recent studies of mentoring programs, like the Big Brothers/Big Sisters (BB/BS) and the Philadelphia Futures' Sponsor-A-Scholar (SAS) programs, have shown broad positive social and academic impacts on participating school-age children and adolescents. BB/BS pairs unrelated adult volunteers with youth from single-parent households for the purpose of providing youth with an adult friend. This promotes private youth development and surrogate parenthood. No specific attempts are made to ameliorate particular deficiencies or to reach specific educational goals; a broad, supportive role is envisioned for the mentor. In a random assignment study, Tierney and Grossman (1995) found that 18 months after being matched with a mentor, Little Brothers and Sisters (ages 10 to 16 at the time of the match) were less likely to have initiated drug or alcohol use, to hit someone, to skip class or a day of school, or to lie to their parents; they had higher average grades and were more likely to feel competent in their school work and report a better relationship with their parents.

The primary goal of SAS is to help students from Philadelphia public high schools make it to college. The program provides long-term mentoring (throughout high school and for one year beyond), substantial academic support, help with college application and financial aid procedures, and financial support for college-related expenses. Individually matched mentors serve as surrogate parents, and provide a successful role model, monitor student progress, and provide encouragement and support. SAS provides students with $\$ 6,000$ in financial assistance throughout college for those choosing to enroll in an accredited two- or four-year postsecondary institution. The program also provides a coordinator for groups of about 30 students to ensure a successful relationship is built between mentors and mentors. Using a matched sample of non-SAS students in Philadelphia high schools $^{38}$, Johnson (1996) estimates statistically significant increases in grade point averages for tenth and eleventh grades, as well as a $22 \%$ (16\%) increase in college attendance one year (two

\footnotetext{
${ }^{38}$ Comparison students were matched with participants on the basis of race, gender, school attended and ninth grade academic performance.
} 
years) after graduation from high school. Because the primary goal of SAS was to increase college enrollment, other social and psychological measures were not studied.

Much like SAS, the Quantum Opportunity Program (QOP) offered disadvantaged minority students counseling and financial incentives (one dollar up front and one dollar put in a college fund) for every hour spent in activities aimed at improving social and market skills. Students who were randomly chosen to participate in the program were provided with a mentor at the beginning of ninth grade. All participants were kept in the program for four years regardless of whether they dropped out of school or not. Over four years, the average participant logged 1,286 hours of educational activities like studying with tutors or visiting museums. Two years after program completion, about a third more participating students graduated from high school (or obtained a GED) than similar non-participants. Since many participants were enrolled in post-secondary schooling at the time of the follow-up study, it is difficult to determine the program's effect on earnings. However, arrest rates for program participants were one-half those for non-participants. These benefits did not come without cost, however, as the average four-year cost per participant was $\$ 10,600$. Still, a cost-benefit analysis estimated positive net social returns to QOP. See Taggart (1995) for a more detailed description of the program and an evaluation of its impacts. Tables 9-10 present the evidence from a randomized trial evaluation of the Quantum Program. Again, the evidence is that these programs can dramatically improve social skills and the adaptation of persons to society.

Two other studies provide additional evidence that creative programs designed to keep adolescents in school can be effective. These are discussed more extensively in Heckman (2000) and Heckman and Lochner (2000) and we summarize these discussions here. Ohio's Learning, Earning, and Parenting (LEAP) program and the Teenage Parent Demonstration (TPD) provided financial incentives for teenage parents on welfare to stay in school or take GED classes (or, alternatively, imposed financial penalties for non-enrollment). LEAP showed increases in high school graduation or GED rates among randomly assigned participants who were still enrolled in school when they 
entered the program. TPD showed mixed results on education depending on the program site. For young women who had already dropped out of school at the time of enrollment in the program (and, to a lesser extent, those who were still attending school when they entered the program), there is a cause for concern that participants may have substituted GED training for high school graduation as an easier means for meeting program requirements. ${ }^{39}$ Both of these programs show positive post- program effects on earnings and employment for students who were still in school when they entered the program. The effects were often negative, however, for participants who had already dropped out of school before entering the program. A key finding from both of these studies is that they show more positive impacts for individuals still enrolled in school (when compared with dropouts). ${ }^{40}$ It is still unknown whether that is because, on average, they are of higher ability than those who have already dropped out, or because there is some advantage to intervening before adolescents leave school.

The literature demonstrates that financial incentives to stay in school and participate in learning activities for disadvantaged students can increase schooling and improve employment outcomes. It should be noted that while these programs proved to positively influence employment and earnings (and, in the case of QOP, reduce crime), they do not perform miracles. Impacts are modest, but positive (see the estimate Table 10. We discuss the Job Corps estimates in the next section).

The Summer Training and Employment Program (STEP) provided remedial academic education and summer jobs to disadvantaged youth ages 14 and 15. Each summer, participants enrolled in 110 hours of classes and 90 hours of part-time work. While the program achieved modest shortterm gains in reading and math skills, those gains did not last. Two to three years after program completion, there were no effects on high school graduation rates, grades, or employment (see Table 10). One criticism of the program is that it did not attempt to follow-up on its summer program with a school-year curriculum. Maryland's Tomorrow program did just that. It combined an intensive

\footnotetext{
${ }^{39}$ Cameron and Heckman (1993) have shown that a GED commands lower wages than a high school diploma in the labor market.

${ }^{40}$ See Granger and Cytron (1998) for a summary of both.
} 
summer program with a school-year follow-up, offering participants summer jobs and academic instruction, career guidance, and counseling through adult mentors, peer support, or tutoring. While the program did not reduce final dropout rates, it did seem to delay dropout (dropout rates were lower during the 9 th grade but not by the end of the 12 th grade). The program also increased the pass rate for 12th grade students taking the Maryland Functional Tests a basic skills test (see Heckman and Lochner, 2000).

The evidence on these programs suggests that sustained interventions targeted at adolescents still enrolled in school can positively impact learning and subsequent employment and earnings. ${ }^{41}$ These studies also suggest that interventions for dropouts are much less successful. Unfortunately, they do not tell why. We do not know whether there is some advantage to intervening before the dropout decision is already made, or if those who choose to drop out have less motivation and lower ability, making programs less effective for them regardless of when the intervention takes place. However, these interventions only alleviate and do not reverse early damage caused by bad family environments.

\subsection{Public and Private Job Training}

Due to a lack of data and a bias in favor of the funding of studies of government training, the returns to private sector training are less well studied than the returns to public sector training. Studies by Lynch (1992, 1993), Lillard and Tan (1986), Bishop (1994) and Bartel (1992) find sizable effects of private sector training. In comparison with studies of public sector training, most of these studies do not attempt to control for the bias that arises because more able persons are more likely to take training, so estimated rates of return overstate the true returns to training by combining them with the return to ability. Part of the measured return may be that more motivated and able persons take training. Estimated returns range from 16 - 26\% and are comparable to those obtained from education (see Table 11). These are upper-bound estimates of the return to training for marginal

\footnotetext{
${ }^{41}$ See the report entitled "What's Working (And What's Not)?" by the U.S. Department of Labor (1995) for a more comprehensive survey of programs aimed at increasing the skills and earnings of disadvantaged youth.
} 
entrants.

An important feature of private sector training is that the more skilled do more investing even after they attain high skill levels. Different types of training and learning have strong complementarities with respect to each other. The hypothesis of universal complementarity that underlies Figure 6 receives support in recent U.S. data. See Table 12 for an analysis of participation in training for different demographic groups. As shown in column 1, more able people (as measured by AFQT) and people with more schooling are more likely to participate in company training. This is further evidence on dynamic complementarity that supports our thesis that skill begets skill and that motivates Figure 6. However, those with higher parental income (as measured by family income at age 14 and by father's education), after controlling for their own education and their own ability, are more likely to train in companies after completing their schooling. Private financing arrangements between workers and firms appear to offset family income constraints and partially offset initial disadvantages. However on net, post school training is neither equalizing nor disequalizing. See Table 12, column 2 which reports the net effect of parental background and family income not controlling for schooling and ability. For most demographic groups private job training is neutral with respect to family background after netting out its effects on ability and schooling.

Low-skilled persons typically do not participate in private sector training. Firms can be exclusive in ways that government training programs for disadvantaged workers are designed not to be. The lack of interest of private firms in training disadvantaged workers indicates the difficulty of the task and the likely low return to this activity. The best available evidence indicates that public training programs are an inefficient transfer mechanism and an inefficient investment policy for low-skill adult workers. We present that evidence next. 


\subsubsection{Evidence About Conventional Public Training and Work-Welfare Programs}

Before turning to a discussion of the benefits of specific training programs, it is important to reiterate a few general points that critically affect how we interpret the evidence on training. In evaluating any public project, it is necessary to account for the welfare costs of raising public funds as well as the direct costs of providing the services. In accounting for human capital projects (or any other investment project) it is necessary to accurately estimate the time series of the returns and to discount it appropriately to compare with costs. Table 13 shows the importance of applying these principles. It takes experimental estimates from the JTPA evaluation (see Bloom et al., 1993) and makes alternative assumptions about benefit duration, costs, welfare costs, interest rates for discounting and welfare cost of public funds. Accounting for these factors vitally affect the estimates of the economic return to training. Especially important is the assumption about benefit duration. The JTPA evaluation followed participants for only 30 months. When the benefits are assumed to persist for seven years, the estimated effects are larger in absolute value ${ }^{42}$. On the other hand, Ashenfelter (1978) estimated a 25\% annual depreciation rate, which suggests that an assumption of no depreciation is grossly at odds with the evidence. Heckman, LaLonde and Smith (1999) present a comprehensive survey of the economic return to public sector training so it is unnecessary to restate their evidence here. Table 14 taken from a recent survey by Martin and Grubb (2001) suggests some general lessons from this literature.

Job training is a heterogeneous activity. It includes classroom education, make work, subsidized employment and job search. When we look at the rate of return to classroom training, it is sizeable (Heckman, Hohmann, Khoo and Smith, 2000). The rates of return for other components of training are generally lower, although subsidized work (as in the National Supported Work study) appears to have a large payoff. Even when an activity such as job search assistance is profitable, the scale and gains from the activity are low. One cannot expect substantial benefits from job training. Missing

\footnotetext{
${ }^{42}$ Seven years is used because Couch (1992) shows that one intensive wage subsidy program has annual benefits of that duration.
} 
from the literature is a detailed cost-benefit analysis of specific activities of training programs, although Heckman, LaLonde and Smith (1999) and Martin and Grubb (2001) go part of the way in this direction. Such assessments move the discussion beyond blanket statements about entire programs and allow discussions of public policy to focus on parts of the programs targeted to specific populations that are effective.

Just as in the study of education, there is considerable evidence of heterogeneity in response to treatment in job training (Heckman, Smith and Clements, 1997). Treatment is most effective for those at the high end of the wage distribution. There is no effect of training at the bottom. There are substantial gains from targeting treatment. The information required to do so is generally not available (see Heckman, Heinrich and Smith, 2002). The returns for older workers and displaced workers are very low, a consistent finding of the literature that is also consistent with the general story told in Figure 6-1.

\subsubsection{The Recent Job Corps Study}

Job Corps has recently been evaluated using experimental methods and the results have been widely trumpeted as a success for government training (Burghardt and Schochet, 2001). While results for some groups are encouraging, the findings from the new Job Corps story are consistent with the previous literature. Except for white teenagers 16-17, the results for earnings and employment are in line with the disappointing results found for most job training programs. It would be surprising to find a substantial impact of Job Corps given that it is a GED factory and the economic return to the GED is low (see Figure 16). Among white and black males 20-24, the annualized impacts are substantial. Over the four year course of the experiment, however, the net benefit is only $\$ 264$ (over four years) and not statistically significant. The large positive results for Job Corps reported in the popular press (Krueger, 2000) are based on out-of-sample forecasts assuming that benefits last indefinitely. Table 16 is taken from the recent Job Corps study. The substantial excess of benefit over cost reported in the first line of the second panel is a consequence of the assumption by the 
Job Corps analysts that benefits last indefinitely. Making the opposite assumption that they do not last at all, the net return is negative (see the second line of the second panel). It is also negative if one uses Ashenfelter's 25\% estimated depreciation rate. Accounting for the social costs of taxation required to finance the Job Corps makes these negative benefit-cost accounts even more negative. There is no empirical support for the assumptions of indefinite benefits and no social welfare cost of taxation used in the main Job Corps report. As previously noted, many other programs have substantial rates of return if we assume that benefits persist into the indefinite future and if social costs of taxation are ignored. Before serious policy can be based on the Job Corps study, a stronger defense of its maintained assumptions has to be given. The most accurate assessment of what the Job Corps study shows is best summarized by a quotation from the final report:

"Over the whole period Job Corps participants earned about \$3 per week (or about \$264 overall) more than they would have if they had not enrolled in Job

Corps. This impact, however, is not statistically significant."

(Burghardt and Schochet, 2001)

\subsubsection{Summary of Training Impacts}

A comparison of these programs suggests a few important lessons. First, you get what you pay for. The recently terminated JTPA program costs very little and produced very few results. An exception is classroom training where the returns are substantial (Heckman, Hohmann, Khoo and Smith, 2000). Second, the effects of treatment vary substantially among subgroups (Heckman, LaLonde and Smith, 1999). Third, these programs also affect behavior beyond schooling and work which should be considered. Reductions in crime may be an important impact of programs targeted at male youth (see Table 10 for evidence on Job Corps). The evidence summarized in Heckman,

LaLonde and Smith (1999) indicates that the rate of return to most U.S. and European training programs is far below $10 \%$, although the benefits to certain groups may be substantial and some pass cost-benefit tests. We cannot look to public job training to substantially remedy or alleviate 
skill deficits that arise at early ages. We next consider tax policy.

\subsection{Tax and Subsidy Policy}

The U.S. has a progressive income tax system and this retards skill formation. Aside from the progressiveness of the current tax system, tax rules in the United States tend to promote human over physical capital formation (Quigley and Smolensky, 1990). There is some evidence that tax laws are more favorable towards investment by more skilled and wealthier workers, although there are elements in the tax code that favor low- skill workers as well. Tax rules also tend to encourage investments made on the job over investments in formal schooling, especially schooling that requires substantial out-of-pocket or tuition costs. While many of the effects of the current tax system on human capital investment may be unintended, those effects may be substantial and favor certain workers as well as certain types of investment over others.

In order to understand how taxes influence human capital investment, it is helpful to understand the costs and returns of such investment. The costs of investment are foregone earnings net of taxes plus any additional tuition or out-of-pocket expenses. Higher proportional taxes reduce the costs of spending an hour in school by the amount they reduce the return of working an hour in the market.

The simplest case to consider is a regime with flat (proportional) taxes where the only investment cost is foregone income. In this case, changes in the level of the flat wage tax will have no effect on human capital accumulation. Increases in the tax rate reduce the return by the same proportion as they reduce the cost, so there is no change in the incentive to invest. The ratio of marginal returns to marginal costs remains unaffected. Hence, proportional taxes on labor income have no effect on investment in human capital. On the other hand, if there are tuition expenses that are not tax deductible, a higher tax rate discourages investment, because it lowers the returns to investment more than the costs. In the case of a $10 \%$ increase in the tax rate, the return to investment falls by $10 \%$, the cost of foregone income declines by $10 \%$, but the tuition cost remains unchanged if 
tuition cannot be deducted, as it cannot be in the U.S. tax system. Thus, the return declines by more than the costs, so human capital investment is discouraged.

The intuition behind the neutrality of flat labor income taxes on human capital investment arises from the fact that the cost of time inputs to investment is foregone earnings, which are tax deductible. If tax rates are $10 \%$ and one earns $\$ 10$ less, one pays $\$ 1$ less in taxes-the net loss is only $\$ 9$. The costs of other inputs to on-the-job training can typically be expensed by the workers' employers and can be financed through lower wages, thereby making them tax deductible as well. The only major cost of human capital investment that is not tax deductible is college tuition. While this cost is substantial for some, a majority of youth do not attend college, and a majority of those who do attend community colleges or state colleges where tuition costs are modest. Because most of the costs of investment are financed through foregone earnings and are tax deductible, changes in the rate of a flat tax on wages will have little effect on human capital accumulation.

In a modern society, where human capital is a larger component of wealth than is land, a proportional tax on human capital is like a non-distorting Henry George tax as long as labor supply responses are negligible. Estimated inter-temporal labor supply elasticities are small and welfare effects from labor supply adjustment are negligible. See the evidence summarized in Browning, Hansen and Heckman (1999). Taxes on human capital should be increased while taxes on capital should be decreased in order to promote wage growth and efficiency.

However, the current U.S. tax system is not flat. The progressiveness in the tax schedule discourages human capital investment. For some individuals, the gain in earnings resulting from human capital investment causes them to move up tax brackets. In this case, the returns from investment are taxed at a higher rate, but the cost is expensed at a lower rate. This discourages human capital accumulation. Consider a progressive tax system where the only cost of investment is foregone earnings. Suppose an individual's current marginal tax rate is $10 \%$. If he chooses to invest, his increased earnings will cause him to switch to a marginal tax rate of $20 \%$. In this case the returns are taxed at the $20 \%$ level, but the costs are deducted at the $10 \%$ level, and progressive 
taxes discourage human capital investment when compared to a flat tax regime.

Taxes on physical capital are another important component of the tax system that can affect human capital investment decisions. The level of human capital investment declines when the aftertax interest rate increases, because the discounted returns to investment are lower. Reducing the tax on interest income can have a beneficial effect on both capital accumulation and on real wages.

Heckman, Lochner and Taber (1998b, 2000) and Heckman (2001), estimate that for the U.S. economy a revenue neutral move to a flat tax on consumption in the steady state raises the wages of both skilled and unskilled workers, raises aggregate output by $5 \%$ (and aggregate consumption by $3.7 \%$ ) while raising the wages of college graduates and high school graduates equally (7\%). Such a move would barely affect overall inequality while promoting greater levels of both human capital and physical capital. However, the major effect of this reform is on physical capital, and its feedback effects on wages through the increased productivity of labor. The effects on human capital accumulation of these reforms are small. Tilting the bias in the tax system toward capital and away from human capital will improve the earnings of both capital and labor in the long run. Low ability and unskilled members of the current generation do not benefit from a switch to a flat tax. Most ability types benefit from a flat consumption tax. Heckman (2001) shows that both types of reform are more popular in a period of skill-biased technical change because tax reform facilitates transition.

Tax reforms on interest income are either ignored or misrepresented in popular discussions. Populists see such a move as favoring capital and hence rich people. They ignore the crucial point that higher levels of capital stocks raise the wages of all workers in a roughly uniform way.

Heckman, Lochner, and Taber (1998b, 2000) also show revenue neutral movements to a flat income tax have more modest effects on wages and only small effects on human capital accumulation. Based on these simulations, one cannot expect tax reform to substantially change human capital stocks, but a move to flat consumption tax will improve welfare.

We next consider which individuals are encouraged to invest by the current tax system and what 
types of investment they are encouraged to undertake. Various features of the current tax code are biased toward more skilled workers with higher earnings. For individuals who are employed, investment costs are typically financed through foregone earnings. To the extent that formal educational expenses are not paid for this way, they can be deducted from gross earnings provided that they are itemized and that itemizations from all sources exceed $2 \%$ of adjusted gross income. This feature of the tax code tends to favor high-skill individuals who are more likely to itemize expenses.

Until recently, individuals have been unable to deduct interest paid on educational loans from their taxable income. The disincentive effects of this exclusion can be substantial. While individuals must pay taxes on interest from savings, they cannot deduct the interest they pay on educational loans. However, mortgage interest is still deductible. It is possible for families with home equity to take out mortgages to finance their children's education, and there is some evidence that post1986 families have done so. Again, it is the more skilled and wealthy who are most likely to own homes, so they and their children are hurt less by a policy that only allows mortgage interest to be deducted.

The tax system favors public schooling investment at the primary and secondary level over private schooling and any type of post-secondary schooling. Any student can attend public elementary and high school for free and the costs of those public schools are financed primarily through local and state taxes, which are fully deductible. However both private school and college tuition is not deductible, so the current tax system is biased against college education and private education. Moreover, the level of tuition tends to increase with college quality, so the current tax system discourages students from attending higher quality universities. Since private school tuition is not tax deductible, but local taxes are, communities have incentives to set up good public schools rather than send their children to private schools.

The current tax system favors human capital accumulation on the job versus full-time schooling. Human capital investments can be separated into those undertaken while working (or paid for by 
the employer) and those taken elsewhere (and paid for by the individual). Current tax laws favor the former over the latter, encouraging individuals to seek training on the job. Virtually all investments made through an employer can be expensed and financed through foregone wages. The employee does not need to itemize deductions to realize this tax benefit.

Educational assistance programs exempt tuition paid for by employers from personal income tax, provided the schooling is job-related. Portable vocational or employer-based training can be sold to employees by firms and paid for by lower wages. The foregone earnings are essentially written-off on personal income taxes. Individuals seeking training are, therefore, encouraged to look to their employer rather than formal schools. In addition, training and schooling expenditures that are not job-related can be immediately written-off by firms up to $\$ 5,250$ per year for each worker. However, tuition support is restricted to undergraduate level education (Joint Committee on Taxation, 1992). Again, this shifts schooling and training to the workplace environment.

Relative to physical capital, some types of human capital investment are favored by the tax system, while others are not. To the extent that many human capital investments are immediately tax-deductible while physical capital investments must be amortized, the current tax system encourages human over physical capital investment. In cases where schooling or training costs cannot be deducted - primarily tuition costs for formal schooling - investment in physical capital is favored. While it is ambiguous as to which groups current tax provisions benefit most - the most or the least skilled - employer provided training is certainly favored over training undertaken away from the workplace. This asymmetry of tax treatment is often justified by the argument that there is a much larger consumption value of academic education than job-specific training and that this consumption value should be taxed.

Another argument for taxation and subsidy of human capital is the presence of idiosyncratic risk. Judd (2000) shows that under certain conditions on labor supply parameters, riskiness in physical assets and levels of idiosyncratic risk, there is scope for optimal tax policy if idiosyncratic risk is exogenous, i.e. it cannot be affected by individual decisions. To the extent that there is 
moral hazard, and risk is not exogenous, the scope for optimal tax interventions is more limited. Indeed if firms can insure workers against the idiosyncratic risk through optimal contracts, there is no scope for government tax or transfer policy as the market provides efficient risk sharing.

\subsection{The Problem of the Transition}

Skill biased technical change operates to make workers trained under old regimes obsolete at prevailing wages in new regimes. This phenomenon operates with a vengeance in transition economies in Eastern Europe and Latin America that have opened up markets and now trade at world prices.

Younger workers trained under old technologies can, and have, adapted to new technologies through retraining and education. For older workers, with more limited horizons and lower levels of skill and ability, such re-education is not always economically efficient. Displaced American workers in their 40s offered generous retraining subsidies frequently refused them, and the return to such training is low (see Heckman, LaLonde and Smith, 1999). Overlapping generations models with workers of heterogeneous ability and skill reveal that skill biased technical change creates cohorts of workers with low earning power in the new economy (Heckman, Lochner, Taber 1998b). Their children adapt to the new economy through their investments in human capital. In the long run, the economy adjusts to a new higher level of skill requirements but the long run can last 30 years and the newly disadvantaged workers pose a serious social and economic problem. Investment in them is often not economically efficient. Based on the best available evidence, the most economically justified strategy for improving the incomes of adult low-ability low-skill persons is to invest more in the highly skilled, tax them, and then redistribute the tax revenues to the poor.

However, many people view the work ethic as a basic value and would argue that cultivating a large class of transfer recipients would breed a culture of poverty and helplessness. If value is placed on work as an act of individual dignity, because of general benefits to families, and especially the early environments of young children, and because of benefits to communities and society as a whole, then society may be prepared to subsidize inefficient jobs. Increased subsidies induce 
people to switch out of criminal activities (Lochner, 1999). Subsidies induce output that partially offsets the cost of the subsidy and so this is a cheaper alternative than welfare (Phelps, 1997). The problem with giving such subsidies to adults is that they may discourage skill formation among the young if the subsidies are extended to them (see Heckman, Lochner and Cossa, 2003). To partially alleviate these adverse incentive effects, wage subsidies should be given on a cohort-specific basis. There is evidence that the problem of rising wage inequality is cohort specific (see MaCurdy and Mroz, 1995).

However, job subsidies are not the same as investment subsidies. The evidence points strongly to the inefficiency of subsidizing the investment of low-skill, disadvantaged workers.

\subsection{Migration Policy}

As noted by Borjas, et al. (1997) and Borjas (1999), immigration is a substantial contributor to the growth in the low skill workforce. Figure $2 \mathrm{C}$ reveals that in recent years close to $50 \%$ of all dropouts are immigrants. In principle, one can reduce inequality by redirecting migration policy by letting in only the skilled. One way to do this is to sell entry visas. This would screen out the unskilled.

Given the substantial Mexican representation among the unskilled immigrants, and the porous border with Mexico, the feasibility of such a policy is far from clear to us. Moreover, different groups benefit and lose from the immigration of unskilled workers. A full accounting of the winners and losers from such a policy remains to be developed, although migration policy is a potentially promising policy option to pursue if the borders can be enforced.

\section{Summary and Conclusions}

This paper presents a framework for thinking about human capital policy. It stresses the need to recognize the dynamic nature of the human capital accumulation process and the multiplicity of actors and institutions that determine human capital investments. It emphasizes heterogeneity 
in skills, uncertainty about returns and the need to account for heterogeneity and uncertainty in designing policies to foster skill. It stresses the need to conduct cost-benefit analyses in order to rigorously rank policies.

What has been presented is a blueprint that requires much further elaboration. There are many gaps in the evidence that need to be filled. A more explicit dynamic theory that explicitly accounts for uncertainty is needed to guide future empirical work. When this blueprint is modified and converted into an operational empirical tool, a deeper and more comprehensive approach to the evaluation of human capital policies will be possible.

Because human capital is an investment good, it is important to account for the life cycle dynamics of learning and skill acquisition in devising effective policies. Schooling is only one phase of a lifetime skill accumulation process. Families, firms and schools all create human capital. Any comprehensive analysis of human capital policy must account for the full range of institutions that produce it.

Learning begets learning because of dynamic complementarities. The empirical evidence presented in this paper all points in this direction although gaps in the empirical knowledge base remain to be filled. Recent research has demonstrated the importance of the early years in creating the abilities and motivations that affect learning and foster productivity. Recent research also demonstrates the importance of both cognitive and non-cognitive skills in the workplace and in the skill acquisition process. These skills are a form of human capital and can be produced. Some of the most effective interventions operate on non-cognitive skills and motivations. Evidence from dysfunctional families reveals the value of healthy ones.

This paper also stresses the need to understand the sources of problems in order to devise effective solutions for them. We have demonstrated the first order importance of abilities and motivation in producing skills. Cognitive and non-cognitive deficits emerge early, before schooling, and, if uncorrected, create low skilled adults. A greater emphasis needs to be directed toward family policy. A limited set of small scale, high quality interventions reveal that early deficits can 
be partially remedied. The evidence is tantalizing but not definitive.

The traditional approach to human capital policy focuses on schools. But families are just as important, if not more important, than schools in promoting human capital. The evidence from failed families points to possible benefits from interventions in them. This raises a new set of questions about whether or not society should respect the sanctity of the family for certain dysfunctional groups.

Schools matter. The evidence shows that teachers matter, but that it is difficult to use conventional measures of teacher quality to predict who is a good teacher. Principals and parents know this. Schemes to improve productivity in schools should allow agents to use their local knowledge to create the right incentives. Movement toward choice, competition and local incentives will likely foster productivity in the classroom.

The evidence also shows that policies based on objective quality measures - class size, teacher salaries and the like are unlikely to produce dramatic gains in the U.S. At current levels of support, marginal changes in conventional quality measures yield only modest benefits and often fail a cost benefit test.

The evidence on credit constraints reveals the unimportance of short term family income constraints in accounting for the schooling differentials manifest in Figures 4 and 5. A lot of the evidence that is alleged to support widespread credit market problems is found to be ambiguous on the problem. At the same time, we have identified a small group of high school graduates (0-8\%) who are constrained and for whom a targeted transfer policy may be effective. Broadly based policies, like HOPE, cut too wide a swath. More than $90 \%$ of its recipients would have gone to college without the program, so it generates massive dead weight.

This point is more general. We have identified that heterogeneity and uncertainty of returns as a pervasive feature of human capital investment. Reducing uncertainty has substantial benefits. Targeting the persons who can benefit will improve efficiency. The trick is to identify the groups for whom the interventions are likely to be effective. In many human capital programs this has 
proved to be elusive, although we have identified that certain targeted programs might be effective, much more work on efficient targeting remains to be done.

We have also stressed the need to carefully assess the full life cycle stream of the costs and benefits of human capital interventions. Conventional methods of program evaluation frequently ignore costs altogether and are casual about the treatment of benefit duration. For many large-scale interventions, it is essential to account for general equilibrium effects which reverse or diminish partial equilibrium estimates of policy impacts (see Heckman, Lochner and Taber, 1998a, b, c, 2000).

Tax policy is unlikely to be a strong lever to pull to foster human capital. At the same time, effective tax policy that fosters capital accumulation can have a substantial beneficial effect on wages.

It is important to recognize that all of our discussion has been for policies for the American economy, which has a generous subsidy structure for human capital in place. We have only considered possible changes within the given institutional structure and have not addressed the broader question of whether there should be any subsidy at all. However, many of the same basic principles established for the American economy apply more broadly, albeit with different quantitative scales.

It is also important to recognize that most of our analysis has focused on gaps, and how to eliminate them, and not on trends. Current understanding of the trends that produce the stagnation evident in Figure 1 is limited. ${ }^{43}$ We have already shown that migration of unskilled workers is only a minor contributing factor. We conjecture that the demise of the American family and the growth in single parent families contributes to the stagnation. Figure 17 shows that over time an increasing fraction of all children grow up in adverse environments. Our analysis in Section 2 reveals the harmful consequences of bad family environments. However, this explanation by itself is too simplistic. The trends for failed families show continuing deterioration whereas the trends

\footnotetext{
${ }^{43}$ See the analyses in Card and Lemieux (2000, 2001). Their explanation of the slowdown in college participation rates and high school dropout rates by "cohort size" verges on the tautological.
} 
in schooling participation are flat. Still, growth in bad family environments is a likely candidate in any story that explains Figure 1. Perhaps the educational response to trends in wage differentials just offsets the educational response to trends in adverse environments. If this conjecture is verified, it reinforces the emphasis on early family policy that we have stressed in this paper. 


\section{Appendix A: Rates of Return, Internal Rates of Return and Dis- count Rates for Human Capital Investment Programs ${ }^{44}$}

Following a well-established tradition, in parts this paper, we use the rate of return to compare the productivity of different human capital programs. Many labor economists use the terms "rate of return," the "internal rate of return" (IRR), "the marginal internal rate of return," and the coefficient on schooling from a Mincer earnings equation interchangeably even though these are very distinct concepts. The internal rate of return is usually computed against a null project with no returns or costs. The marginal internal rate of return is computed relative to a "nearby" project using a suitable metric. Heckman, Lochner and Todd (2001) show the conditions under which a Mincer coefficient is a marginal internal rate of return and show that in recent decades these conditions are not satisfied. The required assumptions on the earnings function of separability between schooling and experience and negligible direct costs are violated in the recent data, so in recent years Mincer coefficients are not reliable estimates of marginal internal rates of return (see also Heckman, Lochner and Taber, 1998a).

It is well known that picking investment projects with the highest internal rate of return does not necessarily pick projects with the highest present value. However, the characteristic feature of many human capital projects is that costs are incurred early in the life cycle while returns are incurred late. Compared to less costly human capital projects, costly projects (e.g. those with more schooling) yield higher annual returns which occur later but are characterized by a larger and longer stream of upfront costs. When comparing a high investment with a low investment human capital project, the differences in the cost-return age pattern are initially negative and then become positive. Payoff streams of alternative projects cross once. Comparing higher schooling investment projects with lower schooling investment projects, a comparison of the marginal internal rate of return with the external interest rate yields an appropriate decision rule, i.e. it picks projects with the highest present value as long as there are no credit market imperfections. If the marginal

\footnotetext{
${ }^{44}$ This appendix was motivated by the comments of Lawrence Summers at the April 2002 seminar.
} 
internal rate of return that equates two human capital projects exceeds the rate of interest, the optimal present value maximizing policy is to pick the project with more human capital investment (Hirschleifer 1970, p. 54). This feature of human capital investment projects justifies our use of rates of return as a guide to comparing traditional schooling investment policies. At the same time, it is important to recognize that the returns we present only apply to marginal projects. Large scale projects that alter factor prices and returns require a full general equilibrium analysis (Heckman, Lochner and Taber, 1998a, b, c, and 2000).

The common practice of computing an internal rate of return to an investment (compared to no investment) and ranking projects on the basis of this computed return is known to be potentially misleading (Hirschleifer, 1970). The project with the highest internal rate of return so constructed can have a lower present value than a rival project. The case when payoff streams cross at several ages is the textbook pathological case. While not empirically relevant for the classical schooling problem, it is highly relevant for comparing policies like job training and pre-school policies that have payoff streams that are likely to cross more than once.

As an example, consider two projects. Project $\mathrm{X}$ is a job training program with the feature that costs are incurred at age 18 and payoffs occur after training but decay rapidly. Figure A-1 plots the typical shape of a job training program payoff stream (see the diamond-shaped payoff profile). An enriched pre-school program Y has the characteristic payoff of an early cost, a long latency period and payoffs that begin late and persist (see the squares in Figure A-1). The payoff sequences depicted in the figure cross at multiple ages $(6,19,25)$. The internal rate of return for the training program is $25 \%$. For the pre-school program, it is $7 \%$. Yet at a $5 \%$ interest rate, the net present value for the training program is 13.6 whereas the net present value for the pre-school program is 17.3 .

This example motivates our use of present values in evaluating alternatives when it is possible to do so. A more general analysis would compute the shadow prices and returns to the full portfolio of human capital investment projects to develop an optimal human capital investment strategy. 
Setting up the framework to do this is beyond the scope of this paper. The empirical evidence needed to implement this framework is not yet available.

The question of the appropriate choice of the discount rate to evaluate human capital streams is an old one. It is sometimes argued that human capital projects should be subsidized (or discounted at a lower rate) because of idiosyncratic uncertainty that can be collectively eliminated. This argument ignores two key points. First, as noted by Judd (2000), idiosyncratic risk in human capital policy is associated with moral hazard. Private contracts between workers and firms may provide optimal insurance so there is no role for any government tax or subsidy or for a reduction in the discount rate in evaluating human capital investment projects. Second, as noted by Arrow and Lind (1970), a lower discount rate for government projects is warranted only if all costs and benefits accrue to the government and can be distributed without cost and without risk among taxpayers. But in the case of human capital projects, individual agents bear the risk unless the government provides full insurance against income risk, which is an infeasible policy given moral hazard problems. For that reason, it is inappropriate to use a lower discount rate than the market rate for discounting benefits although it may be appropriate to use a lower discount rate for costs raised from government revenue sources. 


\section{References}

Acemoglu, D. and J. Angrist (2001). "How Large are the Social Returns to Education? Evidence from Compulsory Schooling Laws," in B. Bernanke and K. Rogoff, eds., NBER Macroeconomics Annual 2000, Cambridge, MA: MIT Press, 9-59.

Altonji, J. and T. Dunn (1996). "The Effects of Family Characteristics on the Return to Education," Review of Economics and Statistics, 78(4):692-704.

Arrow, K. and R. Lind (1970). "Uncertainty and the Evaluation of Public Investment Decisions," American Economic Review, 60(3):364-78.

Ashenfelter, O. (1978). "Estimating the Effect of Training Programs on Earnings," Review of Economics and Statistics, 6(1):47-57.

Autor, D. and L. Katz (1999). "Changes in Wage Structure and Earnings Inequality," in O. Ashenfelter and D. Card, eds., Handbook of Labor Economics, Vol. 3A, Amsterdam: Elsevier-North Holland, 1463-1555.

Barnett, W. S. (1993). "Benefit-Cost Analysis of Preschool Education: Findings from a 25-Year Follow-Up," American Journal of Orthopsychiatry, 63(4):500-08.

- - - - (2002). Private Communication.

Bartel, A. (1992). "Productivity Gains from the Implementation of Employee Training Programs," NBER working paper No. 3893.

Becker, G. (1964). Human Capital: A Theoretical and Empirical Analysis with Special Reference to Education. New York: Columbia University Press.

Ben-Porath, Y. (1967). "The Production of Human Capital and the Life Cycle Earnings," Journal of Political Economy, 75(4, Part 1):352-65.

Bishop, J. (1994). "Formal Training and Its Impact on Productivity, Wages and Innovation," in L. Lynch, ed., Training and the Private Sector: International Comparisons. Chicago: University of Chicago Press.

Blau, F. and L. Kahn (2001). "Do Cognitive Test Scores Explain Higher US Wage Inequality?" 
NBER working paper No. 8210.

Bloom, H., L. Orr, G. Cave, S. Bell, and F. Doolittle (1993). The National JTPA Study: Title II-A Impacts on Earnings and Employment at 18 Months. Bethesda, MD: Abt Associates.

Blossfeld, H.P. and Y. Shavit (1993). Persistent Inequality: Changing Educational Attainment in Thirteen Countries. Boulder, CO: Westview Press.

Boesel, D., N. Alsalam and T. Smith (1998). Educational and Labor Market Performance of GED Recipients. Washington, D.C.: U.S. Department of Education.

Borjas, G. (1999). Heaven's Door. Princeton: Princeton University Press.

Borjas, G., R. Freeman and L. Katz (1997). "How Much Do Immigration and Trade Affect Labor Market Outcomes?" Brookings Papers on Economic Activity, 1-67.

Bowles, S. and H. Gintis (1976). Schooling in Capitalist America. New York: Basic Books.

Bowles, S., H. Gintis and M. Osborne (2001). "The Determinants of Earnings: A Behavioral Approach," Journal of Economic Literature, 39:1137-1176.

Browning, E. (1987). "On the Marginal Welfare Cost of Taxation," American Economic Review, $77(1): 11-23$.

Browning, M., L. Hansen and J. Heckman (1999). "Micro Data and General Equilibrium Models," in J. Taylor and M. Woodford, eds., Handbook of Macroeconomics. Amsterdam: Elsevier, 543-633.

Bureau of Labor Statistics (2001). NLS Handbook 2001. Washington, D.C.: U.S. Department of Labor.

Burghardt, J. and P. Schochet (2001). National Job Corps Study: Impacts by Center Characteristics Executive Summary. Princeton: Mathematica Policy Research, Inc.

Cameron, S. and J. Heckman (1993). "The Nonequivalence of High School Equivalents," Journal of Labor Economics, 11:1-47.

(1998). "Life Cycle Schooling and Dynamic Selection Bias: Models and Evidence for Five Cohorts of American Males," Journal of Political Economy, 106(2):262-333. 
(1999). "Can Tuition Policy Combat Rising Wage Inequality?" in M. Kosters, ed., Financing College Tuition: Government Policies and Educational Priorities. Washington, D.C.: American Enterprise Institute Press.

_-_-_ (2001). "The Dynamics of Educational Attainment for Black, Hispanic, and White Males," Journal of Political Economy, 109:455-499.

Cameron, S. and C. Taber (2000). "Borrowing Constraints and the Returns to Schooling," NBER working paper No. 7761.

Card, D. (1999). "The Causal Effect of Eduction on Earnings" in O. Ashenfelter, and D. Card, eds., Handbook of Labor Economics, Vol 3A. Amsterdam: Elsevier Science, North-Holland, 1801-63. _-_- (2001). "Estimating the Return to Schooling: Progress on Some Persistent Econometric Problems," Econometrica, 69(5):1127-60.

Card, D. and A. Krueger (1992). "Does School Quality Matter? Returns to Education and the Characteristics of Public Schools in the United States," Journal of Political Economy, 100(1):1-40. ___-_ (1997). Comment on "Class Size and Earnings," Journal of Economic Perspectives, 11(4):226-227.

Card, D. and T. Lemieux (2000). "Dropout and Enrollment Trends in the Post-War Period: What Went Wrong in the 1970s?" in J. Gruber, ed., An Economic Analysis of Risky Behavior Among Youth. Chicago: University of Chicago Press.

_-_-_ (2001). "Can Falling Supply Explain the Rising Return to College for Younger Men?

A Cohort-Based Analysis," Quarterly Journal of Economics, 116(2):705-746.

Carneiro, P. and K. Hansen, and J. Heckman (2001). "Removing the Veil of Ignorance in Assessing The Distributional Impacts of Social Policies," NBER working paper No. 8840, and Swedish Economic Policy Review, volume 8.

(2003). "Estimating Distributions of Treatment Effects with an Application to the Returns to Schooling," forthcoming in International Economic Review.

Carneiro, P. and J. Heckman (2002). "The Evidence on Credit Constraints in Post-Secondary 
Schooling," Economic Journal, 112(482):705- 734.

Carneiro, P., J. Heckman and E. Vytlacil (2001). "Estimating the Rate of Return to Education When It Varies Among Individuals," working paper, University of Chicago.

Carnevale, A. and R. Fry (2000). "Crossing the Great Divide: Can We Achieve Equity When Generation Y Goes to College?" Prepared for the Educational Testing Service Leadership 2000 Series, Princeton, NJ.

Cawley, J., J. Heckman, L. Lochner and E. Vytlacil (2000). "Understanding the Role of Cognitive Ability in Accounting for the Recent Rise in the Return to Education," in K. Arrow, S. Bowles and S. Durlauf, eds., Meritocracy and Economic Inequality, Princeton: Princeton University Press.

Cawley, J., J. Heckman, and E. Vytlacil (1999). "On Policies to Reward the Value Added by Educators," Review of Economics and Statistics, 81(4):720-727.

Coleman, J. and T. Hoffer (1983). Public and Private High Schools. New York: Basic Books.

Cossa, R. (2000). "Determinants of School Attainment in Argentina: An Empirical Analysis with Extensions to Policy Evaluation," unpublished Ph.D. dissertation, The University of Chicago.

Couch, K. (1992). "New Evidence on the Long-Term Effects of Employment Training Programs," Journal of Labor Economics, 10(4):380-88.

Cullen, J., B. Jacob and S. Levitt (2000). "The Impact of School Choice on Student Outcomes: An Analysis of the Chicago Public Schools," NBER working paper No. 7888.

Currie, J. and D. Thomas (1995). "Does Head Start Make a Difference?" American Economic Review, 85(3):341-64.

DeLong, J. B., C. Goldin and L. Katz (2002). "Sustaining U.S. Economic Growth," working paper, University of California, Berkeley.

Donohue, J. and P. Siegelman (1998). "Allocating Resources Among Prisons and Social Programs in the Battle Against Crime," Journal of Legal Studies, 27(1):1-43.

Duncan, G. and J. Brooks-Gunn (1997). "Income Effects Across the Life Span: Integration and Interpretation," in G. Duncan and J. Brooks-Gunn, eds., Consequences of Growing Up Poor. 
New York: Russell Sage Foundation.

Dynarski, S. (2000). "Hope for Whom? Financial Aid for the Middle Class and Its Impact on College Attendance," National Tax Journal, 53:629-62.

- _-_-_ (2001). "Does Aid Matter? Measuring the Effects of Student Aid on College Attendance and Completion," working paper, Harvard University.

Edwards, R. (1976). "Individual Traits and Organizational Incentives: What Makes A Good Worker?" Journal of Human Resources, 11(1):51-68.

Ellwood, D. (2001). "The Sputtering Labor Force of the 21st century: Can Social Policy Help?" working paper, Harvard University.

Ellwood, D. and T. Kane (2000). "Who is Getting a College Education?: Family Background and the Growing Gaps in Enrollment," in S. Danziger and J. Waldfogel, eds., Securing the Future: Investing in Children from Birth to College. New York: Russell Sage Foundation.

Fryer, R. and S. Levitt (2002). "Understanding the Black-White Test Score Gap in the First Two Years of School," NBER working paper No. 8975.

Garber, H. (1988). The Milwaukee Project: Preventing Mental Retardation in Children at Risk. Washington, D.C.: American Association of Mental Retardation.

Glazerman, S., P. Z. Schochet and J. Burghardt (2001). "National Job Corps Study: The Impacts of Job Corps on Participants' Literacy Skills," Washington, D.C.: U.S. Department of Labor.

Granger, R. and R. Cytron (1998). "Teenage Parent Programs: A Synthesis of the Long-Term Effects of the New Chance Demonstration, Ohio's Learning, Earning, and Parent (LEAP) Program, and the Teenage Parent Demonstration (TPD)," working paper, MDRC.

Gray, S., B. Ramey and R. Klaus (1982). From Three to Twenty: The Early Training Project. Baltimore, MD: University Park Press.

Griliches, Z. (1977). "Estimating the Returns to Schooling: Some Econometric Problems," Econometrica, 45(1):1-22. 
Grogger, J. and D. Neal (2000). "Further Evidence on the Effects of Secondary Schooling," Brookings-Wharton Papers on Urban Affairs, 151-192.

Hansen, K., J. Heckman and K. Mullen (2002). "Educational Attainment, Ability and Test Scores," working paper, University of Chicago.

Hanushek, E. (1971). "Teacher Characteristics and Gains in Student Achievement: Estimation Using Micro-Data," American Economic Review, 61(2):280-288.

(1997). "Budgets, Priorities, and Investment in Human Capital," in M. Kosters, ed., Financing College Tuition: Government Policies And Social Priorities. Washington, D.C.: AEI Press.

___-_ (1998). "The Evidence on Class Size," working paper, W. A. Wallis Center, University of Rochester.

(2000). "Further Evidence of the Effects of Catholic Secondary Schooling: Comment," Brookings-Wharton Papers on Urban Affairs, 194-97.

- _-_- (2002). "The Failure of Input Based Schooling Policies," forthcoming in Economic Journal.

Hanushek, E. and J. Luque (2000). "Smaller Classes, Lower Salaries? The Effects of Class Size on Teacher Labor Markets?" in S. Laine and J. Ward, eds., Using What We Know: A Review of the Research on Implementing Class-Size Reduction Initiatives for State and Local Policymakers, Oak Brook, IL: North Central Regional Educational Laboratory, 35-51.

Hauser, R. (1993). "Trends in College Attendance Among Blacks, Whites, and Hispanics," in C. Clotfelter and M. Rothschild, eds., Studies of Supply and Demand in Higher Education. Chicago: University of Chicago Press.

Heckman, J. (1995). "A Life-Cycle Model of Earnings, Learning and Consumption." in O. Ashelfelter and K. Hallock, eds., Labor Economics, Vol. 2. Brookfield, VT: Elgar/Ashgate. (1999). "Education and Job Training: Doing It Right," Public Interest, (135):86-107. (2000). "Policies to Foster Human Capital," Research in Economics, 54(1):3-56. 
(2001). "Micro Data, Heterogeneity, and the Evaluation of Public Policy: Nobel Lecture," Journal of Political Economy, 109(4):673-748.

- _-_- (2002). The GED. Book manuscript, University of Chicago.

Heckman J., C. Heinrich and J. Smith (2002). "The Performance of Performance Standards," forthcoming in Journal of Human Resources.

Heckman, J., N. Hohmann, M. Khoo and J. Smith (2000). "Substitution and Dropout Bias in Social Experiments: A Study of an Influential Social Experiment," The Quarterly Journal of Economics, 115(2):651-694.

Heckman, J., J. Hsee and Y. Rubinstein (2001). "The GED is a 'Mixed Signal': The Effect of Cognitive and Noncognitive Skills on Human Capital and Labor Market Outcomes," working paper, University of Chicago.

Heckman, J. and P. Klenow (1998). "Human Capital Policy," in M. Boskin, ed., Policies to Promote Capital Formation. Stanford, CA: Hoover Institution.

Heckman, J., R. LaLonde and J. Smith (1999). "The Economics and Econometrics of Active Labor Market Programs," in O. Ashenfelter and D. Card, eds., Handbook of Labor Economics, Vol. 3. Amsterdam: Elsevier.

Heckman, J., A. Layne-Farrar and P. Todd (1996). "Human Capital Pricing Equations with an Application to Estimating the Effect of Schooling Quality on Earnings," The Review of Economics and Statistics, 78(6):562-610.

Heckman, J. and L. Lochner (2000). "Rethinking Myths About Education and Training: Understanding the Sources of Skill Formation in a Modern Economy," in S. Danziger and J. Waldfogel, eds., Securing the Future: Investing in Children from Birth to College. New York: Russell Sage Foundation.

Heckman, J., L. Lochner and R. Cossa (2003). "Understanding the Incentive Effects of the EITC on Skill Formation," working paper, University of Chicago.

Heckman, J., L. Lochner, J. Smith and C. Taber (1997). "The Effects of Government Policy on 
Human Capital Investment and Wage Inequality," Chicago Policy Review, 1(2):1-40.

Heckman, J., L. Lochner and C. Taber (1998a). "Explaining Rising Wage Inequality: Explorations With A Dynamic General Equilibrium Model of Earnings With Heterogeneous Agents." Review of Economic Dynamics, 1:1-58.

(1998b). "General Equilibrium Treatment Effects: A Study of Tuition Policy," American Economic Review, 88(2):381-6.

(1998c). "Tax Policy and Human Capital Formation," American Economic Review, 88(2):293-297.

- _-_ (2000). "General Equilibrium Cost Benefit Analysis of Education and Tax Policies" in G. Ranis and L.K. Raut, eds., Trade, Growth and Development: Essays in Honor of T. N. Srinivasan, Chapter 14. Amsterdam: Elsevier Science, B.V., 291-393.

Heckman, J., L. Lochner and P. Todd (2001). "Fifty Years of Mincer Regressions," working paper, University of Chicago.

Heckman, J. and Y. Rubinstein (2001). "The Importance of Noncognitive Skills: Lessons from the GED Testing Program," American Economic Review, 91(2):145-149.

Heckman J., and J. Smith (1998). "Evaluating the Welfare State," in S. Strøm, ed., Econometrics and Economic Theory in the 20th Century: The Ragnar Frisch Centennial Symposium. Cambridge: Cambridge University Press.

Heckman J., J. Smith and N. Clements (1997). "Making The Most Out of Social Experiments: The Intrinsic Uncertainty in Evidence From Randomized Trials With An Application To The National JTPA Experiment," Review of Economic Studies, 64(4):487-535.

Heckman, J. and E. Vytlacil (2001). "Identifying the Role of Cognitive Ability in Explaining the Level of and Change in the Return to Schooling," Review of Economics and Statistics, 83(1):1-12.

Herrera, C., C. Sipe, W. McClanahan, A. Arbreton, and S. Pepper (2000). Mentoring SchoolAge Children: Relationship Development in Community-Based and School-Based Programs. Philadelphia: Public/Private Ventures. 
Herrnstein, R. and C. Murray (1994). The Bell Curve. New York: The Free Press.

Hill, M. (1992). The Panel Study of Income Dynamics: A User's Guide. Newbury Park, CA: Sage Publications.

Hirschleifer, J. (1970). Investment, Interest and Capital. Englewood Cliffs, NJ: Prentice Hall.

Hoxby, C. (2000). "Does Competition Among Public Schools Benefit Students and Taxpayers?" American Economic Review, 90(5): 1209-1238.

Johnson, A. (1996). An Evaluation of the Long-Term Impacts of the Sponsor-A-Scholar Program on Student Performance. Princeton: Mathematica Policy Research, Inc.

Johnson, D. (1988). "Primary Prevention of Behavior Problems in Young Children: The Houston Parent-Child Development Center," in R. Price, E. Cowen, R. Lorion, and M. Ramos-McKay, eds., 14 Ounces of Prevention: A Casebook for Practitioners, Washington, DC: American Psychological Association, 44-52.

Joint Committee on Taxation, United States Congress (1992). Description and Analysis of Tax Provisions Expiring in 1992: Scheduled for Hearings Before the House Committee on Ways and Means on January 28-29 and February 26, 1992. Washington: D.C.: U.S. G.P.O.

Jorgenson, D. and M. Ho (1999). "The Quality of the U.S. Work Force, 1948-95," working paper, Harvard University.

Judd, K. (2000). "Is Education as Good as Gold? A Portfolio Analysis of Human Capital Investment," working paper, Stanford University.

Kane, T. (1994). "College Entry by Blacks since 1970: The Role of College Costs, Family Background, and the Returns to Education," The Journal of Political Economy, 102(5):878-911.

_College Costs, Borrowing Constraints and the Timing of College Entry," Eastern Economic Journal, 22(2):181-194.

(1999). The Price of Admission: Rethinking How Americans Pay for College, Washington, D.C.: Brookings Institution.

(2001). "College Going and Inequality: A Literature Review," working paper, Russell 
Sage Foundation.

Karoly, L. (2001). "Investing in the Future: Reducing Poverty Through Human Capital Investments," in S. Danzinger and R. Haveman, eds., Understanding Poverty, New York: Russell Sage Foundation.

Karoly, L., P. Greenwood, S. Everingham, J. Hube, M.R. Kilburn, C.P. Rydell, M. Sanders, and J. Chiesa (1998). "Investing in our Children: What We Know and Don't Know About the Cost and Benefits of Early Childhood Interventions," Santa Monica, CA: Rand Corp. ED 419621.

Keane, M. and K. Wolpin (2001). "The Effect of Parental Transfers and Borrowing Constraints on Educational Attainment," International Economic Review, 42(4):1051-1103.

Klein, R., R. Spady and A. Weiss (1991). "Factors Affecting the Output and Quit Propensities of Production Workers," Review of Economic Studies, 58(2):929-54.

Krueger, A. (1999). "Experimental Estimates of Education Production Functions," Quarterly Journal of Economics, 114(2):497-532.

_-_-_ (2000). "Economic Scene: A Study Backs Up What George Foreman Already Said," New York Times, The Job Cops Works, 30 March, C2.

Lally, J., P. Mangione and A. Honig (1988). "The Syracuse University Family Development Research Program: Long-Range Impact on an Early Intervention with Low-Income Children and Their Families," in D. Powell, ed., Parent Education as Early Childhood Intervention. Norwood: Ablex, 79-104.

Laurence, J. (2000). "The Military Performance of GED Holders," in J. Heckman, ed., The GED. Forthcoming, Chicago: University of Chicago Press.

Levenstein, E., M. O'Hara and J. Medden (1983). "The Mother-Child Program of the Verbal Interaction Project," in Consortium for Longitudinal Studies: As the Twig is Bent: Lasting Effects of Pre-school Programs. Hillsdale, NJ: Lawrence Erlbaum, 237-263.

Lillard, L. and H. Tan (1986). "Private Sector Training: Who Gets It and What Are Its Effects?" Santa Monica, California: RAND, R-3331-DOL/RC. 
Lochner, L. (1999). "Education, Work, and Crime: Theory and Evidence," working paper, University of Rochester.

Long, D., C. Mallar and C. Thorton (1981). "Evaluating the Benefits and Costs of the Job Corps," Journal of Policy Analysis and Management, 81:55-76.

Lynch, L. (1992). "Private-Sector Training and the Earnings of Young Workers," American Economic Review, 82(1):299-312.

(1993). Training and The Private Sector: International Comparison. Chicago: University of Chicago Press.

MaCurdy, T. and T. Mroz (1995). "Estimating Macro Effects from Repeated Cross-Sections," discussion paper, Stanford University.

Martin, J. and D. Grubb (2001). "What Works and for Whom: A Review of OECD Countries' Experience with Active Labour Market Policies," S-WoPEc working paper No. 14.

Meghir, C. and M. Palme (1999). "Assessing the Effect of Schooling on Earnings Using a Social Experiment," IFS working paper No. W99/10.

Mincer, J. (1974). Schoolings, Experience, and Earnings. NBER, distributed by Columbia University Press.

(1993). Investment in U.S. Education and Training, Columbia University discussion paper No. 671 .

Monroe, E. and M.S. McDonald (1981). "Follow up Study of the 1966 Head Start Program, Rome City Schools, Rome, Georgia," unpublished paper.

Mulligan, C. (1997). Parental Priorities and Economic Inequality. Chicago: University of Chicago Press.

Murnane, R. (1975). The Impact of School Resources on the Learning of Inner City Children. Cambridge: Ballinger Publishing Co.

National Center for Education Statistics (NCES) (1997). The 1997 Digest of Education Statistics. Washington, D.C.: NCES. 
Neal, D. (1997). "The Effects of Catholic Secondary Schooling on Educational Achievement," Journal of Labor Economics, 15(1):98-123.

OECD and Statistics Canada (1995). Literacy, Economy and Society: Results of the First International Adult Literacy Survey.

Orfield, G. (1992). "Money, Equity, and College Access," Harvard Educational Review, 2(3):337372.

Palmer, F. (1983). "The Harlem Study: Effects by Type of Training, Age of Training and Social Class," in Consortium for Longitudinal Studies: As the Twig is Bent: Lasting Effects of Pre-school Programs. Hillsdale, NJ: Lawrence Elbaum.

Peterson, P. and B. Hassel (1998). Learning From School Choice. Washington, D.C.: Brookings Institution Press.

Phelps, E. (1997). Rewarding Work: How to Restore Participation and to Self-Support Free Enterprise. Cambridge, MA: Harvard University Press.

Phillips, M., J. Brooks-Gunn, G. Duncan, P. Klebanov, and J. Crane (1998). "Family Background, Parenting Practices, and the Black-White Test Score Gap," in C. Jencks and M. Phillips, eds., The Black-White Test Score Gap. Washington D.C.: The Brookings Institution Press.

Quigley, J. and E. Smolensky (1990). "Improving Efficiency in the Tax Treatment of Training and Educational Expenditures," in L. Bassi, and D. Crawford, eds., Labor Economics and Public Policy: Research in Labor Economics, Vol. 11. Greenwich, CT: JAI Press, 77-95.

Ramey, C., D. Bryant, F. Campbell, J. Sparling and B. Wasik (1988). "Early Intervention for High-Risk Children: The Carolina Early Intervention Program," in R. Price, E. Cowen, R. Lorion, and M. Ramos-McKay, eds., 14 Ounces of Prevention: A Casebook for Practitioners. Washington, DC: American Psychological Association, 32-43.

Rouse, C. (1997). "Private School Vouchers and Student Achievement: An Evaluation of the Milwaukee Parental Choice Program," NBER working paper No. 5964.

Schochet, P., J. Burghardt, and S. Glazerman (2001). "National Job Corps Study: The Impact 
of Job Corps on Participants' Employment and Related Outcomes," Washington, D.C.: United States Government Printing Office.

Schweinhart, L., H. Barnes and D. Weikart (1993). Significant Benefits: The High/Score Perry Pre-School Study Through Age 27. Ypsilanti, MI: High Scope Press.

Seitz, V. (1990). "Intervention Programs for Impoverished Children: A Comparison of Educational and Family Support Models," in R. Vasta, ed., Annals of Child Development: A Research Annual, Vol. 7, London, U.K.: Jessica Kingsley Publishers, 73-103.

Shea, J. (2000). "Does Parent's Money Matter?" Journal of Public Economics, 77(2):155-84.

Shonkoff, J. and D. Phillips, eds. (2000). From Neurons to Neighborhoods: The Science of Early Childhood Development. Washington D.C.: National Academy Press.

Spence, M. (1974). Market Signalling. Cambridge, MA: Harvard University Press.

Stanley, M. (1999). "Education, Opportunity, and the Mid-Century G.I. Bills," working paper, Harvard University.

Sternberg, R. (1985). Beyond IQ: A Triarchic Theory of Human Intelligence. Cambridge, U.K.: Cambridge University Press.

Taber, C. (2001). "The Rising College Premium in the Eighties: Return to College or Return to Unobserved Ability?" Review of Economic Studies, 68(3):665-91.

Taggart, R. (1995). Quantum Opportunity Program Opportunities. Philadelphia: Industrialization Center of America.

Tierney, J. and J. Grossman (1995). Making a Difference: An Impact Study of Big Brothers/Big Sisters. Philadelphia: Public/Private Ventures.

United States Department of Labor (1995). What's Working (And What's Not): A Summary of Research on the Economic Impacts of Employment and Training Programs. Washington D.C.: U.S. Department of Labor.

United States General Accounting Office (1996). Job Training Partnership Act: Long-Term Earnings and Employment Outcomes, Report No. GAO/HEHE 96-40. Washington, D.C.: General 
Accounting Office, 22-23.

Urquiola, M. and C. Hsieh (2002). "When Schools Compete, How Do They Compete? An Assessment of Chile's Nationwide School Voucher Program," working paper, Cornell University.

Ventura, S. J. and C. A. Bachrach (2000). "Nonmarital Childbearing in the United States, 1940-99," National Vital Statistics Reports, 48(16). Hyattsville, MD: National Center for Health Statistics.

Walker, C. and F. Viella-Velez (1992). Anatomy of a Demonstration. Philadelphia: Public and Private Ventures.

Willis, R. (1986). "Wage Determinants: A Survey and Reinterpretation of Human Capital Earnings Functions," in O. Ashenfelter and D. Card, eds., Handbook of Labor Economics, Vol. 1, Chapter 10. New York: North Holland.

Willis, R. and S. Rosen (1979). "Education and Self-Selection," Journal of Political Economy, 87(5):S7-S36.

Winship, C. and S. Korenman (1997). "Does Staying in School Make You Smarter? The Effect of Education on IQ in The Bell Curve," in B. Devlin, S. Feinberg, D. Resnick, and K. Roeder, eds., Intelligence, Genes, and Success: Scientists Respond to The Bell Curve. New York: Springer, Copernicus, 215-34.

Witte, J. (2000). The Market Approach to Education: An Analysis of America's First Voucher System, Princeton: Princeton University Press. 
Figure 1

Schooling Participation Rates by Year of Birth

Data from CPS 2000

A. Whites

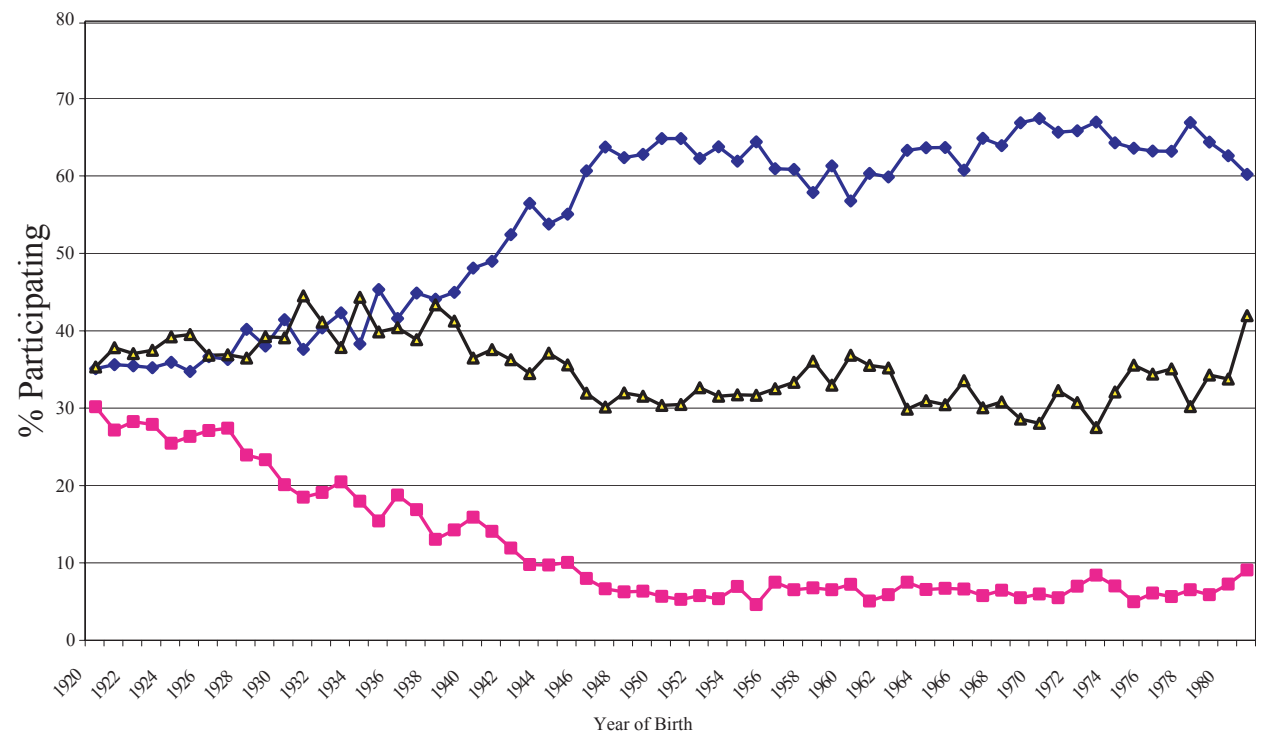

B. Blacks

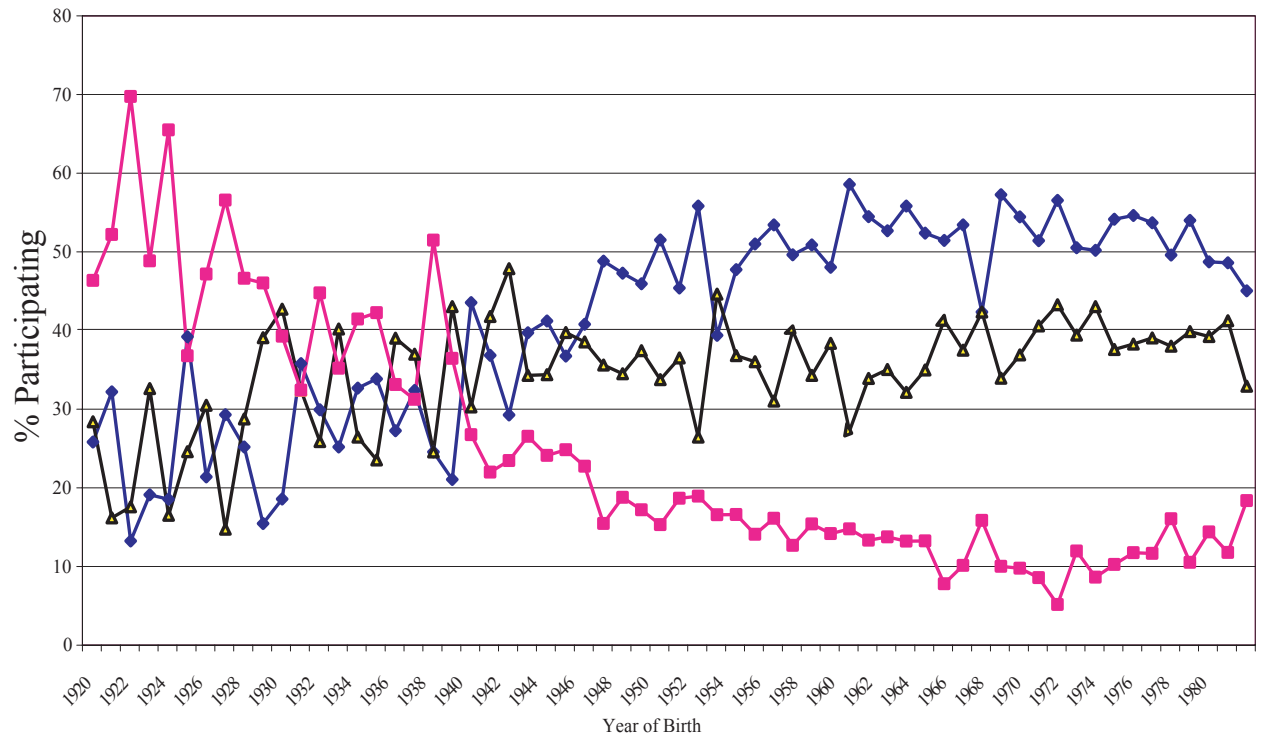

C. Hispanics

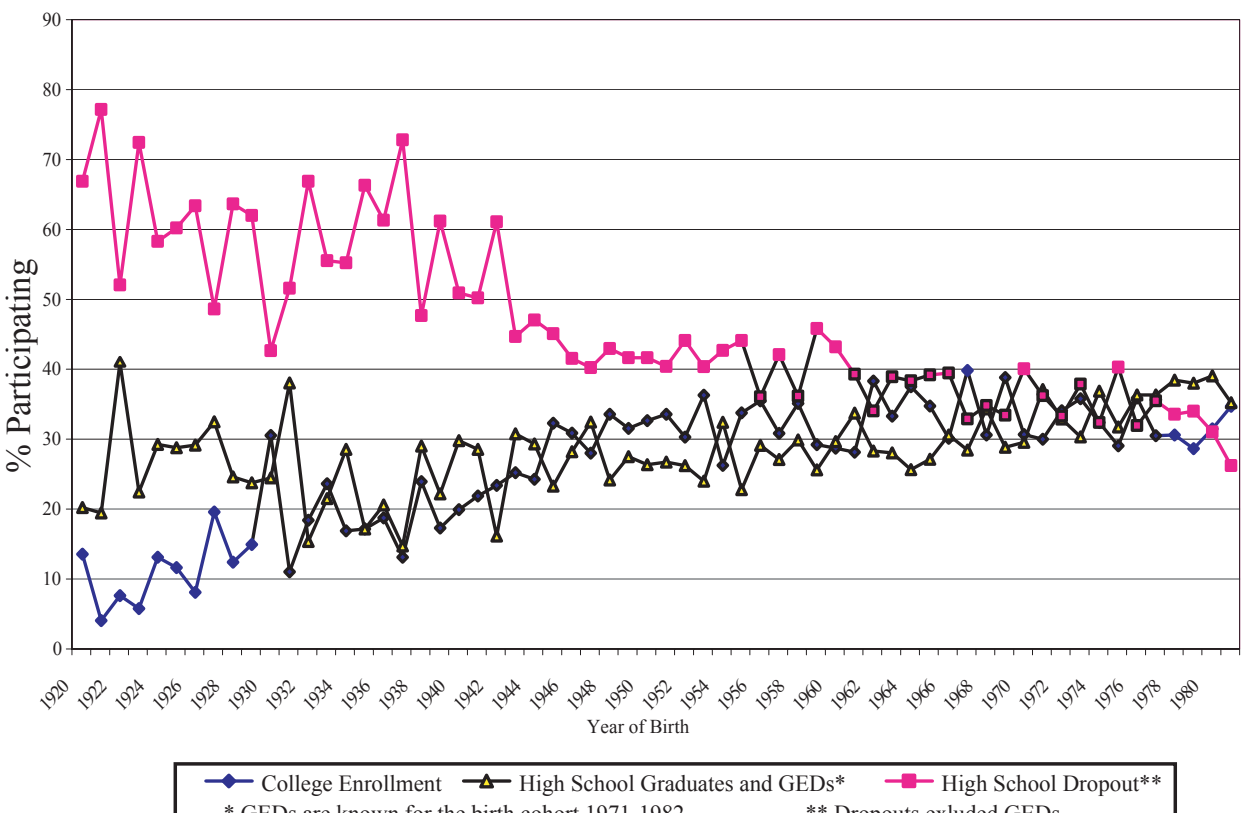

* GED are known for the birth cohort 1971-1982 
Figure 2

\section{A. College Participation Rates by Year of Birth Data from CPS 2000}

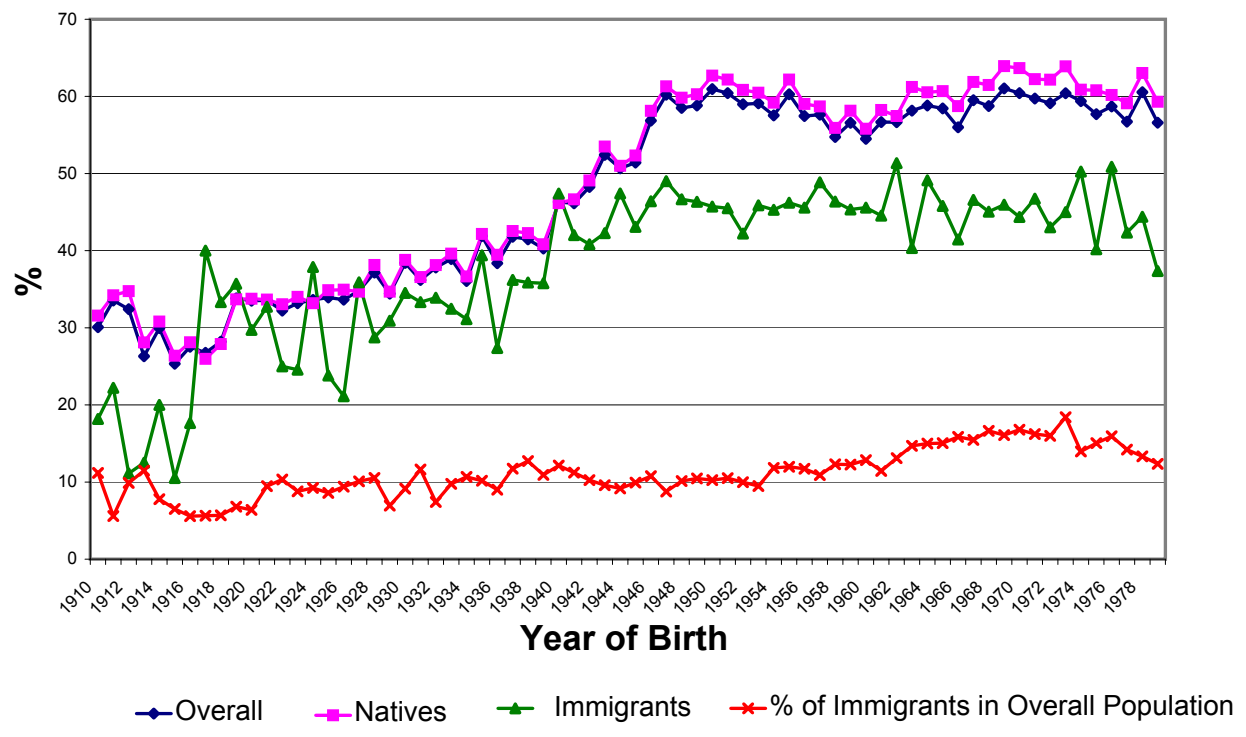

B. High School Dropout Rates (Not Including GEDs) by Year of Birth

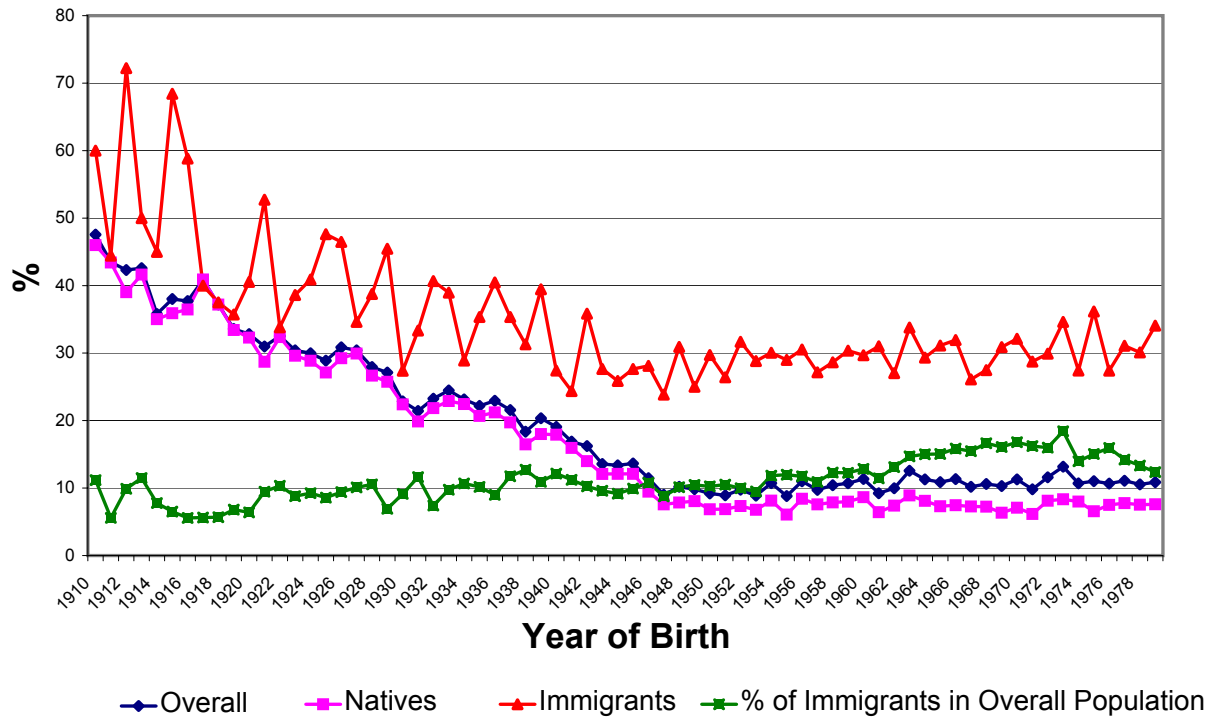

C. Percentage of Overall Educational Participation Rates due to Immigrants by Year of Birth

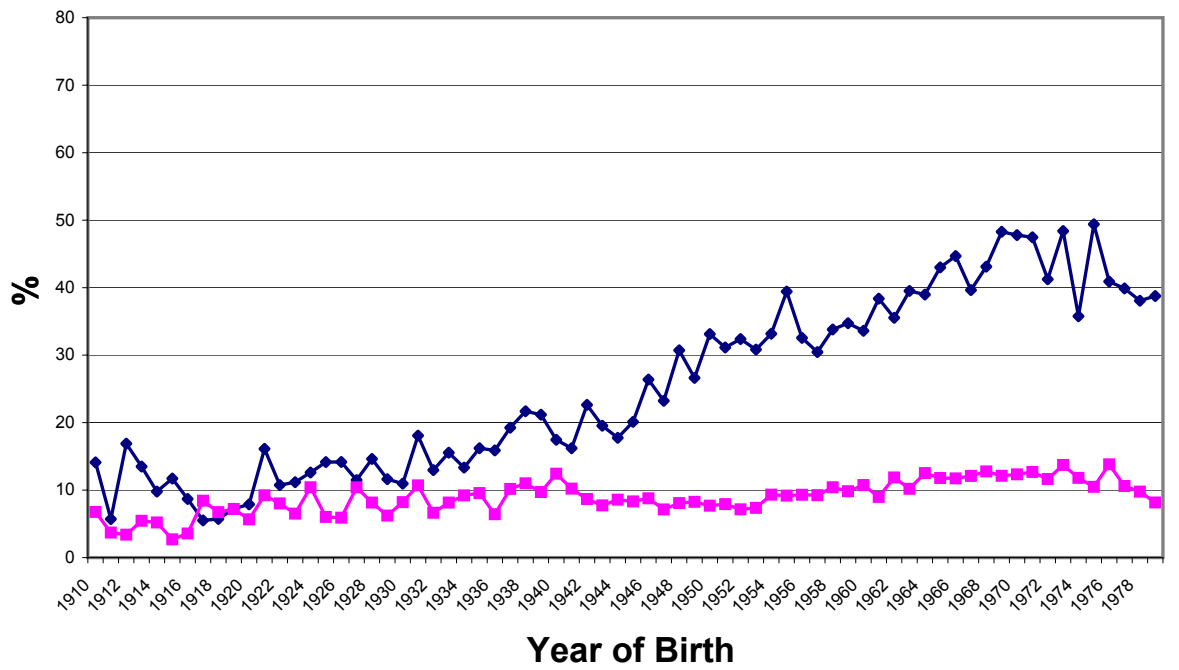


Figure 3

A. The Share of High School Dropouts in the USA, 1971-1998

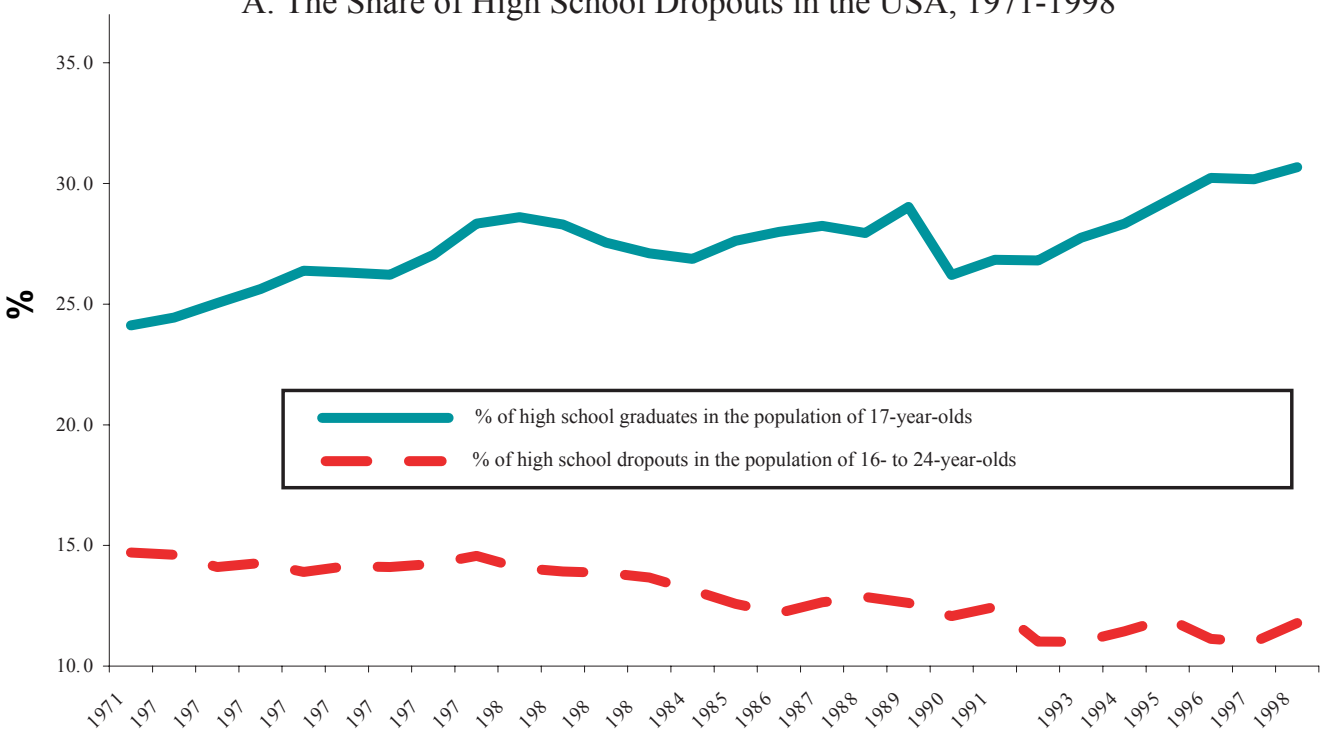

B. People Receiving High School Equivalency Credentials as a Percent of Total High School Credentials Issued by Public Schools, Private Schools and the GED Program USA, 1971- 1999

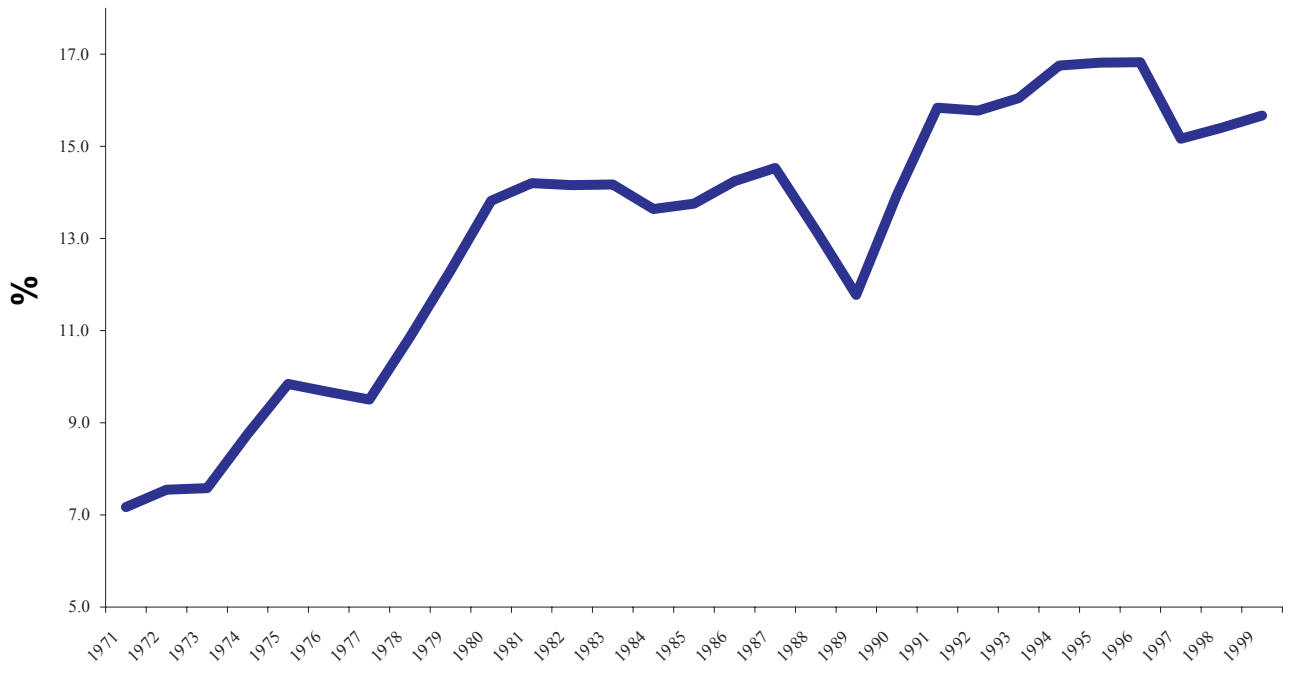

C. High School Graduates of Regular Day School Programs, Public and Private as a Percent of 17 Years Old Population

USA, 1971-1999

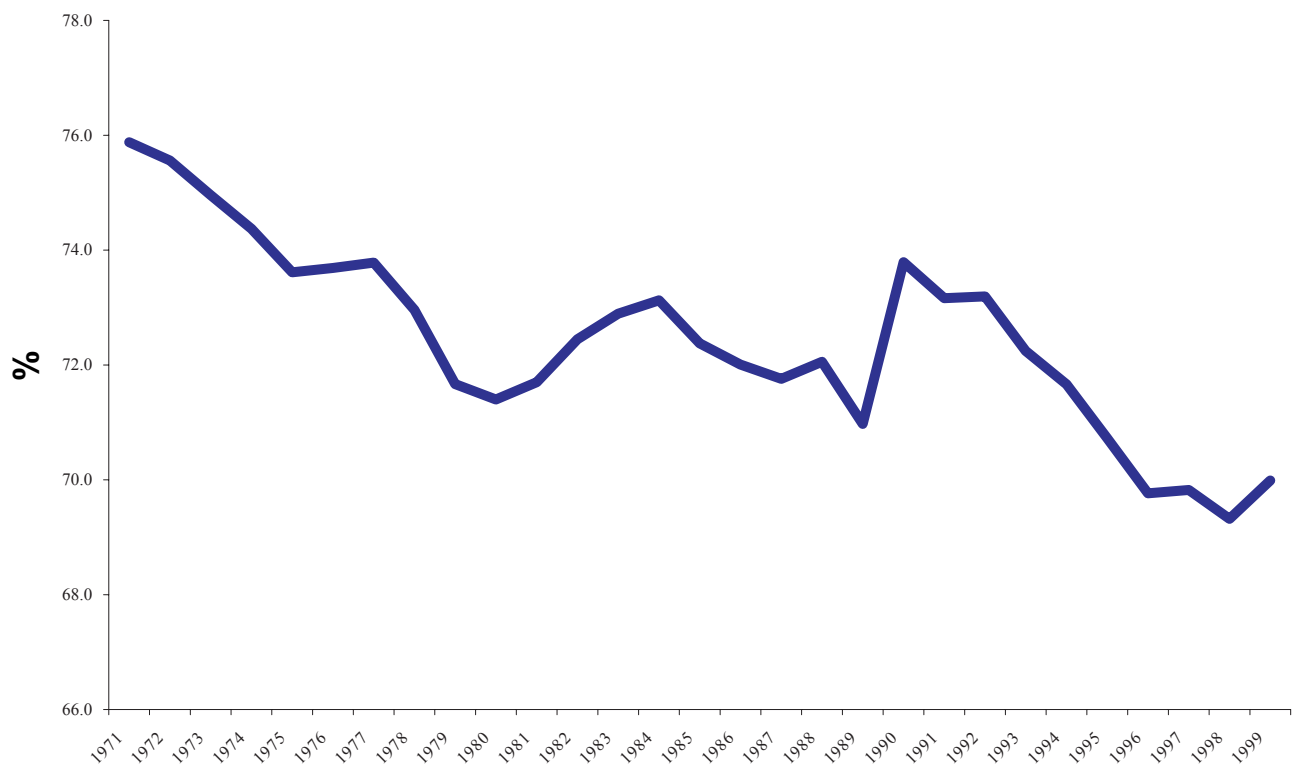

Source: U.S. Based on data from (1) The Department of Education National Center for Education Statistics and (2) American Council on Education, General Educational Development Testing Service. 


\section{Figure 4 \\ College Participation, 18 to 24 Yrs, HS Grads and GED Holders \\ Dependent* White Males}

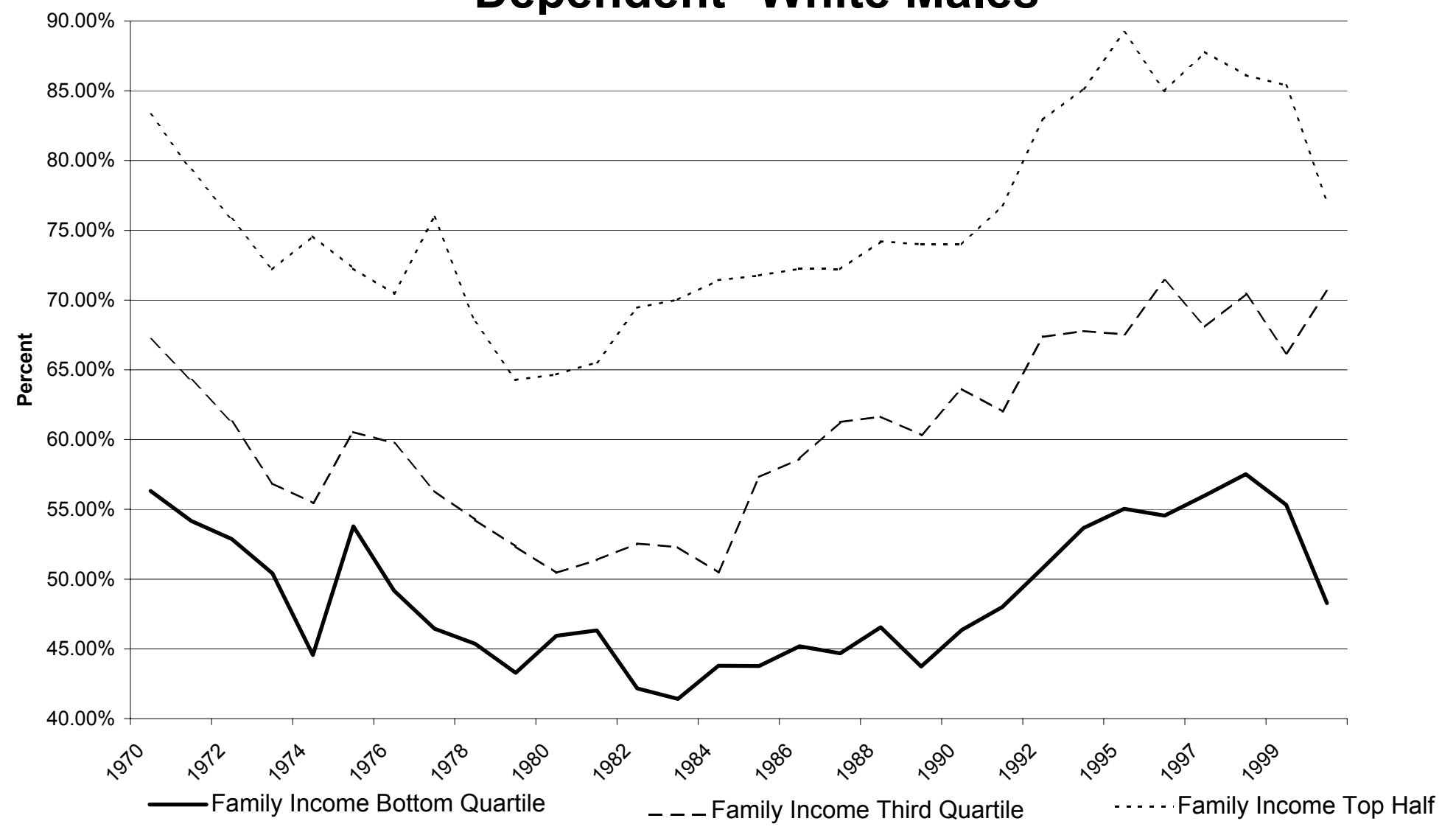

Source: These numbers were computed from the CPS P-20 School Reports and the October CPS.

*Dependent is living at parental home or supported by parental family while at college. 
Table 1

Effects of a \$1,000 Increase in Gross Tuition (Both Two- and Four-Year) on the College Entry Probabilities of High School Completers

By Family Income Quartile and By AFQT Quartile

\begin{tabular}{|c|c|c|c|}
\hline & $\begin{array}{l}\text { Whites } \\
\text { (1) }\end{array}$ & $\begin{array}{l}\text { Blacks } \\
\text { (2) }\end{array}$ & $\begin{array}{l}\text { Hispanics } \\
\text { (3) }\end{array}$ \\
\hline & \multicolumn{3}{|c|}{ A. Overall Gross Tuition Effects } \\
\hline $\begin{array}{l}\text { (1) No explanatory variables except } \\
\text { tuition in the model }\end{array}$ & -.17 & -.10 & -.10 \\
\hline $\begin{array}{l}\text { (2) Baseline specication (see note at } \\
\text { table base, includes family income and } \\
\text { background, and so forth) }\end{array}$ & -.06 & -.04 & -.06 \\
\hline $\begin{array}{l}\text { (3) Adding AFQT to the row (2) } \\
\text { specification }\end{array}$ & -.05 & -.03 & -.06 \\
\hline
\end{tabular}

(4) Top Quartile

(5) Second Quartile

(6) Third Quartile

(7) Bottom Quartile

(8) Joint Test of Equal Effects

Across Quartiles (P-values)

(9) Top Quartile

(10) Second Quartile

(11) Third Quartile

(12) Bottom Quartile

(13) Joint Test of Equal Effects

Across Quartiles (P-values)
B. By Family Income Quartiles (panel A row (2) specification)

$\begin{array}{lll}-.04 & -.01 & -.04\end{array}$

$\begin{array}{lll}-.04 & -.06 & -.05 \\ -.07 & -.03 & -.05\end{array}$

$\begin{array}{lll}-.07 & -.07 & -.08\end{array}$

$\begin{array}{lll}-.06 & -.05 & -.08\end{array}$

$\begin{array}{lll}.49 & .23 & .66\end{array}$

\begin{tabular}{ccc} 
C. By Family Income Quartiles (panel A row (3) specification) \\
\hline-.02 & -.02 & -.02 \\
-.06 & .00 & -.05 \\
-.07 & -.05 & -.09 \\
-.04 & -.04 & -.07 \\
.34 & .45 & .49
\end{tabular}

D. By AFQT Quartiles (panel A row (3) specification plus tuition-AFQT interaction terms)

(14) Top Quartile

(15) Second Quartile

(16) Third Quartile

(17) Bottom Quartile

(18) Joint Test of Equal Effects

Across Quartiles (P-values)

$\begin{array}{lll}-.03 & -.02 & -.03 \\ -.06 & -.01 & -.05 \\ -.06 & -.03 & -.07 \\ -.05 & -.03 & -.05 \\ .60 & .84 & .68\end{array}$

Gross tuition is the nominal sticker-price of college and excludes scholarship and loan support.

Notes: These simulations assume both two-year and four-year college tuition increase by $\$ 1,000$ for the population of high school completers. The baseline specification used in row (2) of panel A and rows (4) through (7) of panel B includes controls for family background, family income, average wages in the local labor market, tuition at local colleges, controls for urban and southern residence, tuition-family income interactions, estimated Pell grant award eligibility, and dummy variables, that indicate the proximity of two- and four-year colleges. Panel D specification adds AFQT and an AFQT-Tuition interaction to the baseline specification.

Source: Cameron and Heckman (1999) 


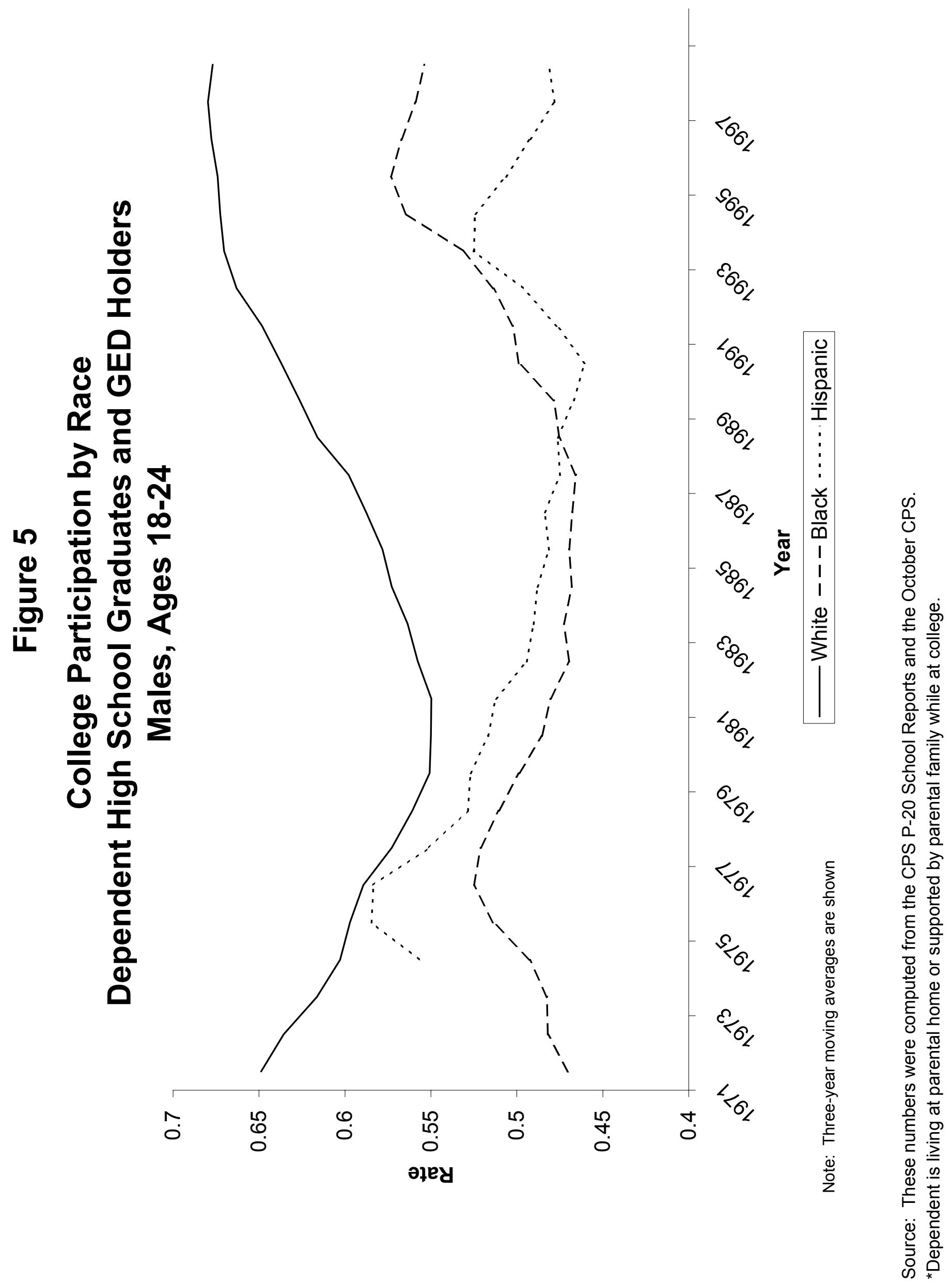




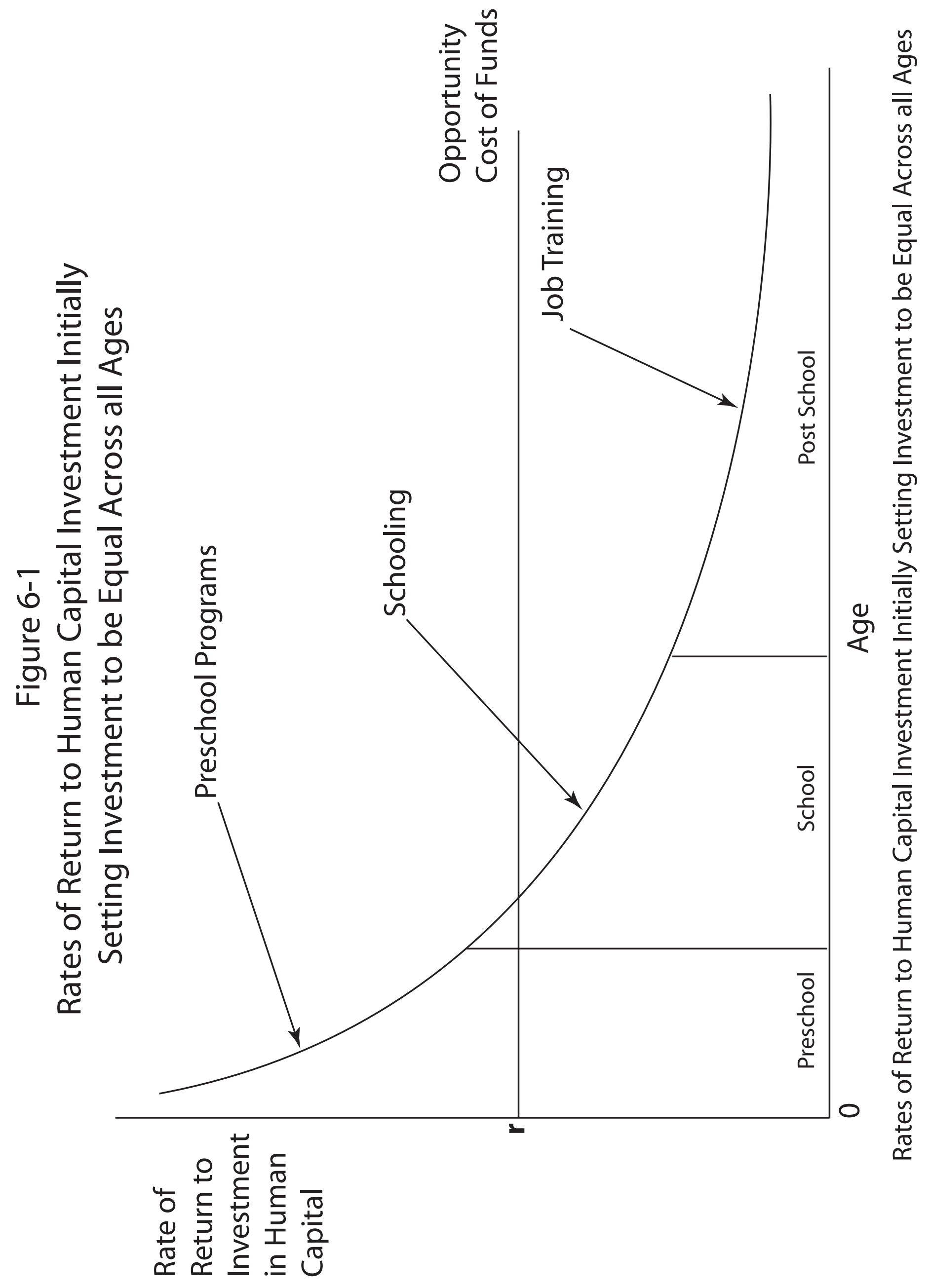




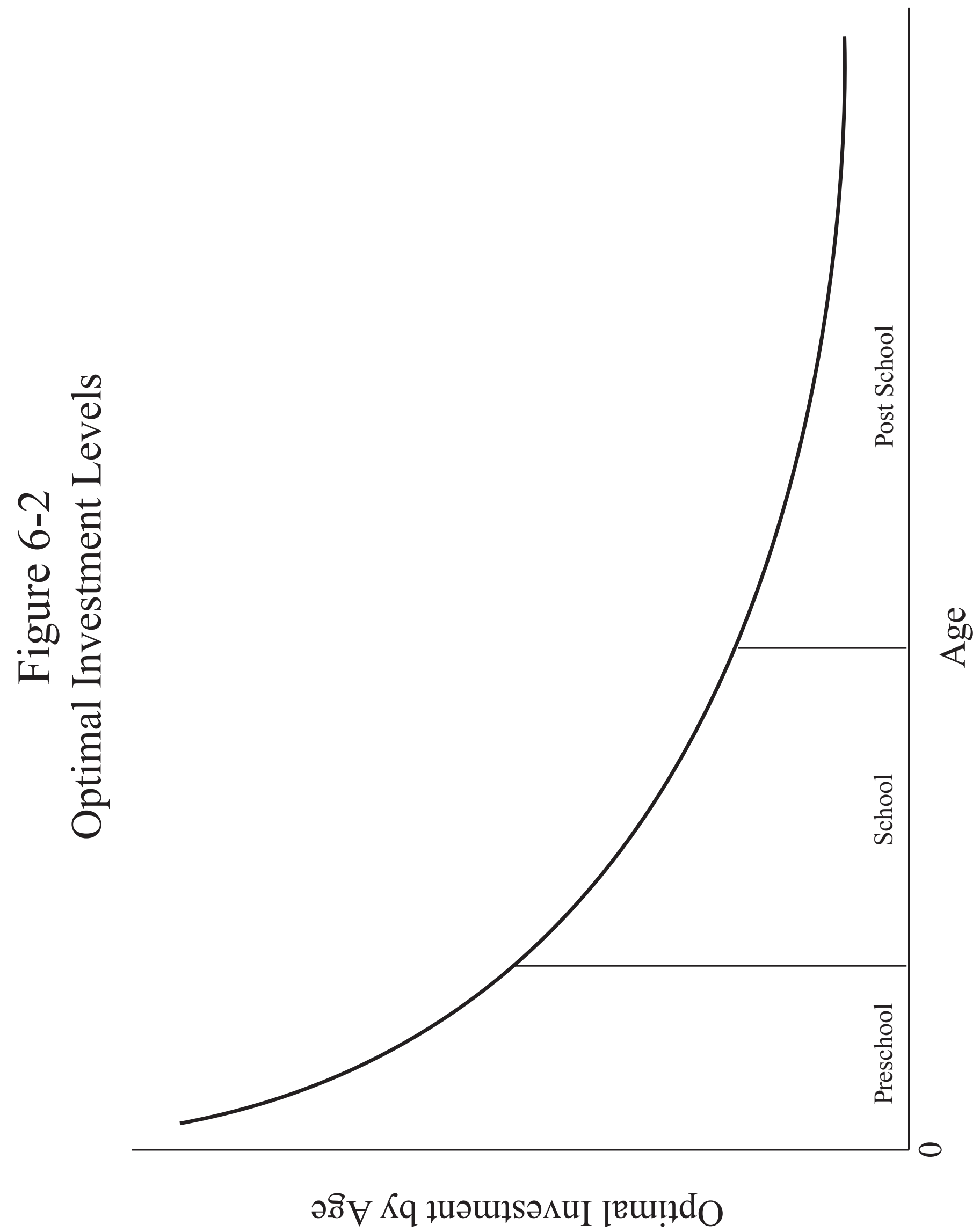


Table 2

Adjusted Gaps in College Participation

A. Percentage of Population Credit Constrained

\begin{tabular}{|c|c|c|c|c|c|c|c|}
\hline & \multicolumn{2}{|l|}{ White } & Black & \multicolumn{3}{|c|}{ Hispanic } & \multirow[t]{2}{*}{ Overall } \\
\hline & Males & Females & Males & Females & Males & Females & \\
\hline Enrollment & .0515 & .0449 & -.0047 & .0543 & .0433 & -.0789 & .0419 \\
\hline Complete 4-year College & -.0621 & 0579 & -.0612 & -.0106 & 0910 & .0908 & -.0438 \\
\hline Complete 2-year College & .0901 & .0436 & -.0684 & -.0514 & .2285 & .0680 & .0774 \\
\hline Proportion of People Not Delaying College Entry & 0872 & -.0197 & -.1125 & -.1128 & 1253 & -.0053 & .0594 \\
\hline Enrollment in 4-year vs. 2-year College & .0646 & .0491 & .1088 & .0024 & .1229 & -.0915 & .0587 \\
\hline \multicolumn{8}{|c|}{ B. Percentage of the Population Credit Constrained - Only Statistically Significant Gaps } \\
\hline & \multicolumn{2}{|c|}{ White } & Black & \multicolumn{3}{|c|}{ Hispanic } & Overall \\
\hline & Males & Females & Males & Females & Males & Females & \\
\hline Enrollment & 0 & .0095 & 0 & .0164 & .0278 & -.0139 & .0018 \\
\hline Complete 4-year College & -.0545 & .0089 & -.0596 & 0 & 0 & 0 & .0461 \\
\hline Complete 2-year College & 0 & 0 & 0 & 0 & 0 & .0409 & .0020 \\
\hline Proportion of People Not Delaying College Entry & .0714 & -.0318 & -.0190 & .0459 & .0487 & 0 & .0538 \\
\hline Enrollment in 4-year vs. 2-year College & .0530 & 0 & 0 & 0 & 0 & -.0451 & .0391 \\
\hline
\end{tabular}

C. Percentage of Population Family Constrained

\begin{tabular}{lccccccc}
\hline & White & \multicolumn{3}{c}{ Black } & Hispanic & & Overall \\
& Males & Females & Males & Females & Males & Females & \\
\hline Enrollment & .3123 & .3280 & .2658 & .2420 & .3210 & .2923 & .2623 \\
Complete 4-year College & .2723 & .2338 & .1435 & .0738 & .4950 & .0205 & .1958 \\
Complete 2-year College & -.1718 & -.0350 & -.0763 & -.0565 & -.1945 & .2168 & -.0785 \\
Proportion of People Not Delaying College Entry & .1965 & .1898 & .1910 & .0460 & .1950 & .1360 & .1135 \\
Enrollment in 4-year vs. 2-year College & .0568 & .2423 & .1643 & .1143 & .1533 & .0738 & .1155 \\
\multicolumn{1}{c}{ D. Percentage of Population Family Constrained - Only Statistically Significant Gaps } \\
\hline \\
\hline
\end{tabular}

Notes: Credit constraints are measured in the following way. Within each AFQT tertile, regress enrollment (completion, delay) on quartiles of the distribution of family income at 17 and family background variables (south, broken, urban, mother's education, father's education): $y=\alpha+F \gamma+Q_{1} \beta_{1}+Q_{2} \beta_{2}+Q_{3} \beta_{3}$, where $y$ is enrollment (completion, delay), $F$ is a vector of family background variables, $Q_{1}$ is a dummy for being in the first quartile of the family income distribution, $Q_{2}$ for the second and $Q_{3}$ for the third. Within each AFQT tertile, the percentage of people constrained in each quartile of family income is measured by $\beta_{1}, \beta_{2}$ and $\beta_{3}$, which are gaps in average enrollment (completion, delay) between each quartile and the top quartile of the family income. To get the numbers in the table we multiply the measured gap in enrollment (completion, delay) for each quartile relative to the highest quartile by the percentage of people in that AFQT tertile-Family Income quartile. Within each AFQT tertile we add over the three bottom quartiles of family income and then add over the three tertiles of AFQT to get the number of credit constrained people in the population. When computing family constraints we use a family background index which is a linear combination of south, broken, urban, mother's education, father's education and AFQT. The coefficients for this linear combination are obtained by doing a linear regression of enrollment (completion, delay) on the variables composing the index. We then construct quartiles of this index. Family constraints are measured in the following way. Regress enrollment (completion, delay) on the family background quartile and family income at age 17: $y=\alpha+Q_{1} \gamma_{1}+Q_{2} \gamma_{2}+Q_{3} \gamma_{3}+\operatorname{Inc} 17 \beta$, where $y$ is enrollment (completion, delay), $Q_{1}$ is a dummy for being in the first quartile of the family background index, $Q_{2}$ for the second and $Q_{3}$ for the third, and Inc17 is family income at age 17. The percentage of people constrained in each quartile of the family background index is measured by $\gamma_{1}, \gamma_{2}$, and $\gamma_{3}$, which are gaps in average enrollment (completion, delay) between each quartile and the top quartile of the family background index. To get the numbers in the table we multiply the measured gap in enrollment (completion, delay) for each quartile relative to the highest quartile by the percentage of people in that quartile. Then we add over the three bottom quartiles to get the number of family constrained people in the population. The coefficients for these regressions for white males are presented in the appendix tables B-1 and B-2. Results for the other demographic groups are available on request from the authors. 
Table 3

Regressions of Enrollment in College on Per Capita Permanent Income, Per Capita Early Income, and Per Capita Late Income: Children of NLSY

\begin{tabular}{|c|c|c|c|c|}
\hline Variable & (1) & $(2)$ & $(3)$ & (4) \\
\hline $\begin{array}{l}\text { Family Income 0-18 (Permanent Income) } \\
\text { (Standard Error) }\end{array}$ & $\begin{array}{c}0.3114 \\
(0.0463)\end{array}$ & $\begin{array}{c}0.2752 \\
(0.0755)\end{array}$ & $\begin{array}{c}0.311 \\
(0.0613)\end{array}$ & $\begin{array}{c}0.2645 \\
(0.0996)\end{array}$ \\
\hline $\begin{array}{l}\text { Income } 0-5 \\
\text { (Standard Error) }\end{array}$ & - & $\begin{array}{c}0.0498 \\
(0.0821)\end{array}$ & - & $\begin{array}{c}0.053 \\
(0.0877)\end{array}$ \\
\hline $\begin{array}{l}\text { Income } 16-18 \\
\text { (Standard Error) }\end{array}$ & - & - & $\begin{array}{l}-0.0005 \\
(0.0605)\end{array}$ & $\begin{array}{c}0.013 \\
(0.0645)\end{array}$ \\
\hline $\begin{array}{l}\text { PIAT-Math at Age } 12 \\
\text { (Standard Error) }\end{array}$ & $\begin{array}{c}0.0074 \\
(0.0018)\end{array}$ & $\begin{array}{c}0.0073 \\
(0.0018)\end{array}$ & $\begin{array}{c}0.0073 \\
(0.0018)\end{array}$ & $\begin{array}{c}0.0073 \\
(0.0018)\end{array}$ \\
\hline $\begin{array}{l}\text { Constant } \\
\text { (Standard Error) }\end{array}$ & $\begin{array}{c}0.154 \\
(0.0259)\end{array}$ & $\begin{array}{c}0.1521 \\
(0.0261)\end{array}$ & $\begin{array}{c}0.1523 \\
(0.0260)\end{array}$ & $\begin{array}{c}0.1506 \\
(0.0262)\end{array}$ \\
\hline $\begin{array}{l}\text { Observations } \\
\mathrm{R}^{2}\end{array}$ & $\begin{array}{c}863 \\
.1 \\
\end{array}$ & $\begin{array}{c}863 \\
.1 \\
\end{array}$ & $\begin{array}{c}854 \\
.1 \\
\end{array}$ & $\begin{array}{c}854 \\
.1 \\
\end{array}$ \\
\hline
\end{tabular}

Notes: Family income (permanent income) 0-18 is average family income between the ages of 0 and 18 . Income 0-5 is average family income between the ages of 0 and 5. Income 16-18 is average family income between the ages of 16 and 18 . Income is measured in per capita terms (dividing family income by family size year by year) in tens of thousands of 1993 dollars.

Average discounted family income: We used a discount rate of 5\%. PIAT-Math is a math test score. For details on this sample see BLS (2001). Let $Y_{i, t}$ be the per capita family income at age $t$ for child $i$. Family income $0-18=\sum_{t=0}^{18} \frac{Y_{i, t}}{(1+r)^{t}} \cdot \frac{\frac{1}{1+r}-1}{\left(\frac{1}{1+r}\right)^{19}-1}$, resources in present value terms over the life of the child where $r$ is theinterest rate $=.05$. Income $0-5=\sum_{t=0}^{5} \frac{Y_{i, t}}{(1+r)^{t}} \cdot \frac{\frac{1}{1+r}-1}{\left(\frac{1}{1+r}\right)^{6}-1}$.

Income $16-18=\frac{1}{(1+r)^{15}} \sum_{t=16}^{18} \frac{Y_{i, t}}{(1+r)^{t}} \cdot \frac{\frac{1}{1+r}-1}{\left(\frac{1}{1+r}\right)^{3}-1}$. 
Figure 7-1

Enrollment, Completion and No Delay Rates by Family Income Quartiles and Age-Adjusted AFQT Terciles White Males, NLSY79

A. Percentage Enrolled in 2-Year and 4-Year Colleges

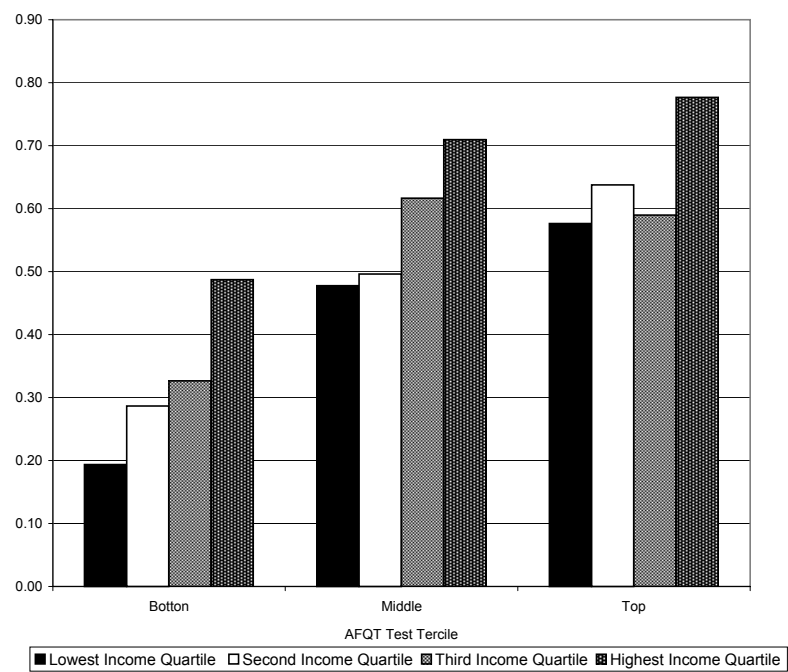

C. 4-Year College Completion Rate

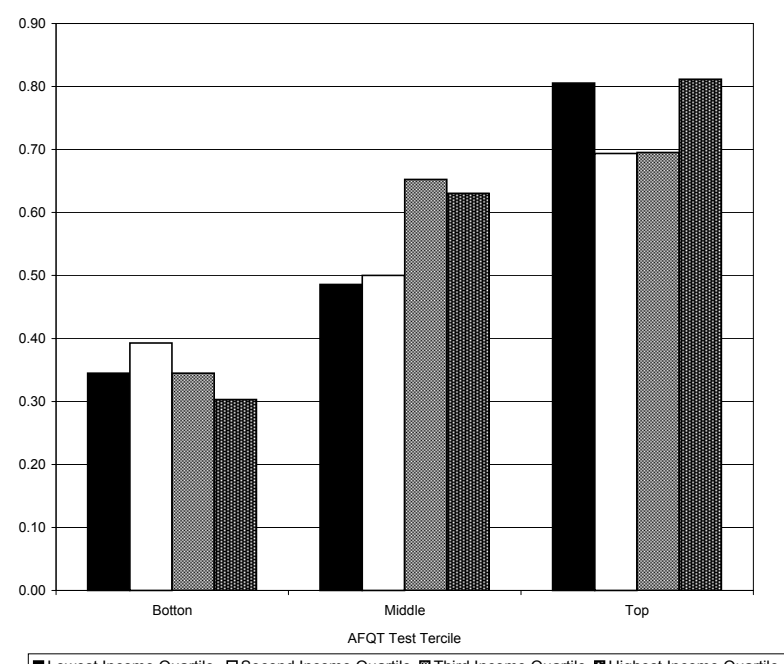

E. Percentage with No Delay in College Entry

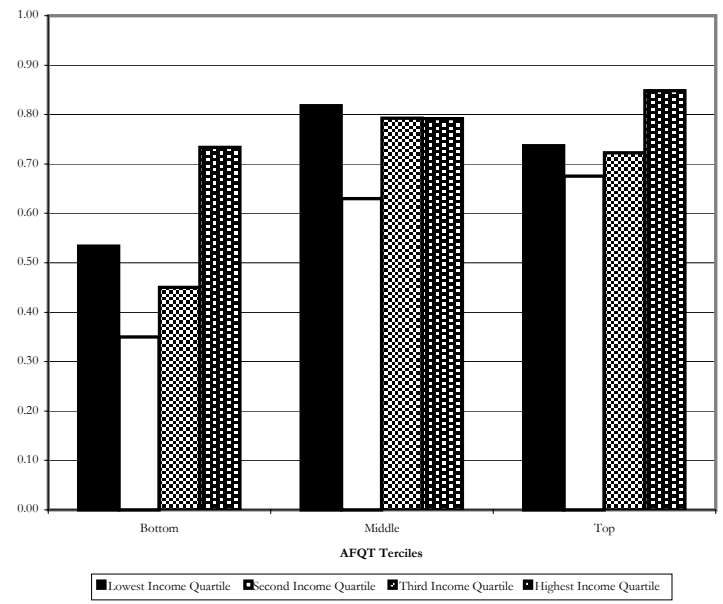

B. Adjusted Percentage Enrolled in 2-Year and 4-Year Colleges

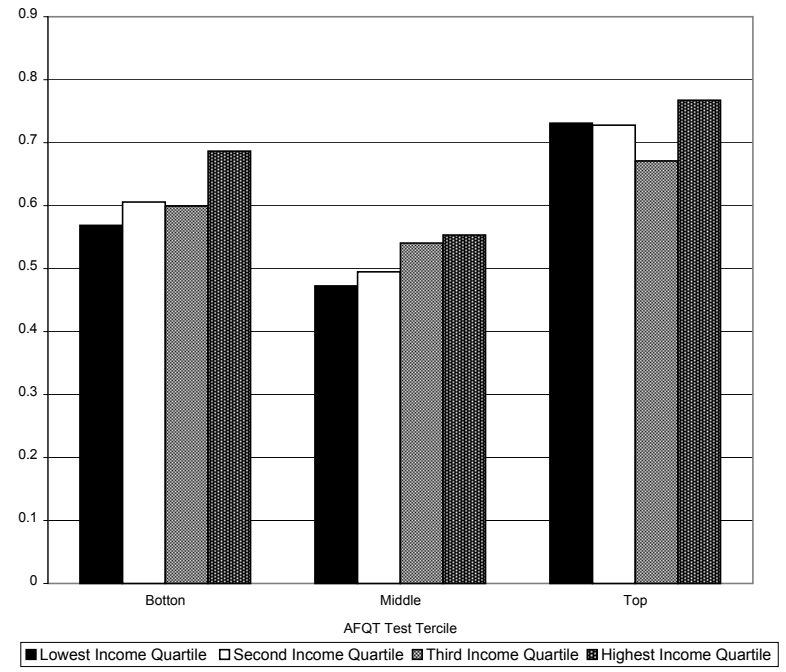

D. Adjusted 4-Year College Completion Rate

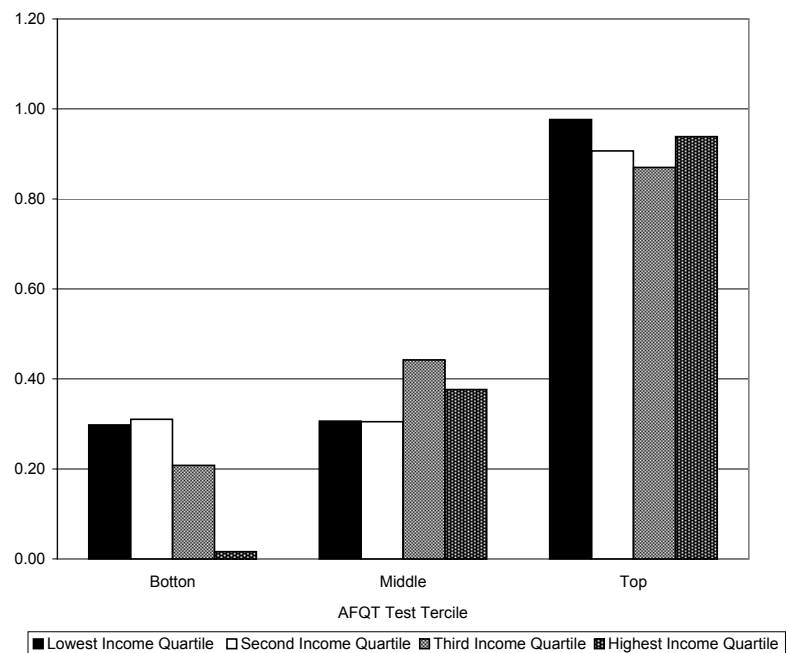

F. Adjusted Percentage with No Delay in College Entry

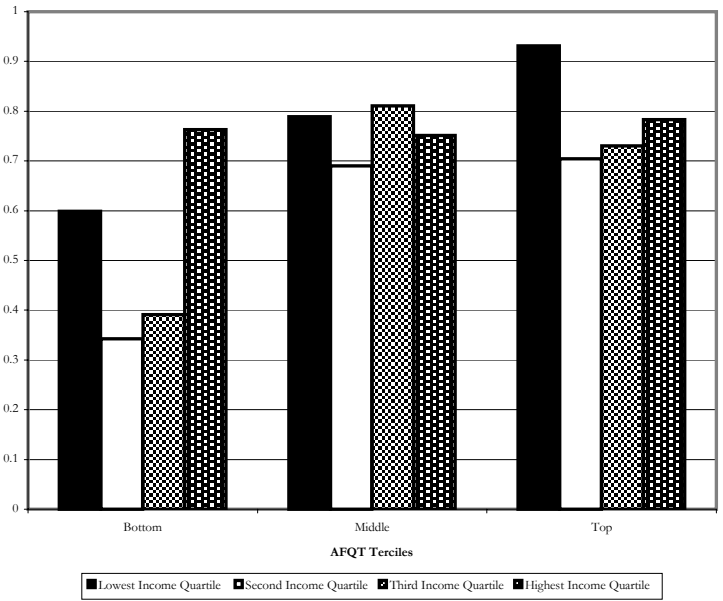

Note: To draw these graphs we performed the following steps. 1) Within each AFQT tercile, we regress percentage enrolled, completion rate, and percentage with no delay on family background: $y=\alpha+F \gamma+Q_{1} \beta_{1}+Q_{2} \beta_{2}+Q_{3} \beta_{3}$, where $y$ is percentage enrolled, completion rate, or percentage with no delay, $\mathrm{F}$ is a vector of family background variables (southern origin, broken home, urban origin, mother's education and father's education), $\mathrm{Q}_{1}$ is a dummy for being in the first quartile of the distribution of family income at $17, \mathrm{Q}_{2}$ is for being in the second quartile and $\mathrm{Q}_{3}$ is for being in the third quartile. 2) Then, within each AFQT tercile, the height of the first bar is given by $\alpha+\overline{\mathrm{F}} \gamma+\beta_{1}$, the second is given by $\alpha+\overline{\mathrm{F}} \gamma+\beta_{2}$, the third by $\alpha+\overline{\mathrm{F}} \gamma+\beta_{3}$ and the fourth by $\alpha+\overline{\mathrm{F}} \gamma$ (where $\overline{\mathrm{F}}$ is a vector of the mean values for the variables in $\mathrm{F}$ ). The coefficients for the regression are given in the appendix table B-3. 
Figure 7-2

\section{Enrollment, Completion and Delay by Family Background - AFQT Quartiles \\ NLSY79 White Males}

A. Enrollment
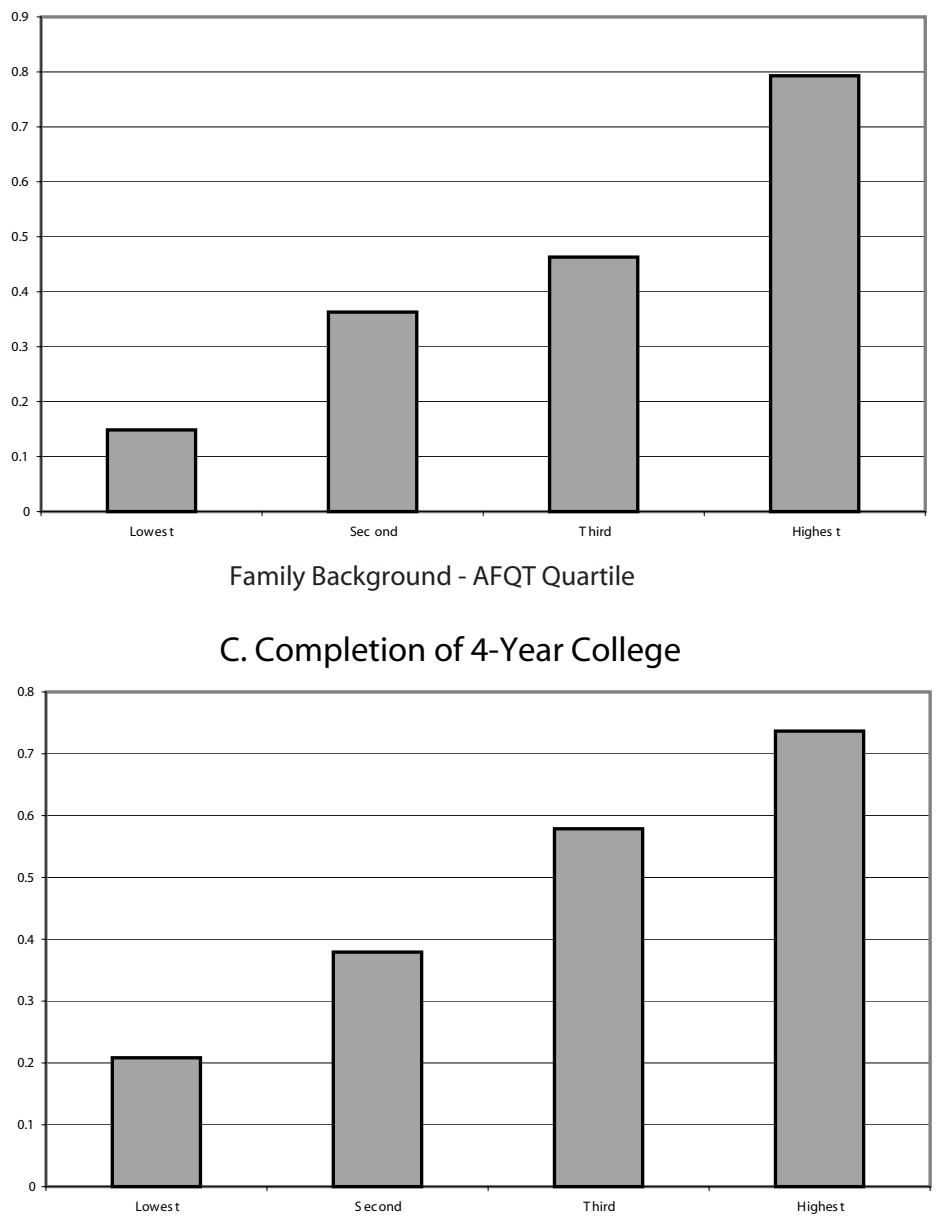

Family Background - AFQT Quartile

E. Proportion Not Delaying College Entry

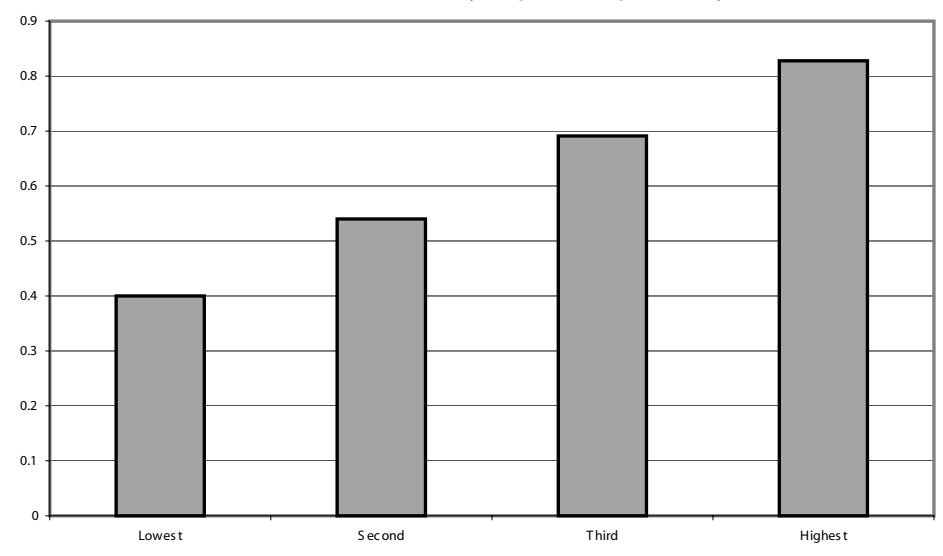

Family Background - AFQT Quartile
B. Adjusted Enrollment

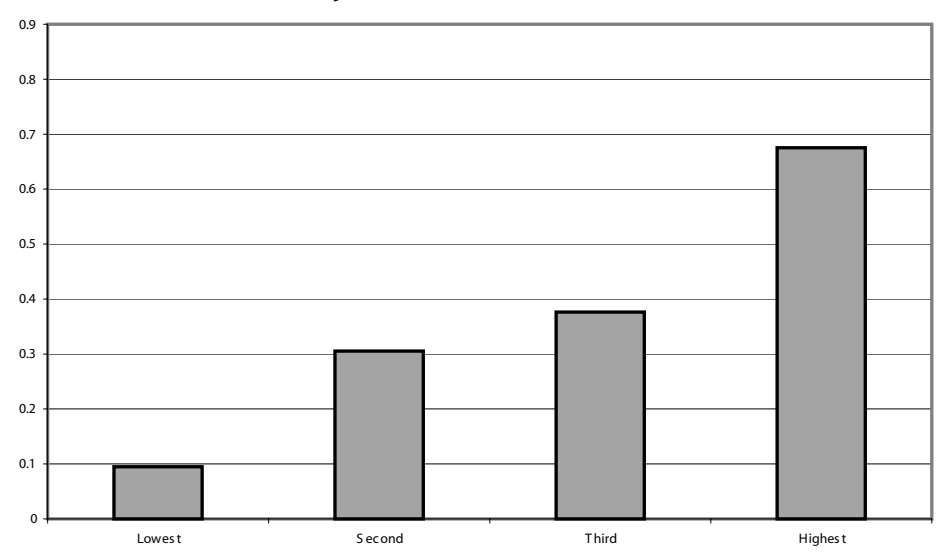

Family Background - AFQT Quartile

D. Adjusted Completion of 4-Year College

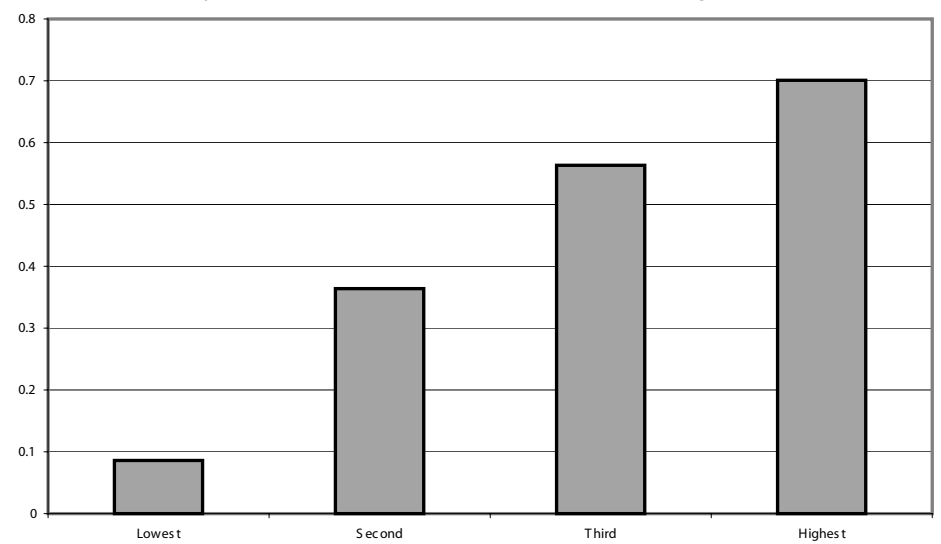

Family Background - AFQT Quartile

F. Adjusted Proportion Not Delaying College Entry

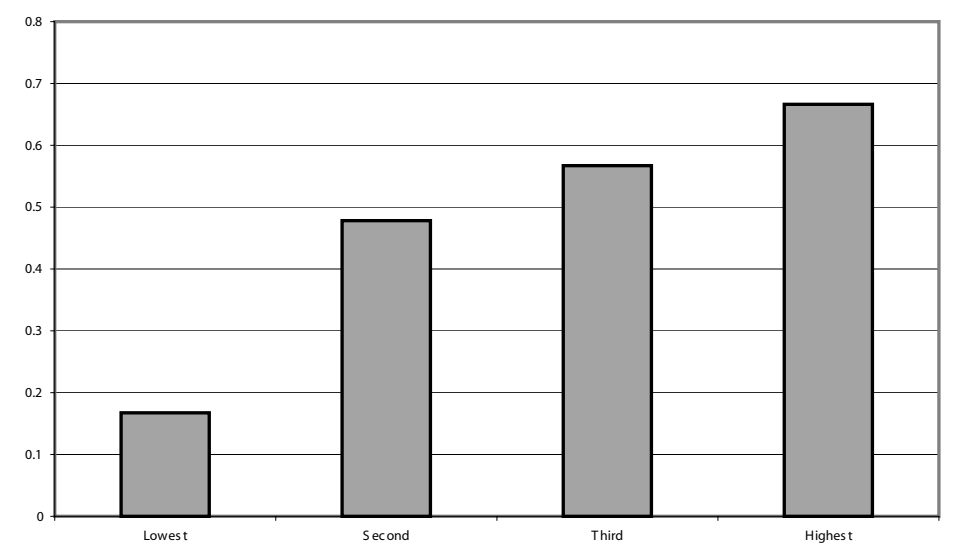

Family Background - AFQT Quartile

We correct for the effect of schooling at the test date on AFQT. The family background-AFQT index is based on a linear combination of south, broken home, urban, mother's education, father's education and AFQT. For the residual plots, we condition on family income at age 17. See table B-4 in the appendix for the coefficients of the linear combination of the variables forming this index. 


\section{Figure 8}

\section{Children of NLSY}

A. Average Percentile Rank on PIAT-Math Score, by Income Quartile*

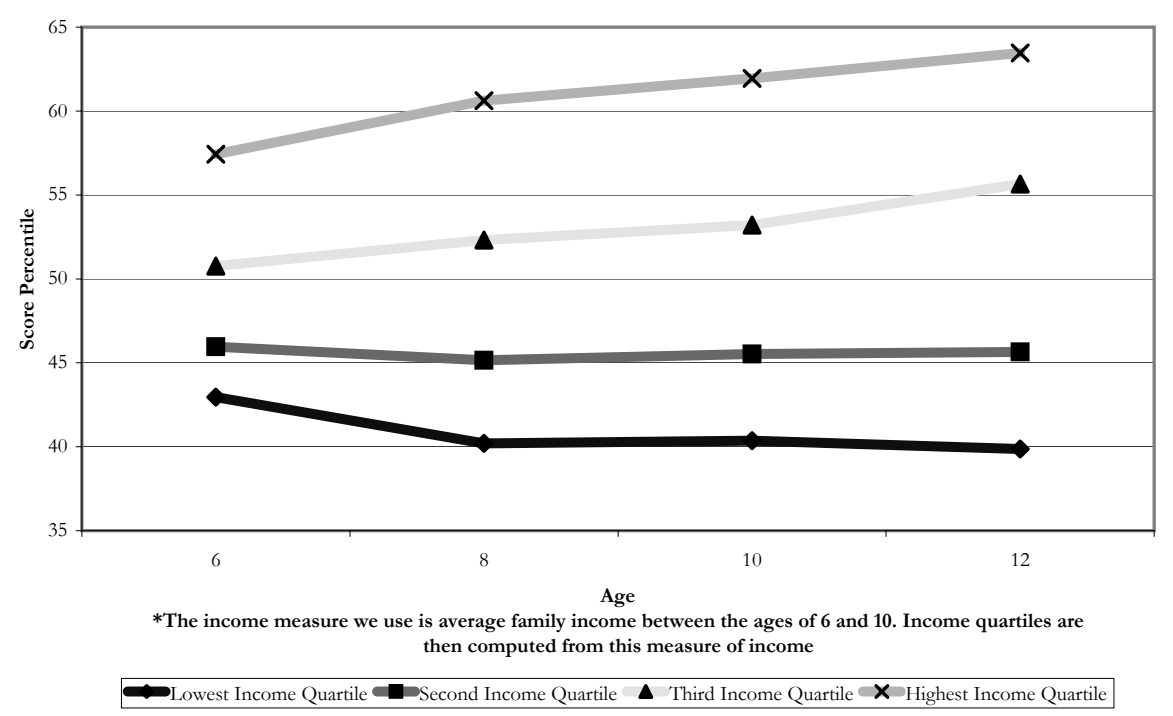

B. Average Percentile Rank on PIAT-Math Score, by Income Quartile* Whites Only

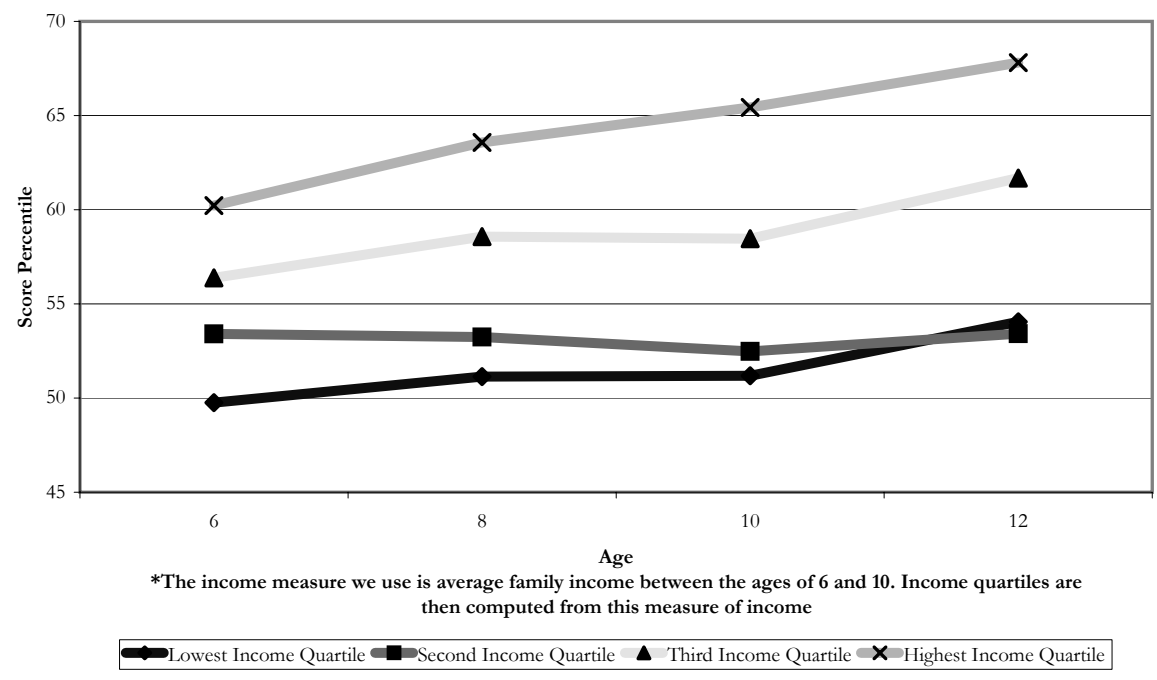

C. Average Percentile Rank on PIAT-Math Score, by Race

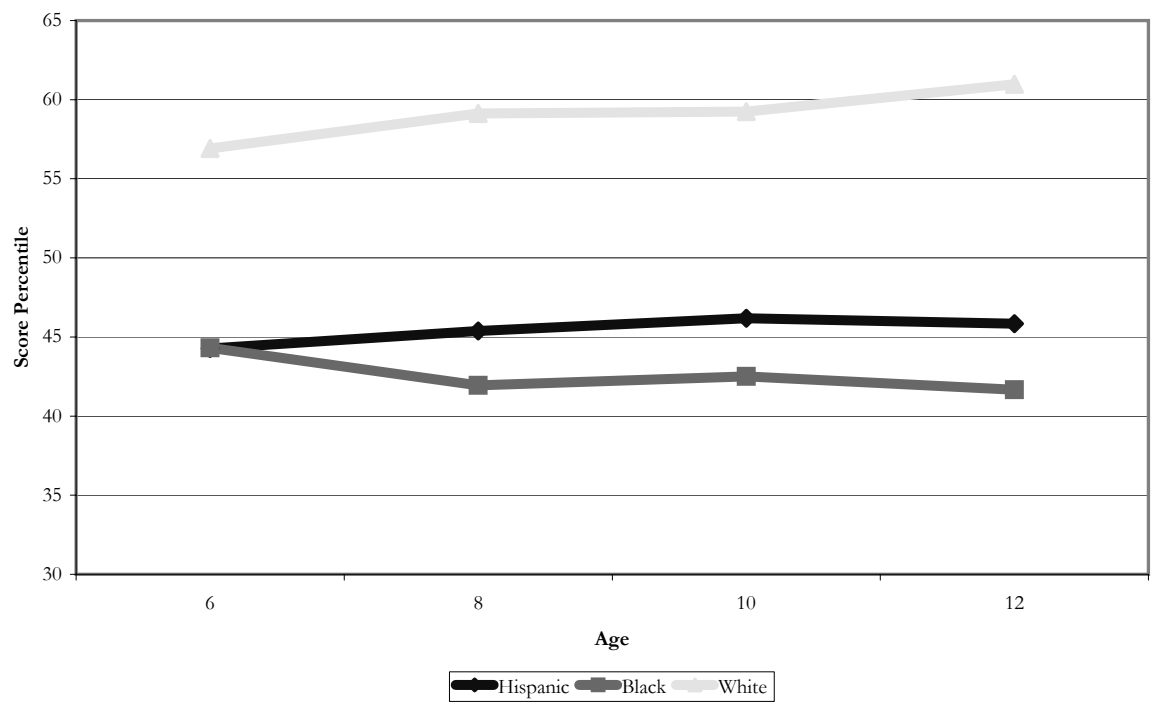


Figure 9

\section{Children of NLSY}

A. Residualized Average PIAT-Math Score Percentiles by Income Quartile*

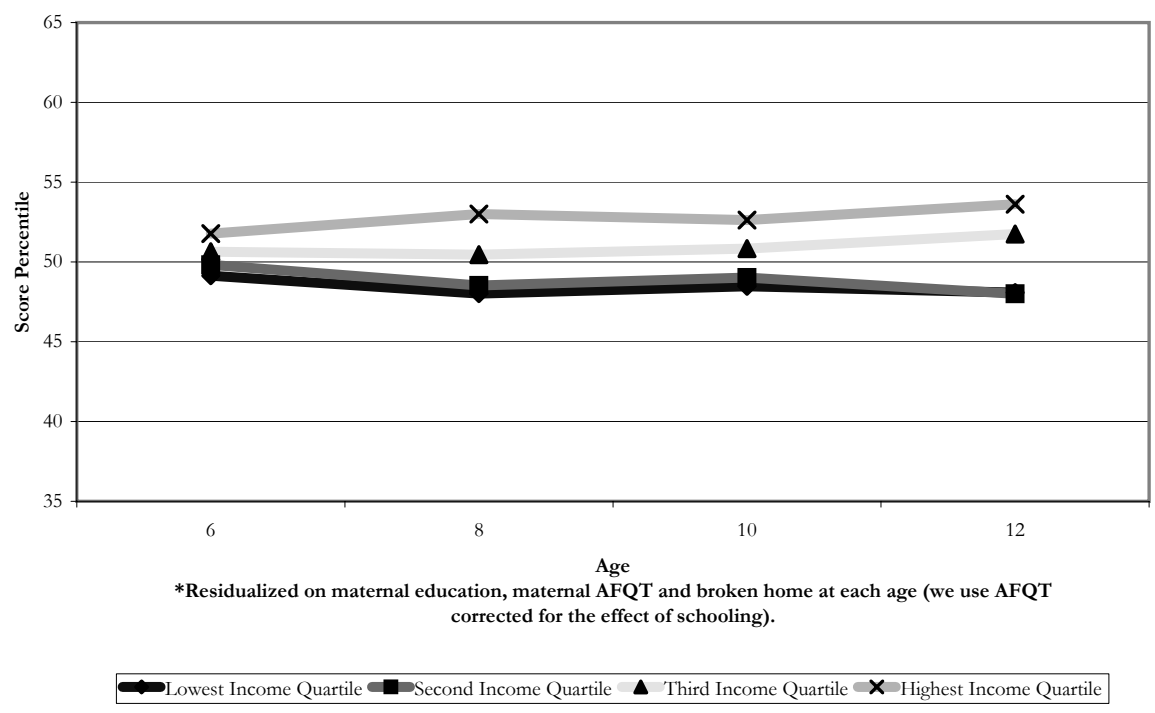

B. Residualized Average PIAT-Math Score Percentiles by Income Quartile* Whites Only

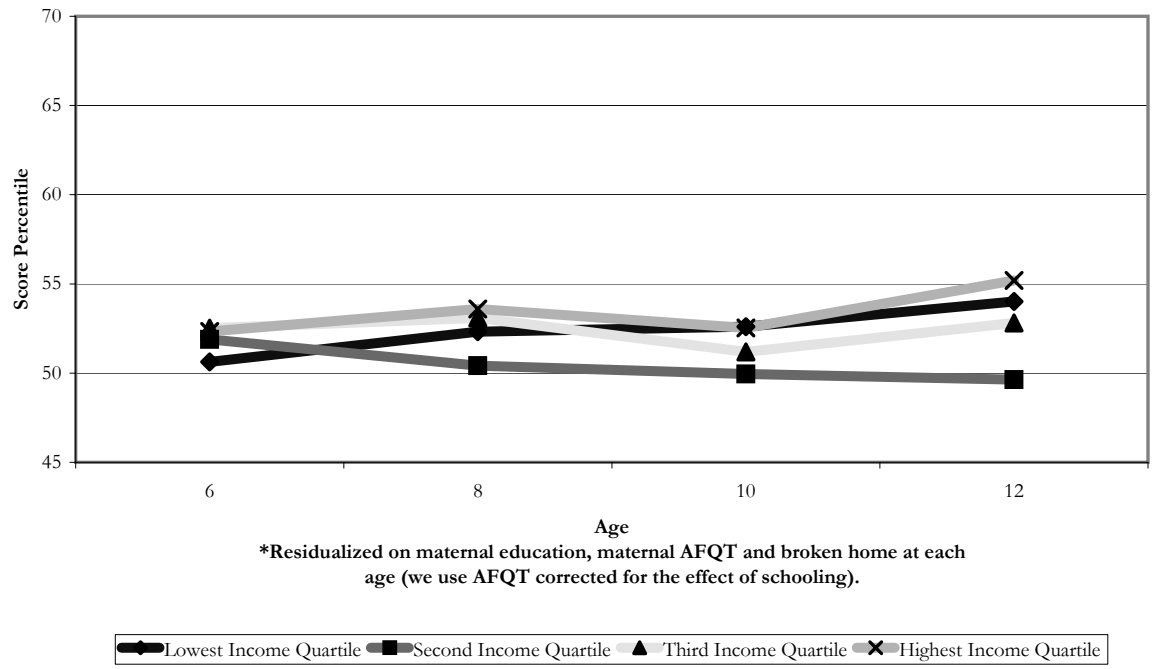

C. Residualized Average PIAT-Math Score Percentile by Race*

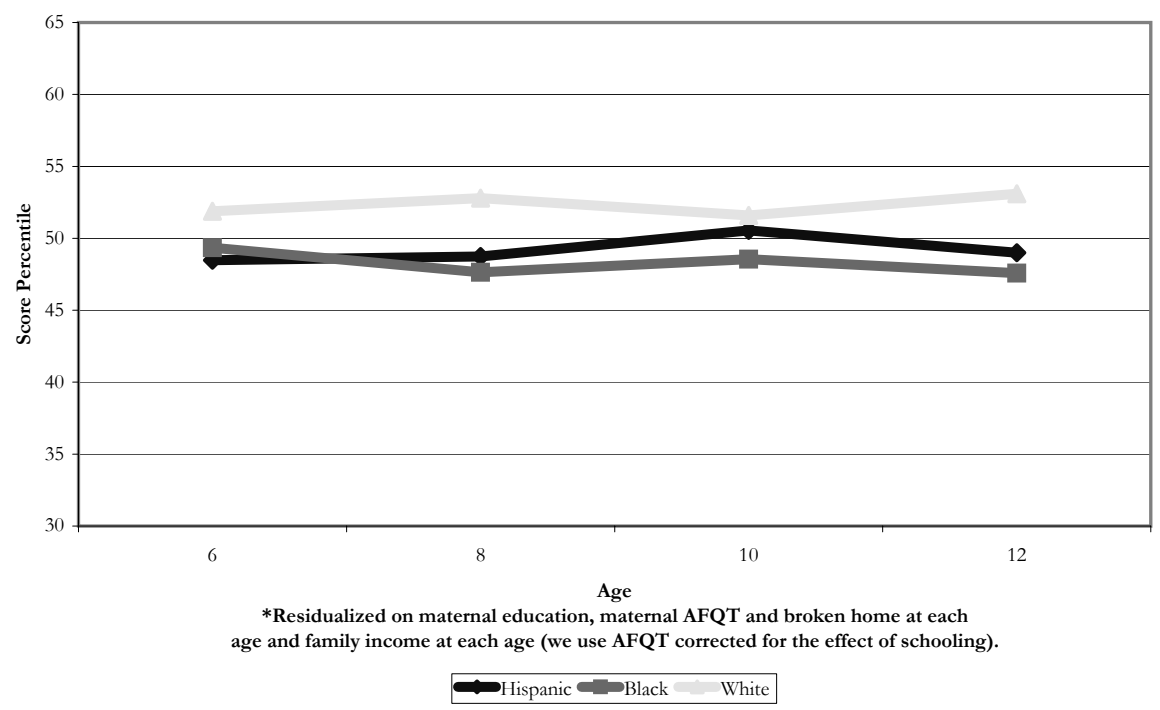


Figure 10

\section{Children of NLSY}

A. Average Percentile Rank on Anti-Social Score, by Income Quartile*

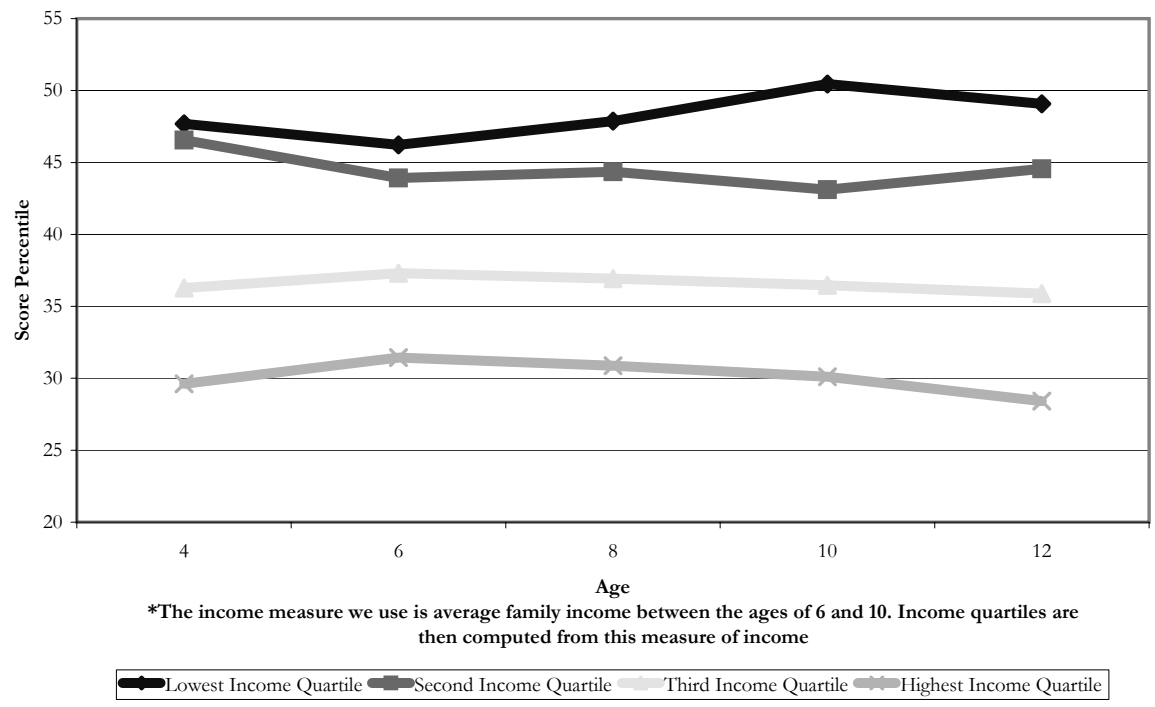

B. Average Percentile Rank on Anti-Social Score, by Income Quartile* Whites Only

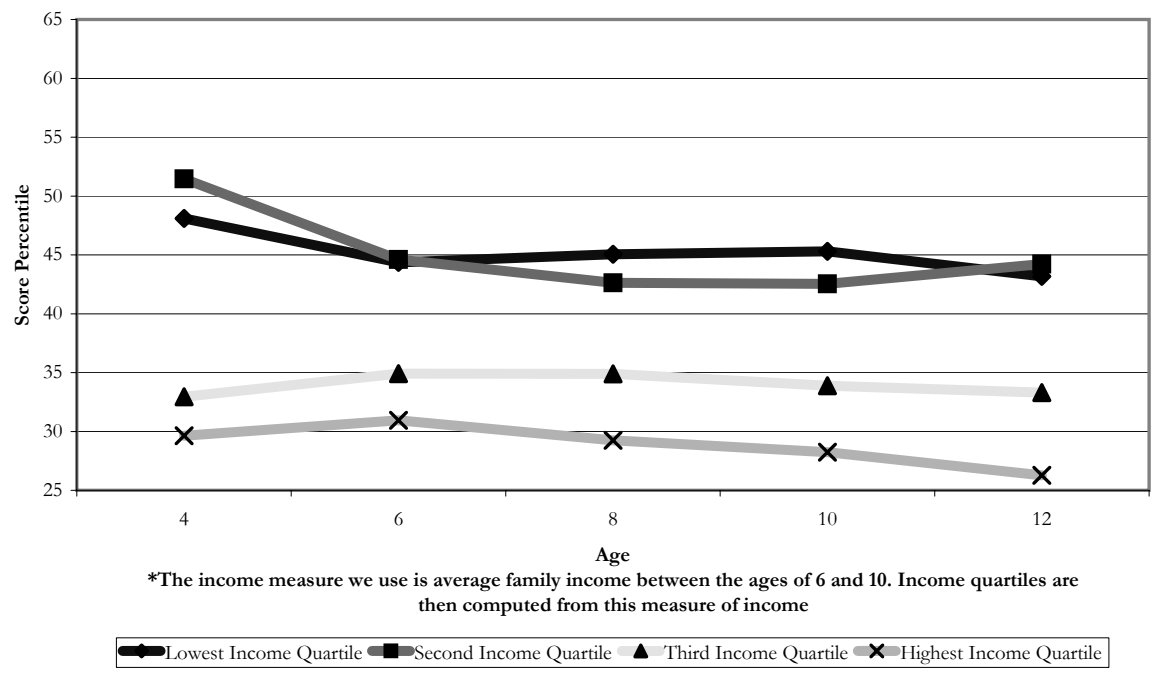

C. Average Percentile Rank on Anti-Social Score, by Race

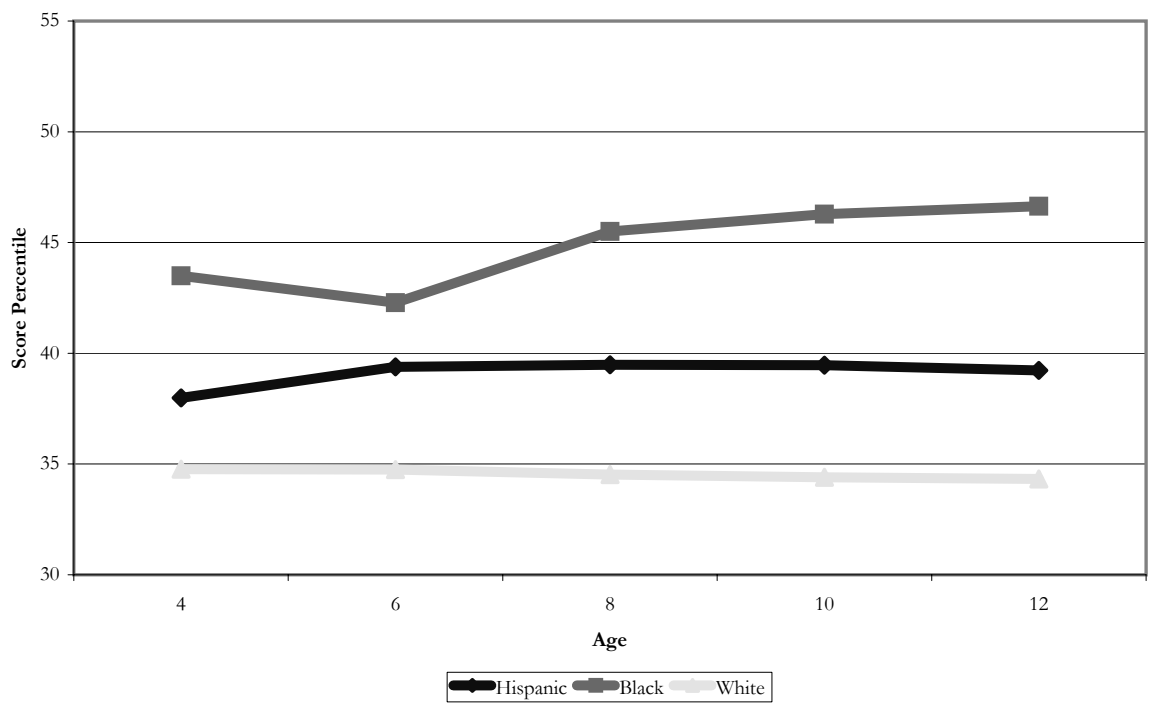




\section{Figure 11}

\section{Children of NLSY}

A. Residualized Average Anti-Social Score Percentile by Income Quartile*

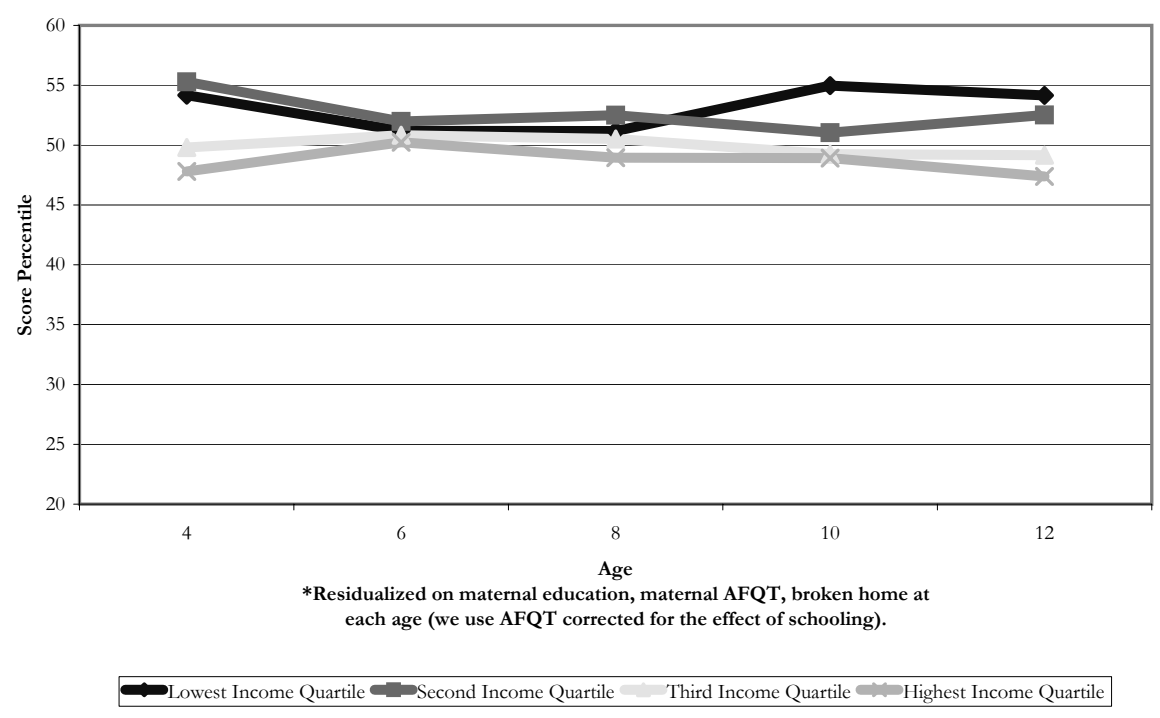

B. Residualized Average Anti-Social Score Percentile by Income Quartile* Whites Only

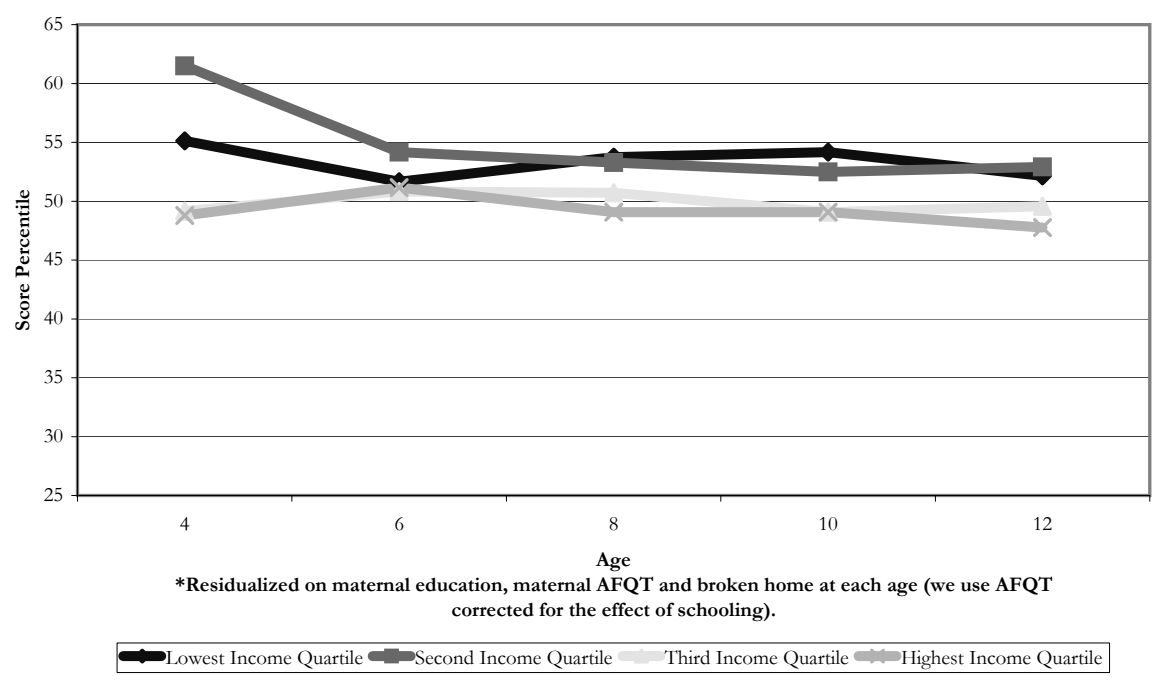

C. Residualized Average Anti-Social Score Percentile by Race*

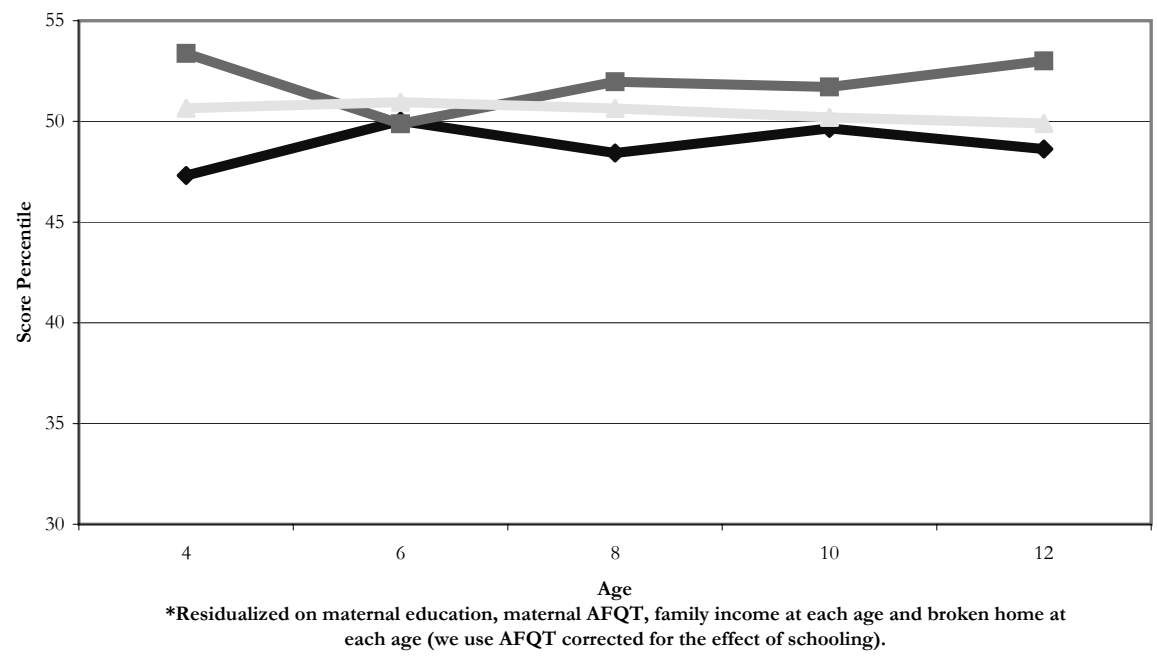


Figure 12

Density of Age Adjusted AFQT Scores,

GED Recipients and High School Graduates with Twelve Years of Schooling

White Males

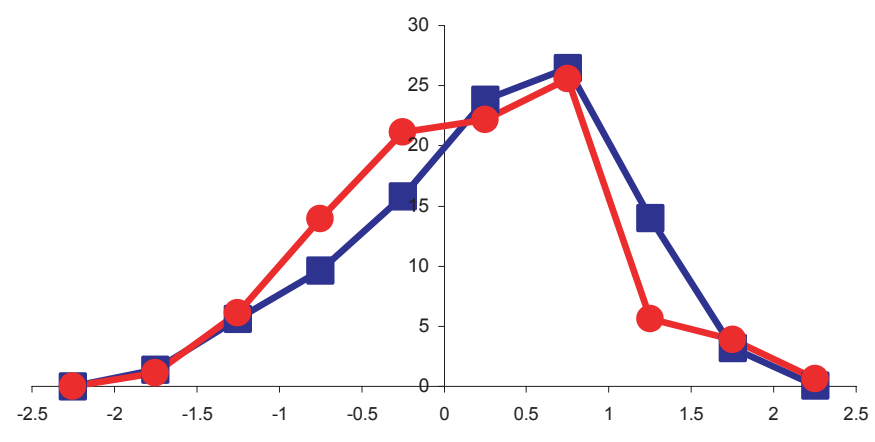

Black Males

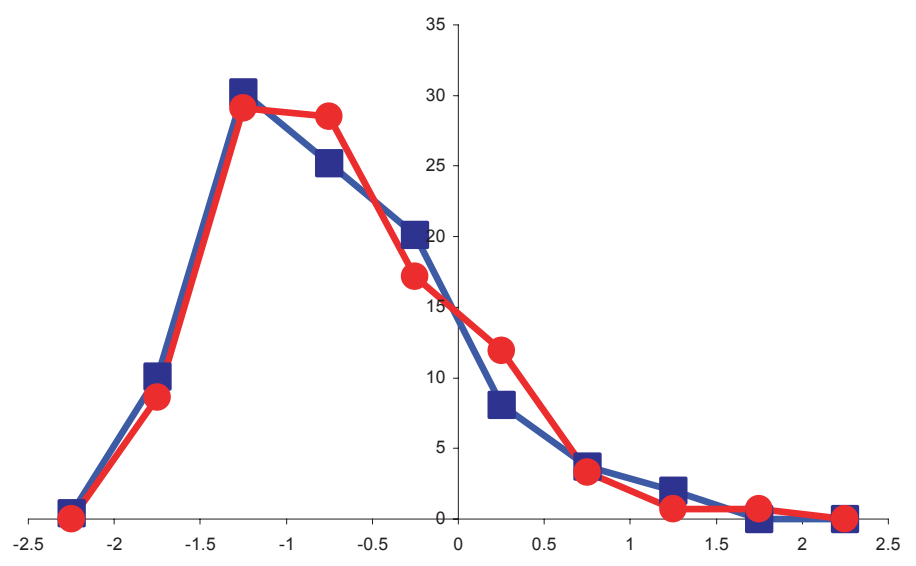

Hispanic Males

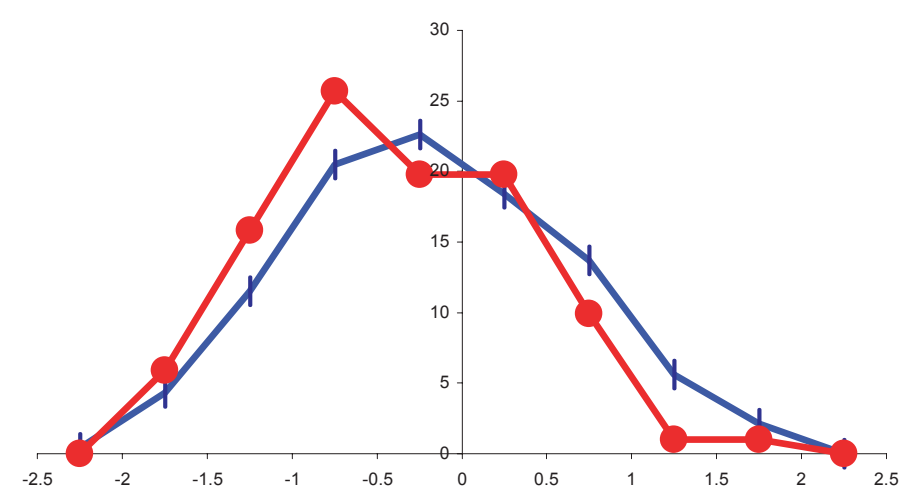

White Females

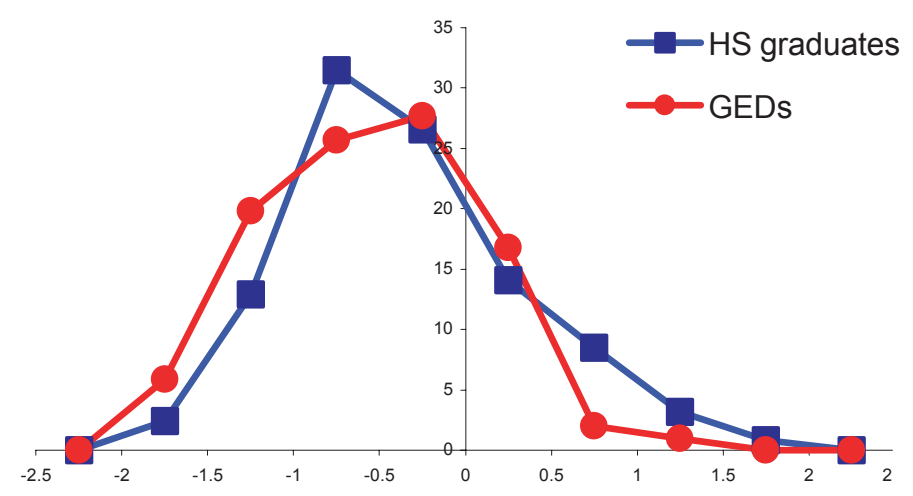

Black Females

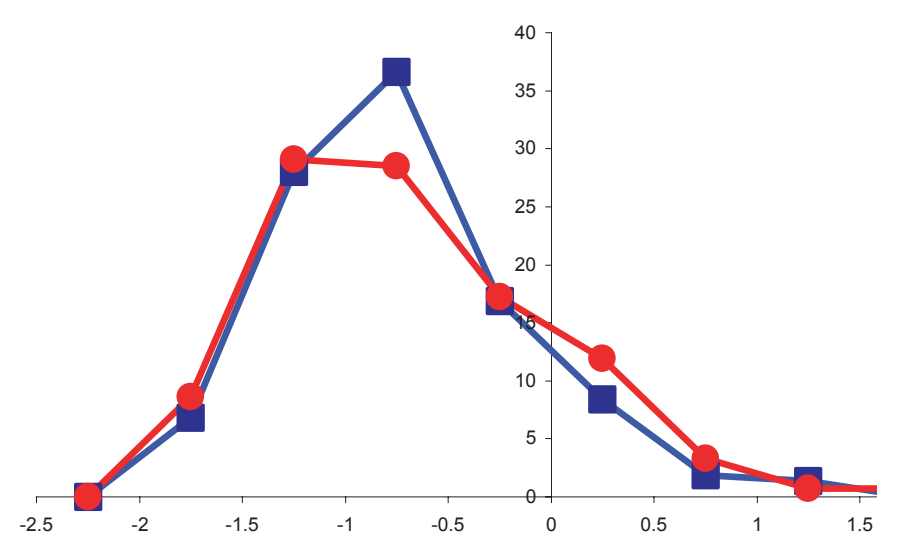

Hispanic Females

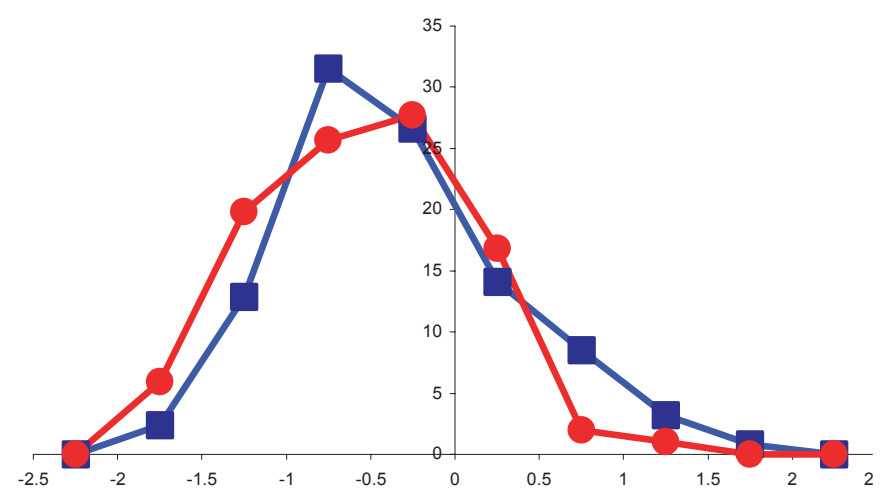

Source: Heckman, Hsee and Rubinstein (2002) 
Figure 13

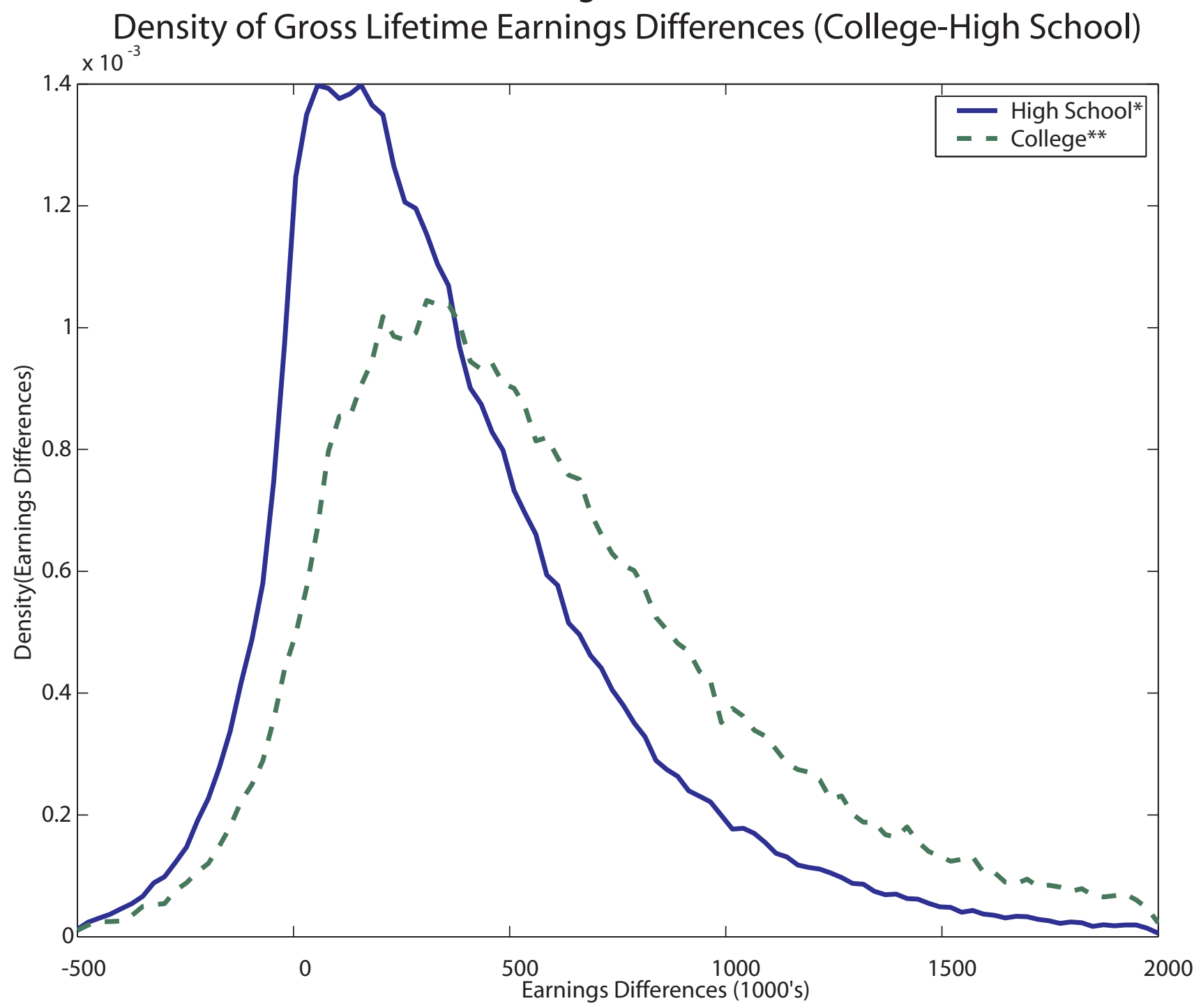

${ }^{*} \mathrm{E}\left(\mathrm{PV} \mathrm{C}_{\mathrm{C}}-\mathrm{PV} \mathrm{h}_{\mathrm{h}} \mid\right.$ Choice $=$ High School $)$

${ }^{*} \mathrm{E}\left(\mathrm{PV}_{\mathrm{C}}-\mathrm{PV}_{\mathrm{h}} \mid\right.$ Choice$=$ College $)$

All densities are estimated using a 100 point grid over the domain and a Gaussian kernel with bandwidth of 0.12 .

Source: Carneiro, Hansen and Heckman (2003) 
Figure 14

Density of Lifetime Earnings Differences (College-High School) Under Different Information Sets

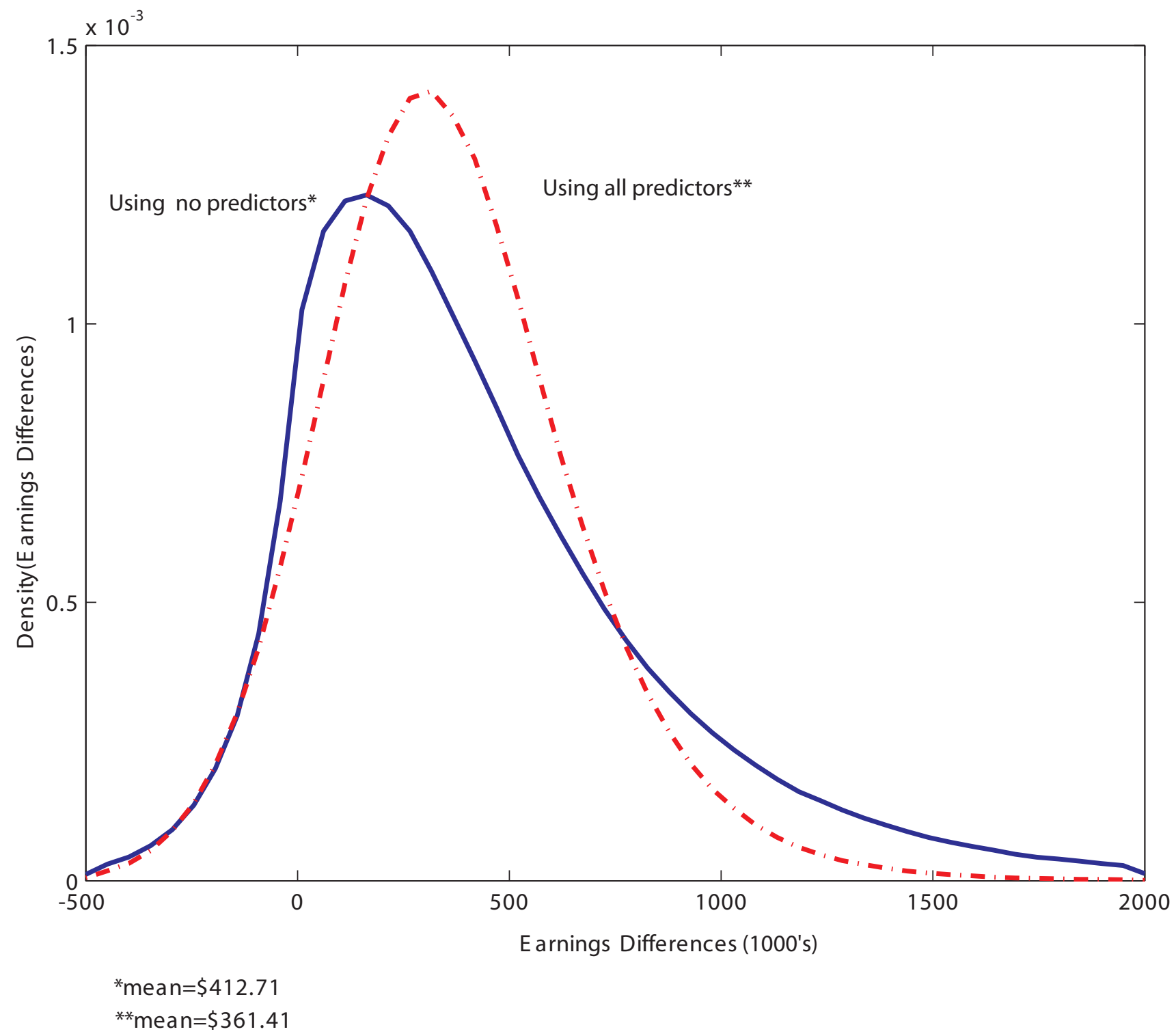

All densities are estimated using a 100 point grid over the domain and a Gaussian kernel with bandwidth of 0.12 .

Source: Carneiro, Hansen and Heckman (2003) 
Table 4

Annualized Returns to College for High School and Beyond White Males ${ }^{\dagger}$

\begin{tabular}{lcc}
\hline \hline & High Ability & Low Ability \\
\cline { 2 - 3 } $\begin{array}{c}\text { Average Returns in the Population } \\
\text { (Average Treatment Effect) }\end{array}$ & 0.1985 & 0.1765 \\
$\begin{array}{c}\text { Returns to Persons Who Attend College } \\
\text { (Treatment on the Treated) }\end{array}$ & 0.3157 & 0.2700 \\
Returns to Marginal Person* & 0.2865 & 0.1974 \\
\hline \hline
\end{tabular}

Notes: ${ }^{\dagger}$ We use wages in year 1991. TT is Treatment on the Treated. We proceed in several steps. First we estimate the Marginal Treatment Effect (MTE). Then we estimate the weights for TT and apply them to the MTE to get the treatment parameters. We apply an analogous method to get the ATE. See Carneiro, Heckman and Vytlacil (2001). High ability individuals have math test scores above 4000. They comprise approximately $30 \%$ of the overall population of white males. The average score in the population is 3325 and the standard deviation is 986 . Low ability individuals are below the 4000 threshold. They comprise the remaining $70 \%$. College graduates have approximately 3.1 years of schooling more than high school graduates. This is the number we use to annualize the returns.

*This is a weighted average of returns to persons in high school at the margin of attending college. For details see Carneiro, Heckman and Vytlacil (2001). 


\section{Table 5}

Evaluating School Quality Policies: Discounted Net Returns to Decreasing Pupil-Teacher Ratio by 5 for People with 12 Years of Schooling in 1990

\begin{tabular}{|c|c|c|c|c|c|}
\hline & $\begin{array}{c}\text { Productivity } \\
\text { Growth } \\
\text { Rate }\end{array}$ & $\begin{array}{c}\text { Includes } 50 \% \\
\text { Social Cost } \\
\text { of Funds }\end{array}$ & $\begin{array}{l}\text { Ann } \\
\text { to } \\
\text { Scho } \\
1 \%\end{array}$ & $\begin{array}{l}\text { al Rate } \\
\text { Earnin } \\
\text { l Qual } \\
2 \%\end{array}$ & $\begin{array}{c}\text { Return } \\
\text { from } \\
\text { Change } \\
4 \%\end{array}$ \\
\hline \multicolumn{6}{|l|}{$7 \%$ Discount Rate } \\
\hline & $0 \%$ & Yes & -9056 & -8092 & -6163 \\
\hline & $0 \%$ & No & -5716 & -4752 & -2823 \\
\hline & $1 \%$ & Yes & -8878 & -7736 & -5451 \\
\hline & $1 \%$ & No & -5538 & -4396 & -2111 \\
\hline \multicolumn{6}{|l|}{$5 \%$ Discount Rate } \\
\hline & $0 \%$ & Yes & -9255 & -7537 & -4103 \\
\hline & $0 \%$ & No & -5597 & -3880 & -445 \\
\hline & $1 \%$ & Yes & -8887 & -6802 & -2632 \\
\hline & $1 \%$ & No & -5230 & -3145 & 1025 \\
\hline \multicolumn{6}{|l|}{ 3\% Discount Rate } \\
\hline & $0 \%$ & Yes & -8840 & -5591 & 905 \\
\hline & $0 \%$ & No & -4810 & -1562 & 4934 \\
\hline & $1 \%$ & Yes & -8036 & -3984 & 4119 \\
\hline & $1 \%$ & No & -4007 & 45 & 8149 \\
\hline
\end{tabular}

Notes: All values, in 1990 dollars, are given as net present values at age 6 of an individual; costs of schooling improvements are incurred between ages 6 to 18 and benefits from increased earnings occur between ages 19 and 65. Data for costs are from NCES (1993). Costs of adding new teachers include salaries and capital, administrative and maintenance expenditures. Estimates of the increases in earnings resulting from a decrease in the pupil-teacher ratio by 5 come from Card and Krueger (1992), Table 3, which produces a range of estimated earnings increases from about $1 \%$ to $4 \%$ whereas most of the estimates are in the $1-2 \%$ range. To capture the benefits of smaller class sizes, students must attend 12 years of higher quality of schooling. We calculate the costs for one year of improvements and then calculate the present value of the costs over the 12 years of school attendance. 


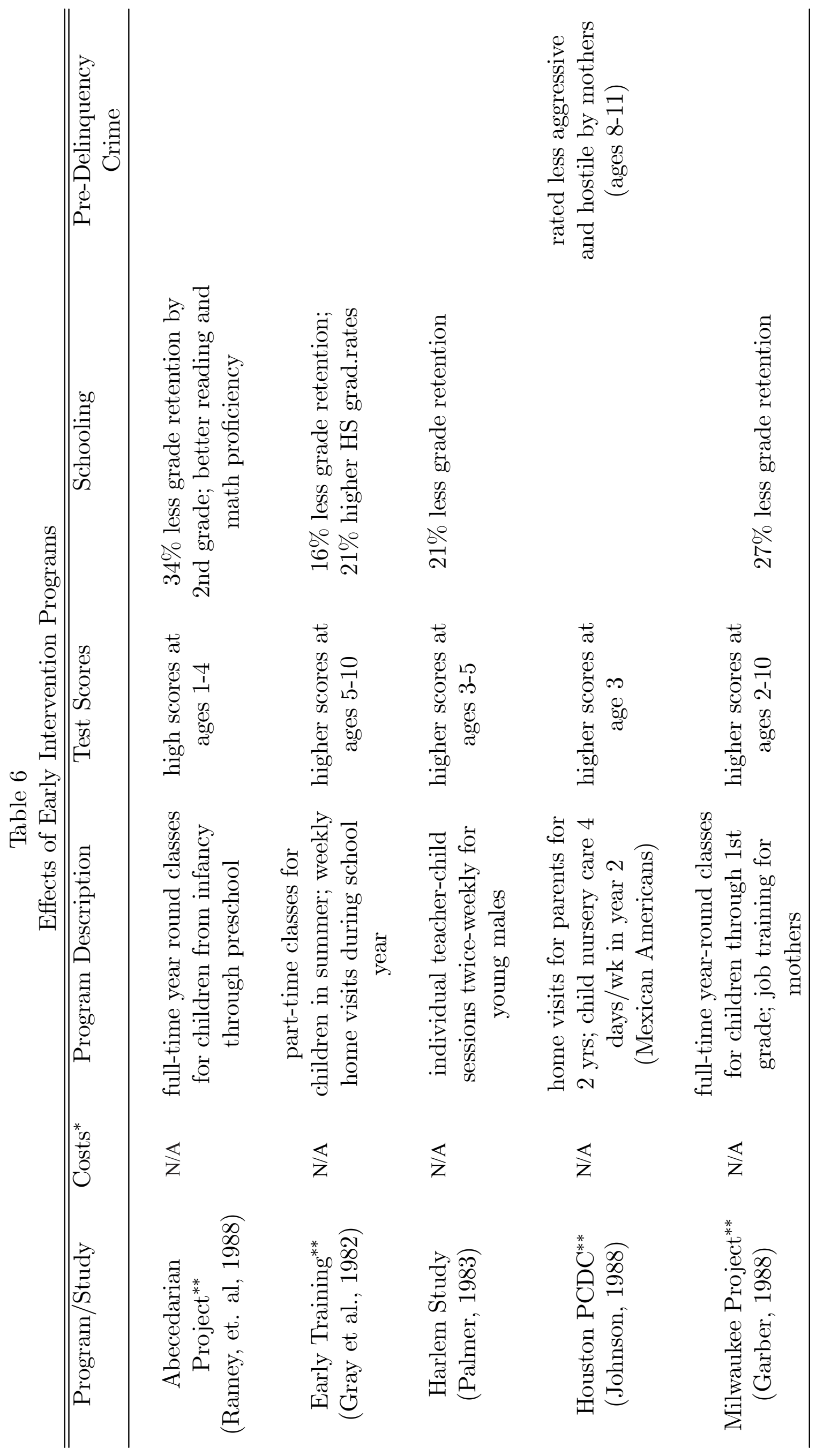




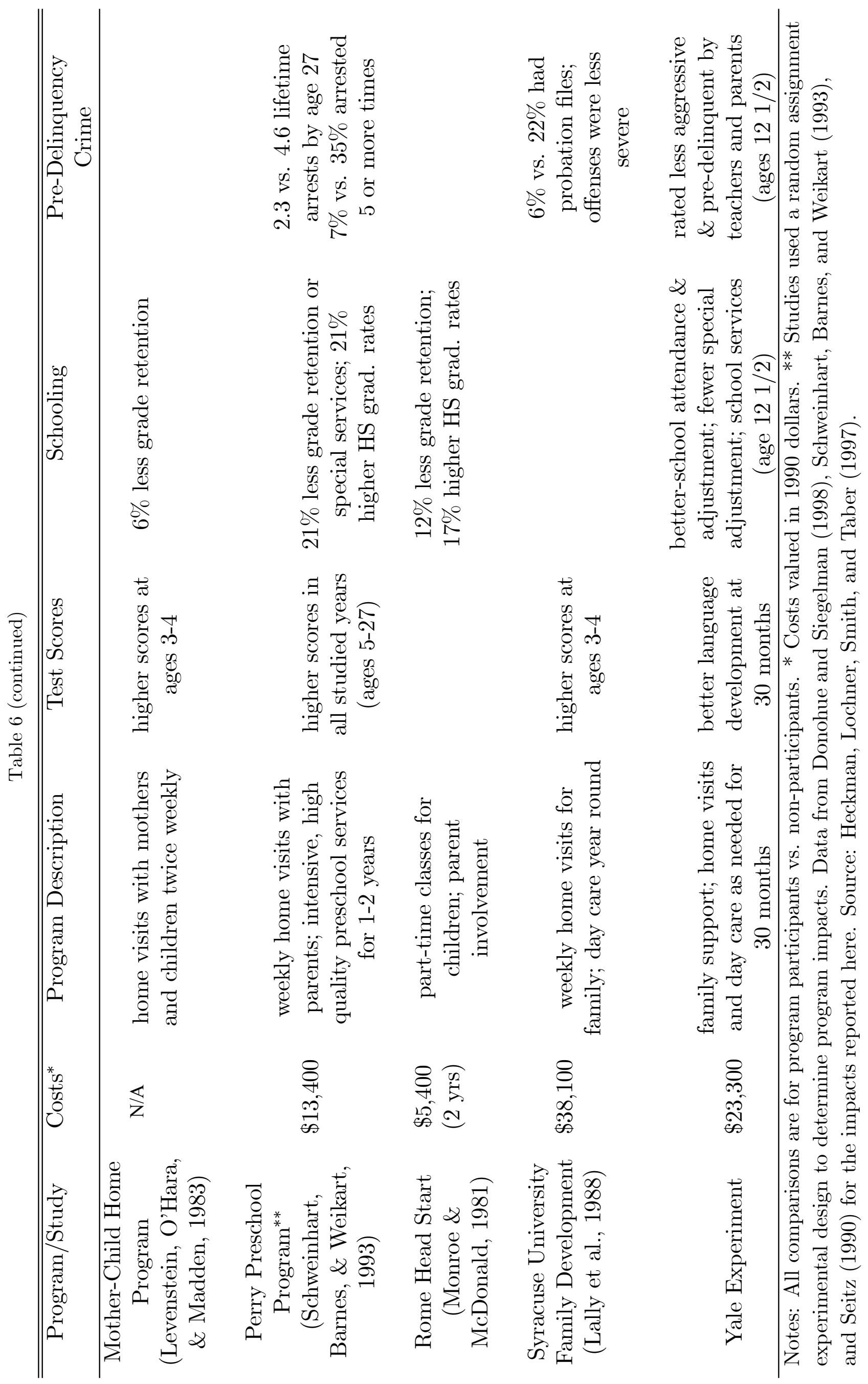




\section{Table 7}

Perry Preschool: Net Present Values of Costs \& Benefits through Age 27*

1. Cost of Preschool, Child Ages 3 to 4

$\$ 12148$

2. Decrease in Cost to Government of K-12

Special Education Courses for Child, Ages 5 to 18

6365

3. Decrease in Direct Criminal Justice System Costs ${ }^{+}$ of Child's Criminal Activity, Ages 15 to 28

7378

4. Decrease in Direct Criminal Justice System Costs ${ }^{+}$ of Child's Projected Criminal Activity, Ages 29 to 442817

5. Income from Child's Increased

Employment, Ages 19 to 27

8380

6. Projected Income from Child's

Increased Employment, Ages 28 to 65

7565

7. Decrease in Tangible Losses to Crime

Victims, Ages 15 to 44

10690

Total Benefits:

43195

Total Benefits Excluding Projections**

32813

Benefits minus Cost

31047

Benefits minus Cost Excluding Projections**

20665

Notes: ${ }^{*}$ All values are net present values in 1996 dollars at age 0 calculated using a $4 \%$ discount rate. ${ }^{+}$Direct Criminal Justice System costs are the administrative costs of incarceration. ${ }^{* *}$ Benefits from projected criminal activity (4) and projected income from increased employment (6) are excluded. Sources: Karoly et al. (1998) and Barnett (1993). 


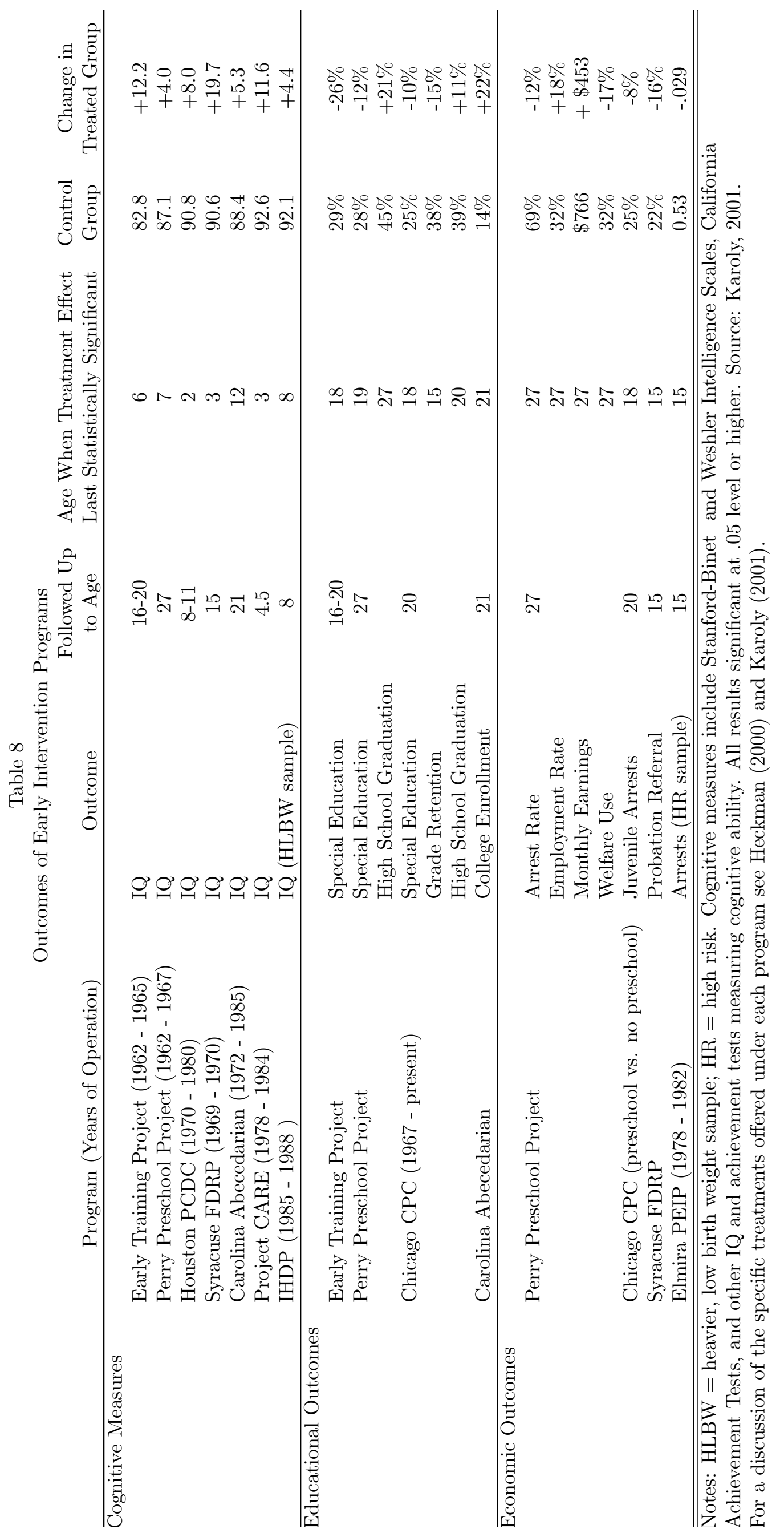




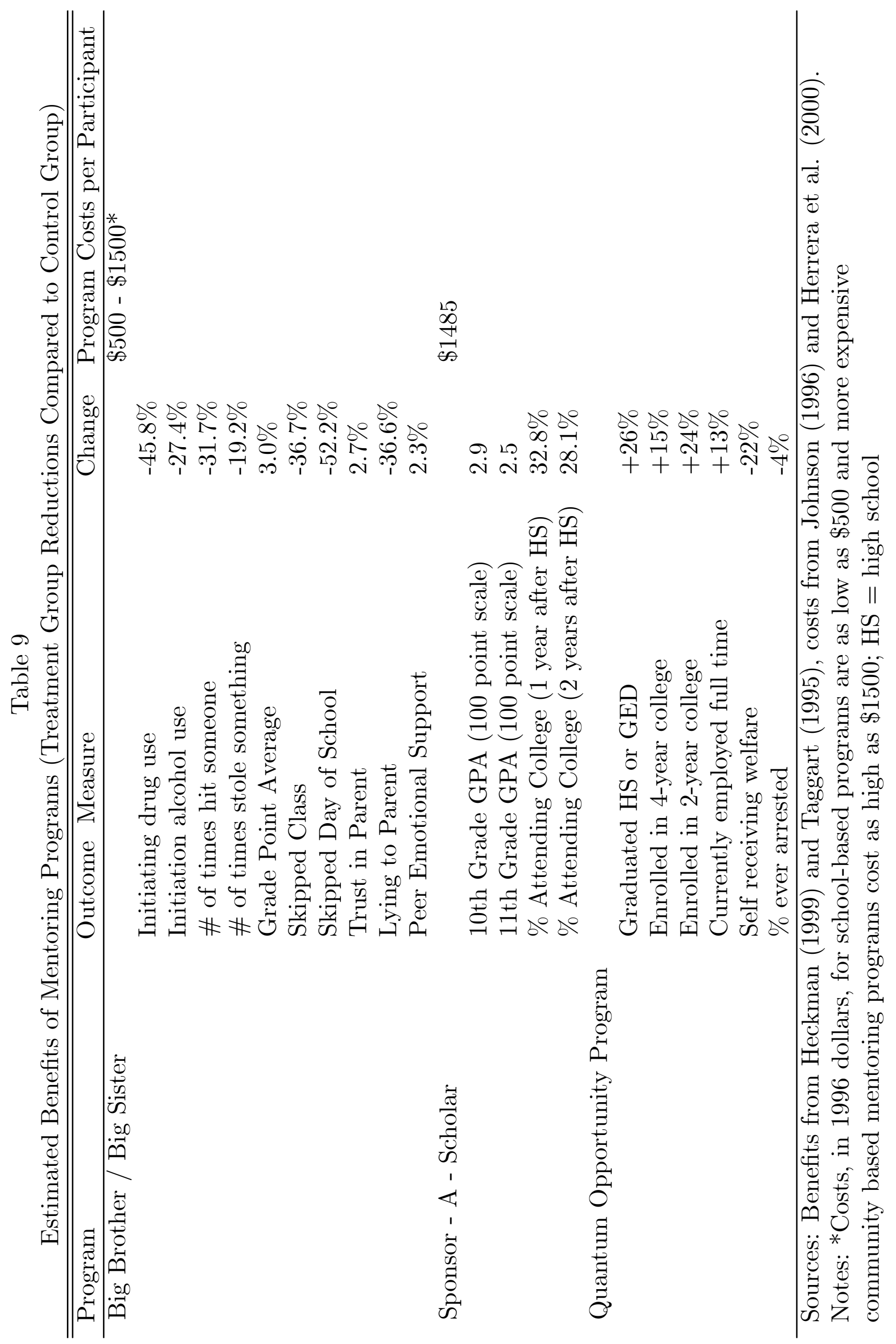




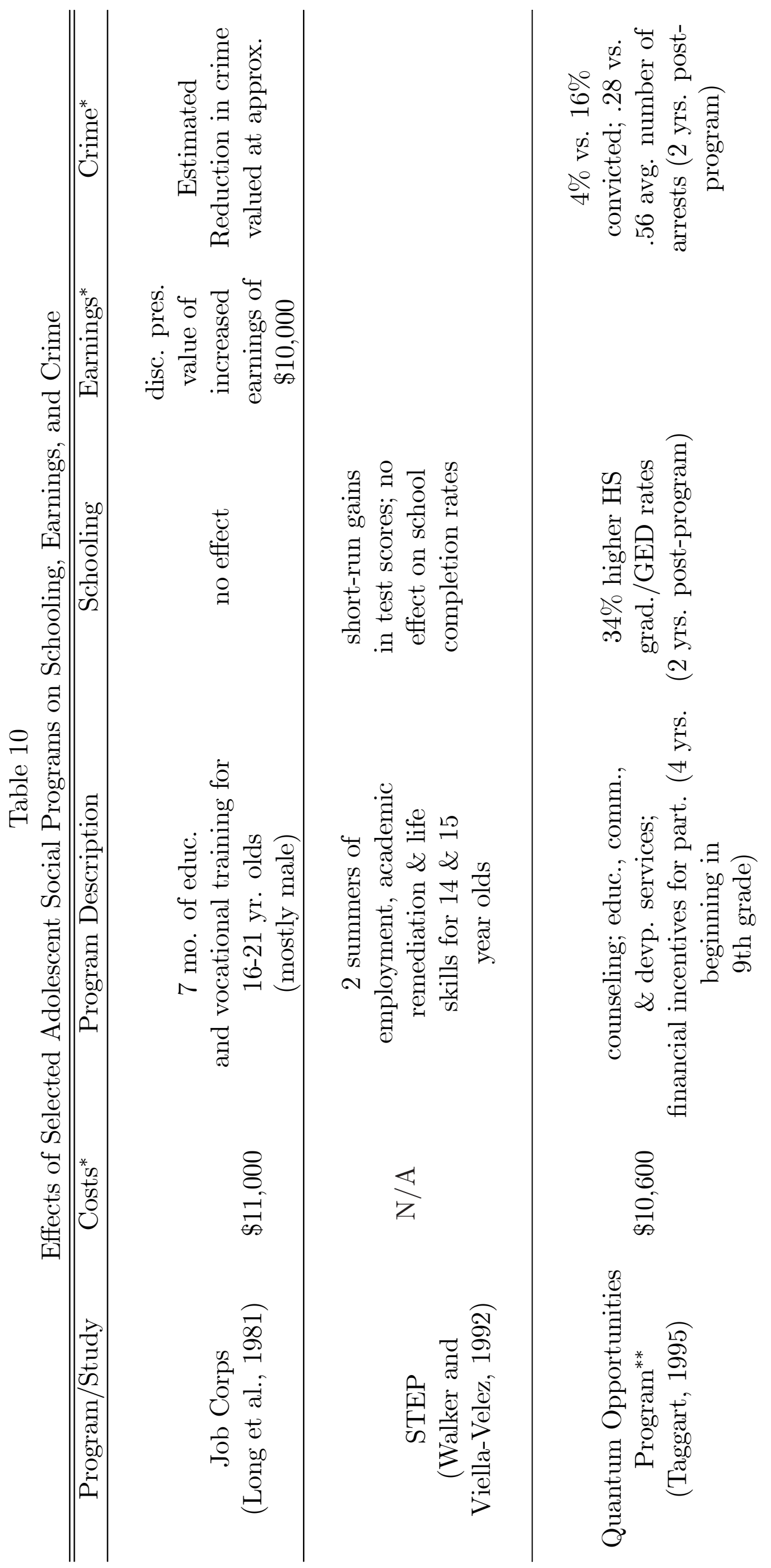




\section{Table 11}

Rates of Return on Investment in Private Job Training

Data Set: Return

PSID, all males $\quad 23.5$

NLS $\quad 16.0$

NLS (Old NLS) $\quad 26.0$

Source: Mincer (1993) 
Table 12

Average Marginal Effect on Participation in Company Training

\begin{tabular}{ccccccc}
\hline \hline & \multicolumn{5}{c}{ Average Marginal Effect } \\
Variables & \multicolumn{7}{c}{ White Males } & \multicolumn{2}{c}{ Black Males } & \multicolumn{1}{c}{ Hispanic Males } \\
\cline { 2 - 7 } & $(1)$ & $(2)$ & $(1)$ & $(2)$ & $(1)$ & $(2)$ \\
\cline { 2 - 7 } Age-Adjusted AFQT & 0.0149 & - & 0.0182 & - & 0.0066 & - \\
& $(0.0024)$ & - & $(0.0033)$ & - & $(0.0037)$ & - \\
Family Income in 1979 & -0.0021 & -0.0005 & -0.0047 & -0.0019 & 0.0011 & 0.0015 \\
(in \$10,000) & $(0.0012)$ & $(0.0011)$ & $(0.0024)$ & $(0.0023)$ & $(0.0024)$ & $(0.0023)$ \\
Grade Completed & 0.0382 & - & 0.0060 & - & 0.0036 & - \\
& $(0.001)$ & - & $(0.0014)$ & - & $(0.0014)$ & - \\
Father's Education & -0.0014 & 0.0007 & 0.0003 & 0.0010 & 0.0002 & 0.0008 \\
& $(0.0006)$ & $(0.0005)$ & $(0.0008)$ & $(0.0008)$ & $(0.0007)$ & $(0.0007)$ \\
Variables & & & & & & Hispanic Females \\
\cline { 2 - 7 } & White Females & Black Females & $(1)$ & $(2)$ \\
\cline { 2 - 7 } Age-Adjusted AFQT & 0.0076 & - & 0.0169 & - & 0.0159 & - \\
Family Income in 1979 & $(0.0025)$ & - & $(0.0038)$ & - & $(0.0045)$ & - \\
(in \$10,000) & -0.0007 & 0.0001 & -0.0006 & 0.0014 & -0.0065 & -0.0043 \\
Grade Completed & $(0.0011)$ & $(0.0011)$ & $(0.0024)$ & $(0.0023)$ & $(0.0031)$ & $(0.0029)$ \\
& 0.0027 & - & 0.0014 & - & 0.0013 & - \\
Father's Education & $(0.0010)$ & - & $(0.0016)$ & - & $(0.0016)$ & - \\
& 0.0001 & 0.0009 & 0.0015 & 0.0021 & -0.00001 & 0.0007 \\
& $(0.0006)$ & $(0.0006)$ & $(0.0008)$ & $(0.0008)$ & $(0.0009)$ & $(0.0008)$ \\
\hline \hline
\end{tabular}

Notes: The panel data set was constructed using NLSY79 data from 1979-1994. Data on training in 1987 is combined with 1988 in the original dataset. Company training consists of formal training run by employer, and military training excluding basic training. Standard errors are reported in parentheses.

Specification (1) includes a constant, age, father's education, mother's education, number of siblings, southern residence at age 14 dummy, urban residence at age 14 dummy, and year dummies. Specification (2) drops age-adjusted AFQT and grade completed. Average marginal effect is estimated using average derivatives from a probit regression. 
Table 13

Effects of Accounting for Discounting, Expected Horizon and Welfare Costs of Taxes:

Benefit Minus Cost Estimates for JTPA under Alternative Assumptions Regarding Benefit Persistence, Discounting, and Welfare Costs of Taxation (National JTPA Study, 30-Month Impact Sample)

\begin{tabular}{lccccccc}
\hline \hline $\begin{array}{l}\text { Benefit } \\
\text { Duration }\end{array}$ & $\begin{array}{c}\text { Direct } \\
\text { Costs } \\
\text { Included? }\end{array}$ & $\begin{array}{c}\text { 6-Month } \\
\text { Interest } \\
\text { Rate }\end{array}$ & $\begin{array}{c}\text { Welfare } \\
\text { Cost of } \\
\text { Taxes }\end{array}$ & $\begin{array}{c}\text { Adult } \\
\text { Males }\end{array}$ & $\begin{array}{c}\text { Adult } \\
\text { Females }\end{array}$ & $\begin{array}{c}\text { Male } \\
\text { Youth }\end{array}$ & $\begin{array}{c}\text { Female } \\
\text { Youth }\end{array}$ \\
\hline 30 Months & No & 0.000 & 0.00 & 1,345 & 1,703 & -967 & 136 \\
30 Months & Yes & 0.000 & 0.00 & 523 & 532 & $-2,922$ & $-1,180$ \\
30 Months & Yes & 0.000 & 0.50 & 108 & -54 & $-3,900$ & $-1,838$ \\
30 Months & Yes & 0.025 & 0.00 & 433 & 432 & $-2,859$ & $-1,195$ \\
30 Months & Yes & 0.025 & 0.50 & 17 & -154 & $-3,836$ & $-1,853$ \\
& & & & & & & \\
7 Years & No & 0.000 & 0.00 & 5,206 & 5,515 & -3843 & 865 \\
7 Years & Yes & 0.000 & 0.00 & 4,375 & 4,344 & $-5,798$ & -451 \\
7 Years & Yes & 0.000 & 0.50 & 3,960 & 3,758 & $-6,775$ & 1,109 \\
7 Years & Yes & 0.025 & 0.00 & 3,523 & 3,490 & $-5,166$ & -610 \\
7 Years & Yes & 0.025 & 0.50 & 3,108 & 2,905 & $-6,143$ & $-1,268$ \\
\hline \hline
\end{tabular}

Notes: (1) "Benefit Duration" indicates how long the estimated benefits from JTPA are assumed to persist. Actual estimates are used for the first 30 months. For the 7-year duration case, the average of the benefits in months 18-24 and 25-30 is used for the benefits in each future period.

(2) "Welfare Cost of Taxes" indicates the additional cost in terms of lost output due to each additional dollar of taxes raised. The value 0.50 lies in the range suggested by Browning (1987).

(3) Estimates are constructed by breaking up the time after random assignment into 6-month periods. All costs are assumed to be paid in the first 6-month period, while benefits are received in each 6 -month period and discounted by the amount indicated for each row of the table.

Source: Heckman and Smith (1998) 


\section{Table 14}

\section{Lessons from the Evaluation Literature}

\begin{tabular}{|c|c|c|c|}
\hline Programmes & Appears to help & Appears not to help & $\begin{array}{l}\text { General observations on } \\
\text { effectiveness }\end{array}$ \\
\hline $\begin{array}{l}\text { Formal classroom } \\
\text { training }\end{array}$ & Women re-entrants & $\begin{array}{l}\text { Prime-age men and older } \\
\text { workers with low initial } \\
\text { education }\end{array}$ & $\begin{array}{l}\text { Important that courses have strong } \\
\text { labour market relevance, or signal } \\
\text { "high" quality to employers. } \\
\text { Should lead to a qualification that is } \\
\text { recognised and valued by } \\
\text { employers. } \\
\text { Keep programmes relatively small } \\
\text { in scale. }\end{array}$ \\
\hline On-the-job training & $\begin{array}{l}\text { Women re-entrants; single } \\
\text { mothers }\end{array}$ & Prime-age men (?) & $\begin{array}{l}\text { Must directly meet labour market } \\
\text { needs. Hence, need to establish } \\
\text { strong links with local employers, } \\
\text { but this increases the risk of } \\
\text { displacement. }\end{array}$ \\
\hline $\begin{array}{l}\text { Job-search } \\
\text { assistance (job } \\
\text { clubs, individual } \\
\text { counselling, etc.) }\end{array}$ & $\begin{array}{l}\text { Most unemployed but in } \\
\text { particular, women and } \\
\text { sole parents }\end{array}$ & & $\begin{array}{l}\text { Must be combined with increased } \\
\text { monitoring of the job-search } \\
\text { behaviour of the unemployed and } \\
\text { enforcement of work tests. }\end{array}$ \\
\hline $\begin{array}{l}\text { Of which: } \\
\text { re- } \\
\text { employment } \\
\text { bonuses }\end{array}$ & Most adult unemployed & & $\begin{array}{l}\text { Requires careful monitoring and } \\
\text { controls on both recipients and their } \\
\text { former employers. }\end{array}$ \\
\hline \multirow[t]{3}{*}{$\begin{array}{l}\text { Special youth } \\
\text { measures (training, } \\
\text { employment } \\
\text { subsidies, direct job } \\
\text { creation measures) }\end{array}$} & & Disadvantaged youths & $\begin{array}{l}\text { Effective programmes need to } \\
\text { combine an appropriate and } \\
\text { integrated mix of education, } \\
\text { occupational skills, work-based } \\
\text { learning and supportive services to } \\
\text { young people and their families. }\end{array}$ \\
\hline & & & $\begin{array}{l}\text { Early and sustained interventions } \\
\text { are likely to be most effective. }\end{array}$ \\
\hline & & & $\begin{array}{l}\text { Need to deal with inappropriate } \\
\text { attitudes to work on the part of } \\
\text { youths. Adult mentors can help. }\end{array}$ \\
\hline $\begin{array}{l}\text { Subsidies to } \\
\text { employment }\end{array}$ & $\begin{array}{l}\text { Long-term unemployed; } \\
\text { women re-entrants }\end{array}$ & & $\begin{array}{l}\text { Require careful targeting and } \\
\text { adequate controls to maximise net } \\
\text { employment gains, but there is a } \\
\text { trade-off with employer take-up. }\end{array}$ \\
\hline $\begin{array}{l}\text { Of which: } \\
\text { Aid to } \\
\text { unemployed } \\
\text { starting } \\
\text { enterprises }\end{array}$ & $\begin{array}{l}\text { Men (below 40, relatively } \\
\text { better educated) }\end{array}$ & & $\begin{array}{l}\text { Only works for a small subset of the } \\
\text { population. }\end{array}$ \\
\hline Direct job creation & & $\begin{array}{l}\text { Most adult and youth } \\
\text { unemployed }\end{array}$ & $\begin{array}{l}\text { Typically provides few long-run } \\
\text { benefits and principle of } \\
\text { additionality usually implies low } \\
\text { marginal-product jobs. }\end{array}$ \\
\hline
\end{tabular}

Source: Martin and Grubb, 2001 


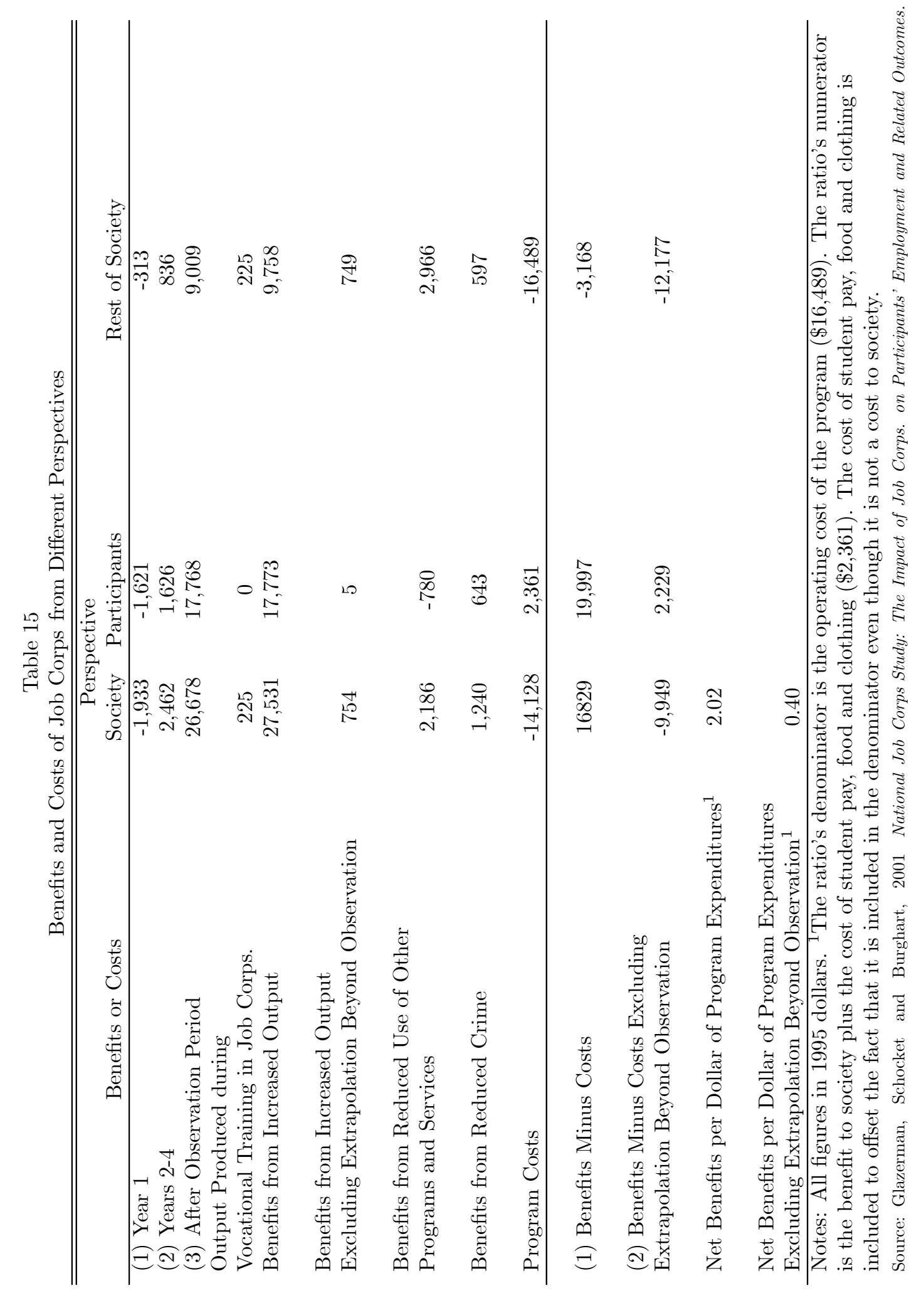


Figure 15

Annualized Average Marginal Return for Those at the Margin of Indifference Between College and High School

NLSY79, White Males

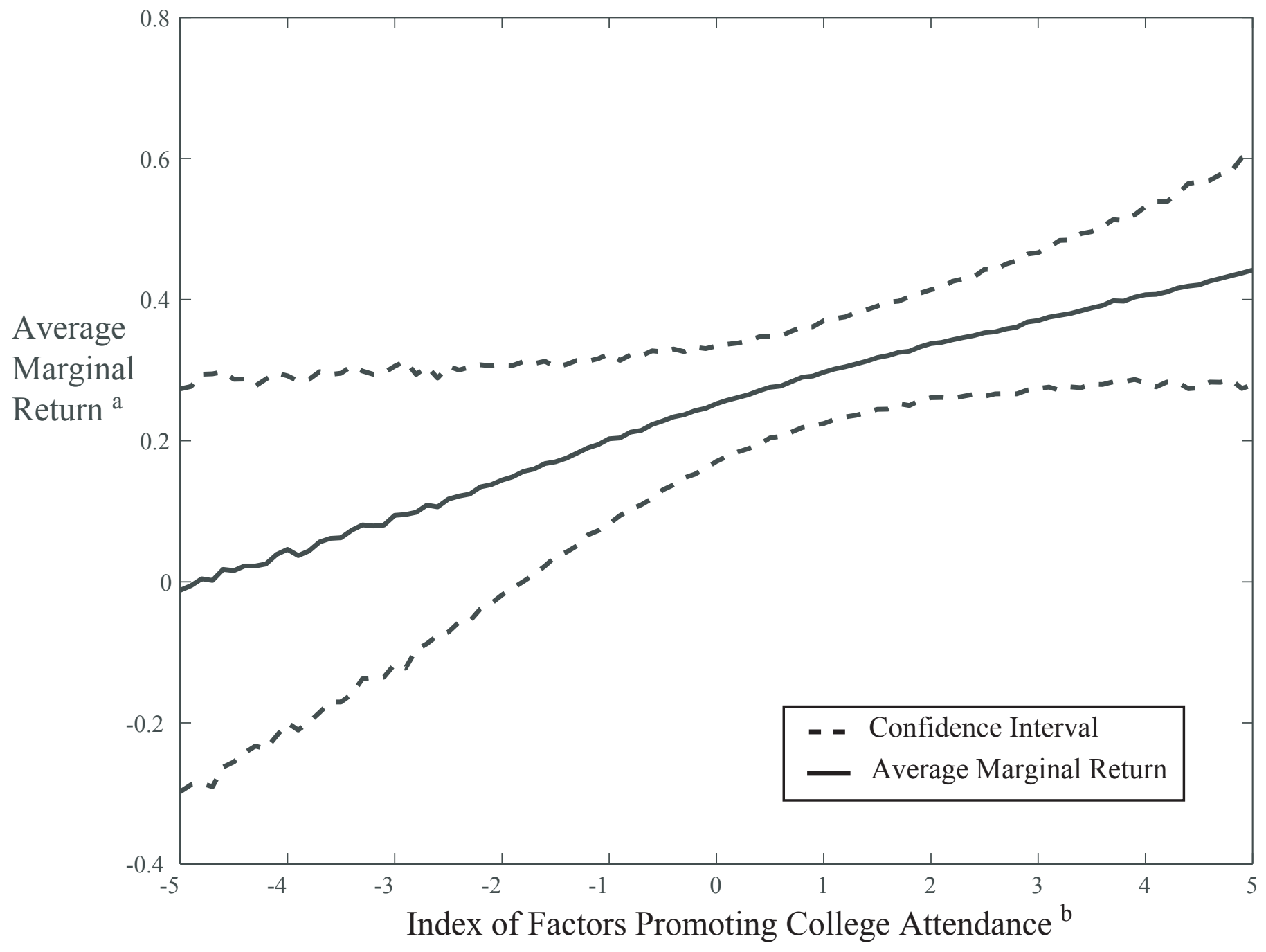

Notes: ${ }^{a}$ Average marginal return to persons at the margin of attending college for a given level of index

${ }^{b}$ Variables related to schooling (higher level of index leads to a higher probability of attending college) 


\section{Figure 16 \\ Job Corps. Evaluation \\ DEGREES, DIPLOMAS, AND CERTIFICATES RECEIVED}

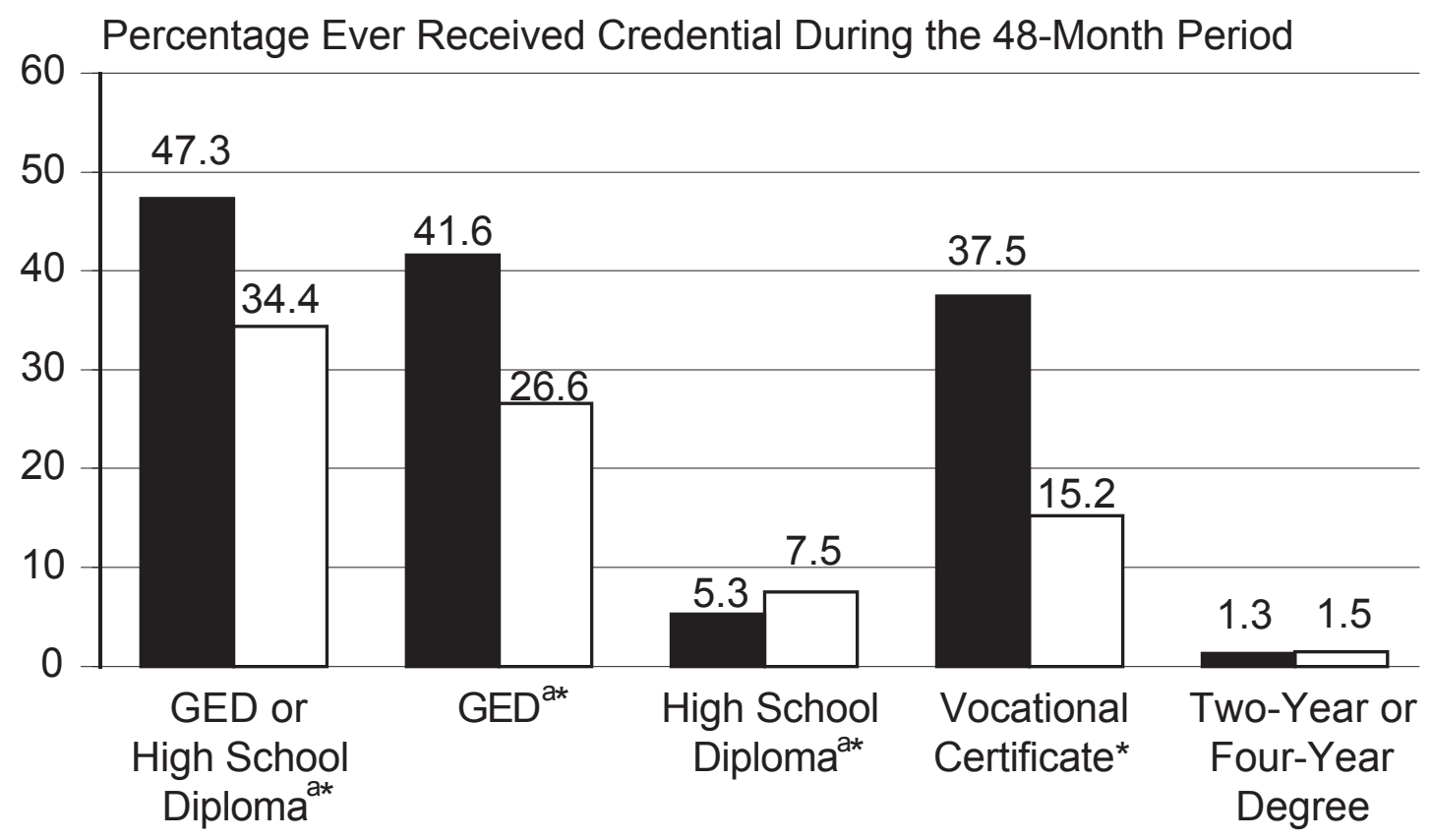

Program Group $\square$ Control Group

Source: Baseline and 12- , 30- , and 48-month follow-up interview data for those who completed 48-month interviews.

See Schochet et alt., 2001

aFigures pertain to those who did not have a high school credential at random assignment.

*Difference between the mean outcome for program and control group members is statistically significant at the 5 percent level. This difference is the estimated impact per eligible applicant. 


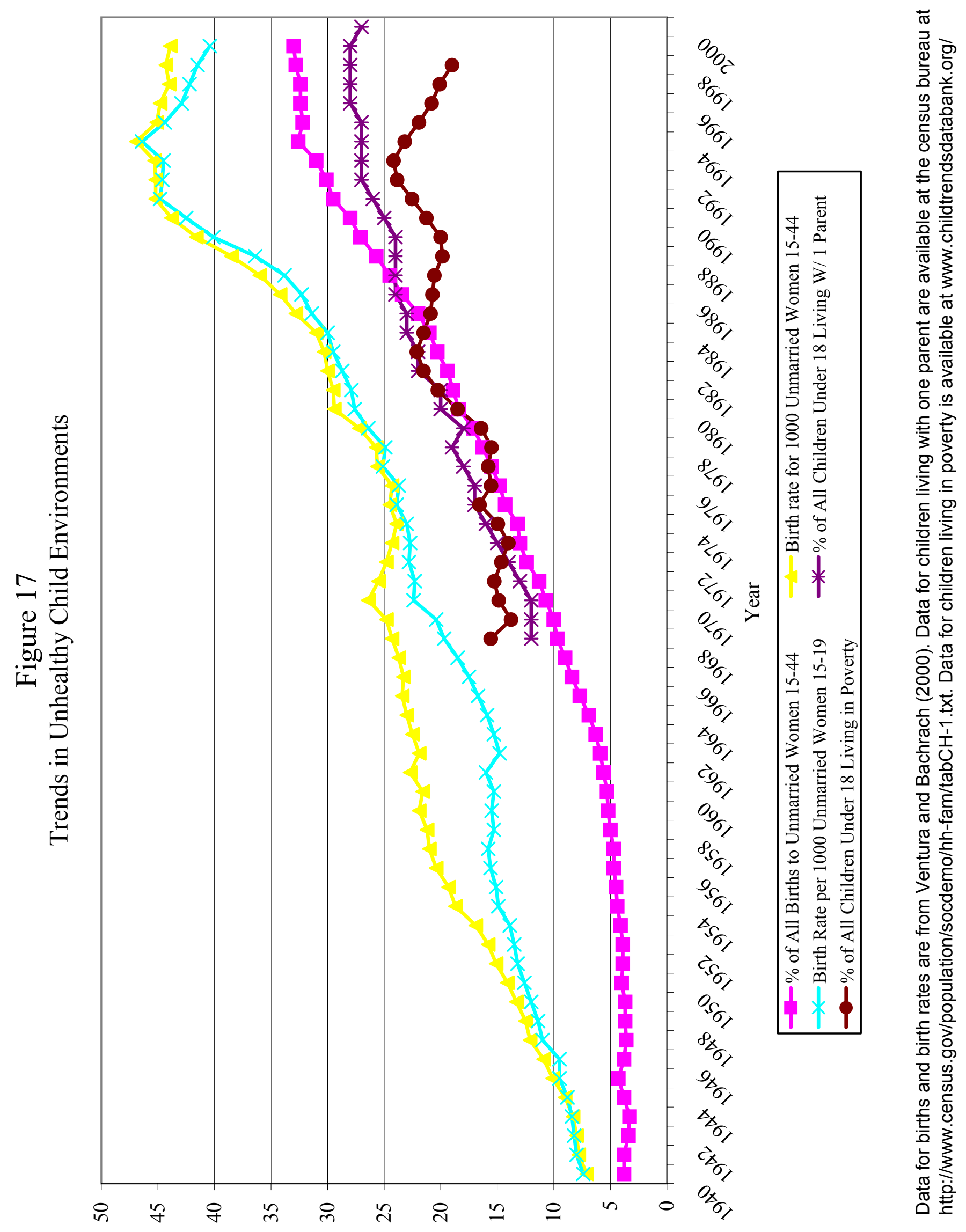




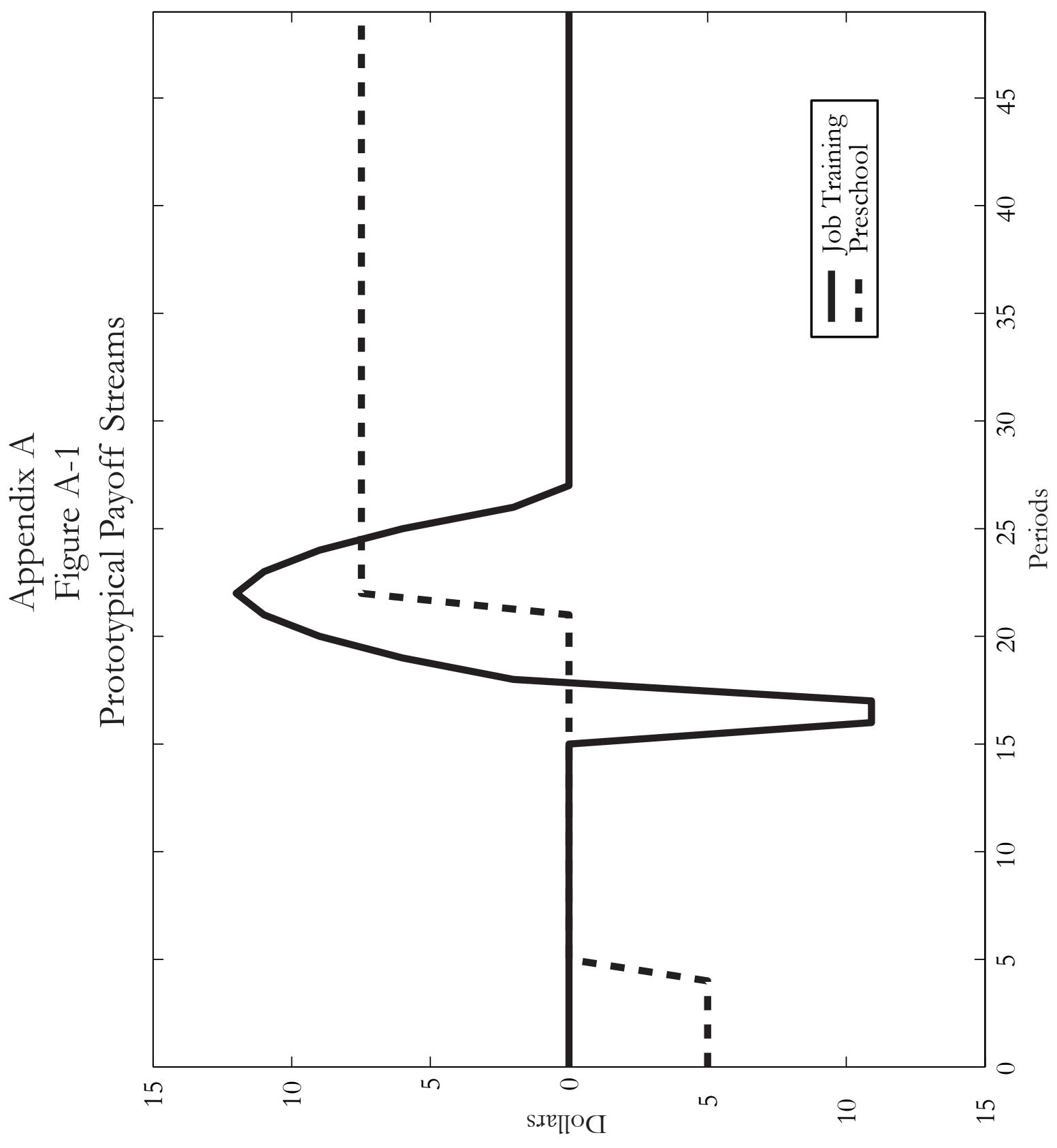




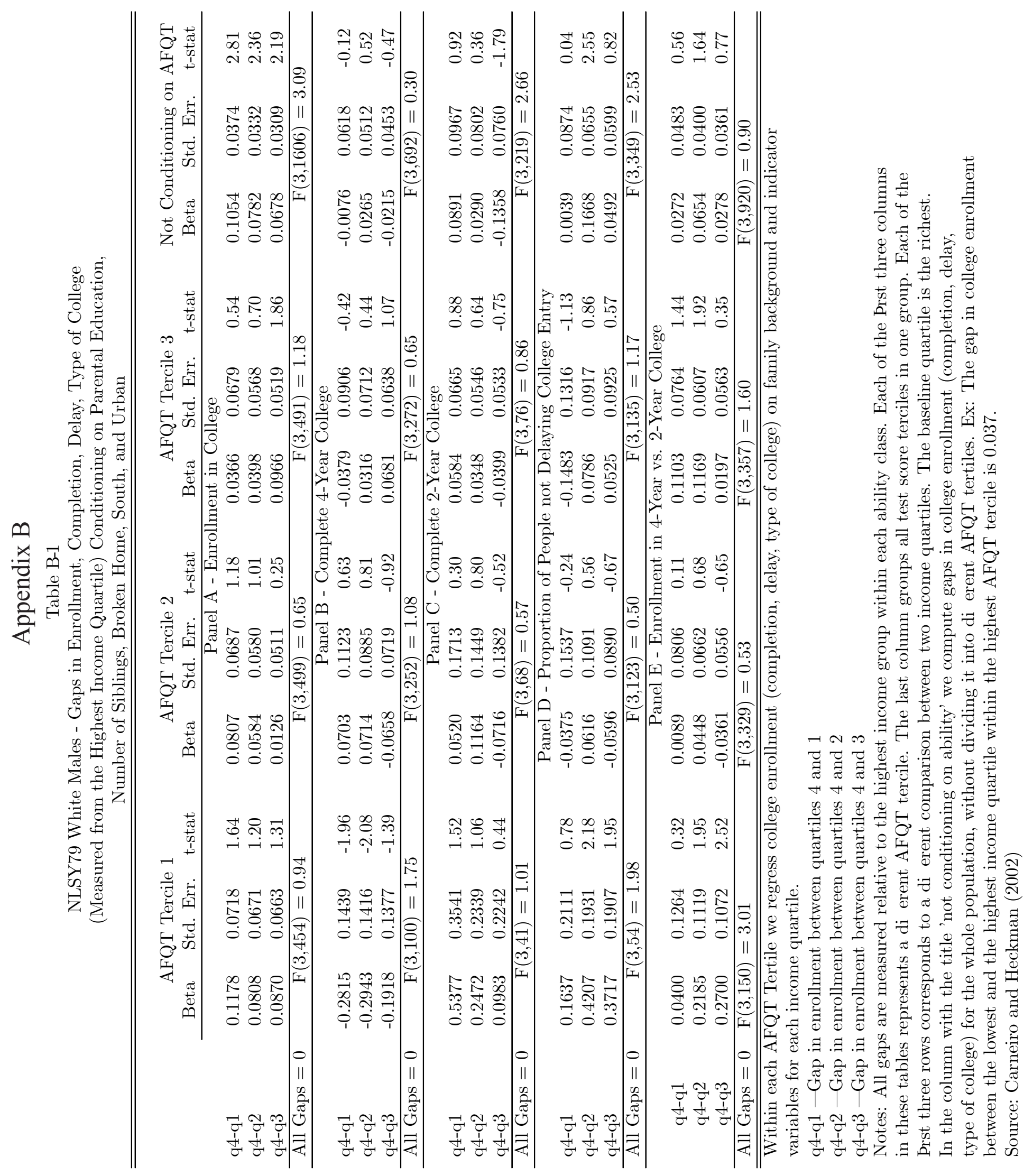


Table B-2

Family Background Gaps for White Males, NLSY79

(Measured Relative to the Highest Family Background/AFQT Quartile)

\begin{tabular}{|c|c|c|c|c|c|c|}
\hline \multirow[b]{2}{*}{ Gap: } & \multicolumn{3}{|c|}{ Enrollment in College } & \multicolumn{3}{|c|}{ 2-Year College Completion } \\
\hline & Coefficient & Std. Err. & $t$-stat & Coefficient & Std. Err. & $t$-stat \\
\hline q4-q1 & 0.580 & 0.042 & 13.810 & -0.374 & 0.154 & -2.429 \\
\hline$q 4-q 2$ & 0.370 & 0.034 & 10.882 & -0.189 & 0.077 & -2.455 \\
\hline \multirow[t]{3}{*}{ q4-q3 } & 0.299 & 0.029 & 10.310 & -0.124 & -0.067 & -1.851 \\
\hline & \multicolumn{3}{|c|}{ 4-Year College Completion } & \multicolumn{3}{|c|}{ Percentage with No Delay of Entry } \\
\hline & Coefficient & Std. Err. & $t$-stat & Coefficient & Std. Err. & $t$-stat \\
\hline q4-q1 & 0.615 & 0.108 & 5.694 & 0.499 & 0.159 & 3.138 \\
\hline q4-q2 & 0.337 & 0.060 & 5.617 & 0.188 & 0.075 & 2.507 \\
\hline q4-q3 & 0.137 & 0.043 & 3.186 & 0.099 & 0.056 & 1.768 \\
\hline & \multicolumn{3}{|c|}{ Years of Delay } & \multicolumn{3}{|c|}{ Enrollment in 4-Year vs. 2-Year College } \\
\hline & Coefficient & Std. Err. & $t$-stat & Coefficient & Std. Err. & $t$-stat \\
\hline q4-q1 & -2.793 & 0.817 & -3.419 & 0.040 & 0.084 & 0.476 \\
\hline$q 4-q 2$ & -1.301 & 0.387 & -3.362 & 0.133 & 0.045 & 2.956 \\
\hline q4-q3 & -0.627 & 0.286 & -2.192 & 0.054 & 0.034 & 1.588 \\
\hline
\end{tabular}


Table B-3

Gaps in Enrollment, Completion, Delay, Type of College

White Males, NLSY79

(Measured from Highest Family Background / AFQT Quartile)

\begin{tabular}{lccccccccc}
\hline \hline & \multicolumn{8}{c}{ Panel A - Enrollment in College } \\
& \multicolumn{1}{c}{ Lowest AFQT Tertile } & \multicolumn{1}{c}{ Middle AFQT Tertile } & Highest AFQT Tertile \\
\cline { 2 - 10 } Variable: & Coefficient Std. Err. & $t$-stat Coefficient Std. Err. $t$-stat & Coefficient Std. Err. $t$-stat \\
q1-q4 & -0.118 & 0.072 & -1.640 & -0.081 & 0.069 & -1.180 & -0.037 & 0.068 & -0.540 \\
q2-q4 & -0.081 & 0.067 & -1.200 & -0.058 & 0.058 & -1.010 & -0.040 & 0.057 & -0.700 \\
q3-q4 & -0.087 & 0.066 & -1.310 & -0.013 & 0.051 & -0.250 & -0.097 & 0.052 & -1.860 \\
Southern Residence at Age 14 & -0.012 & 0.047 & -0.260 & -0.006 & 0.047 & -0.130 & 0.070 & 0.049 & 1.430 \\
Broken Home & -0.076 & 0.051 & -1.500 & 0.002 & 0.060 & 0.040 & -0.069 & 0.057 & -1.200 \\
Urban Residence at Age 14 & 0.054 & 0.048 & 1.120 & 0.042 & 0.048 & 0.870 & -0.013 & 0.047 & -0.280 \\
Mother's Education & 0.024 & 0.011 & 2.310 & 0.035 & 0.011 & 3.150 & 0.023 & 0.011 & 2.100 \\
Father's Education & 0.029 & 0.008 & 3.640 & 0.042 & 0.008 & 5.390 & 0.042 & 0.008 & 5.160 \\
Constant & -0.213 & 0.138 & -1.550 & -0.347 & 0.136 & -2.550 & -0.133 & 0.137 & -0.970 \\
\hline
\end{tabular}

Panel B - 2-Year College Completion Rate

Variable:

Lowest AFQT Tertile Middle AFQT Tertile Highest AFQT Tertile

q1-q4

$\mathrm{q} 2-\mathrm{q} 4$

$\mathrm{q} 3-\mathrm{q} 4$

Southern Residence at Age 14

Broken Home

Urban Residence at Age 14

Mother's Education

Father's Education

Constant

Coefficient Std. Err. $t$-stat Coefficient Std. Err. $t$-stat Coefficient Std. Err. $t$-stat

$-0.538$

$-0.247$

$-0.098$

0.010

$\begin{array}{lll}0.354 & -1.520 & -0.052\end{array}$

0.17

$\begin{array}{lll}0.234 & -1.060 & -0.116\end{array}$

0.145

$\begin{array}{lll}0.224 & -0.440 & 0.072\end{array}$

0.138

$\begin{array}{lll}0.204 & 0.050 & -0.156\end{array}$

$-0.188$

0.268

$-0.700$

$-0.057$

$0.119-1.310$

$\begin{array}{ll}0.154 & -0.370\end{array}$

$\begin{array}{ll}0.139 & -1.770\end{array}$

$-0.247$

$-0.067$

$\begin{array}{ll}0.182 & -0.460\end{array}$

0.020

0.028

0.021

$\begin{array}{lll}0.038 & 0.190 & 0.012\end{array}$

1.510
0.340

0.133

Panel C - 4-Year College Completion Rate

Variable:

q1-q4

$\mathrm{q} 2-\mathrm{q} 4$

$\mathrm{q} 3-\mathrm{q} 4$

Southern Residence at Age 14

Broken Home

Urban Residence at Age 14

Mother's Education

Father's Education

Constant Lowest AFQT Tertile Middle AFQT Tertile Highest AFQT Tertile Lowest AFQT Tertile Middle AFQT Tertile Highest AFQT Tertile Lowest AFQT Tertile Middle AFQT Tertile Highest AFQT Tertile Coefficient Std. Err. $t$-stat Coefficient Std. Err. $t$-stat Coefficient Std. Err. $t$-stat

\begin{tabular}{ccccccccc}
0.281 & 0.144 & 1.960 & -0.070 & 0.112 & -0.630 & 0.038 & 0.091 & 0.420 \\
0.294 & 0.142 & 2.080 & -0.071 & 0.088 & -0.810 & -0.032 & 0.071 & -0.440 \\
0.192 & 0.138 & 1.390 & 0.066 & 0.072 & 0.920 & -0.068 & 0.064 & -1.070 \\
-0.040 & 0.107 & -0.370 & 0.008 & 0.074 & 0.110 & 0.015 & 0.060 & 0.240 \\
-0.186 & 0.120 & -1.550 & 0.091 & 0.100 & 0.910 & 0.008 & 0.077 & 0.110 \\
0.004 & 0.128 & 0.030 & 0.121 & 0.075 & 1.610 & 0.007 & 0.061 & 0.120 \\
0.029 & 0.023 & 1.230 & 0.027 & 0.017 & 1.610 & 0.017 & 0.013 & 1.320 \\
0.035 & 0.018 & 1.960 & 0.026 & 0.012 & 2.260 & 0.015 & 0.009 & 1.640 \\
-0.584 & 0.378 & -1.550 & -0.223 & 0.214 & -1.050 & 0.338 & 0.169 & 2.000 \\
\hline
\end{tabular}


Table B-3 (continued)

Gaps in Enrollment, Completion, Delay, Type of College

White Males, NLSY79

(Measured from Highest Family Background / AFQT Quartile)

\begin{tabular}{lcccccccccc}
\hline \hline & \multicolumn{8}{c}{ Panel D - Percentage With No Delay of Entry } \\
& \multicolumn{1}{c}{ Lowest AFQT Tertile } & \multicolumn{7}{c}{ Middle AFQT Tertile } & \multicolumn{1}{c}{ Highest AFQT Tertile } \\
\cline { 2 - 10 } Variable: & Coefficient & Std. Err. & $t$-stat & Coefficient & Std. Err. $t$-stat & Coefficient Std. Err. $t$-stat \\
q1-q4 & -0.164 & 0.211 & -0.780 & 0.038 & 0.154 & 0.240 & 0.148 & 0.132 & 1.130 \\
q2-q4 & -0.421 & 0.193 & -2.180 & -0.062 & 0.109 & -0.560 & -0.079 & 0.092 & -0.860 \\
q3-q4 & -0.372 & 0.191 & -1.950 & 0.060 & 0.089 & 0.670 & -0.053 & 0.093 & -0.570 \\
Southern Residence at Age 14 & 0.209 & 0.145 & 1.440 & 0.023 & 0.092 & 0.250 & -0.090 & 0.086 & -1.040 \\
Broken Home & 0.023 & 0.185 & 0.120 & 0.117 & 0.119 & 0.980 & -0.242 & 0.095 & -2.540 \\
Urban Residence at Age 14 & -0.180 & 0.152 & -1.190 & 0.142 & 0.096 & 1.480 & 0.009 & 0.080 & 0.110 \\
Mother's Education & 0.056 & 0.030 & 1.860 & 0.022 & 0.024 & 0.930 & 0.025 & 0.020 & 1.280 \\
Father's Education & -0.028 & 0.027 & -1.030 & 0.013 & 0.015 & 0.870 & 0.010 & 0.014 & 0.680 \\
Constant & 0.511 & 0.488 & 1.050 & 0.151 & 0.289 & 0.520 & 0.371 & 0.258 & 1.440 \\
\hline
\end{tabular}

Panel E - Years of Delay of Entry

Variable: Lowest AFQT Tertile Middle AFQT Tertile Highest AFQT Tertile

q1-q4 Coefficient Std. Err. $t$-stat Coefficient Std. Err. $t$-stat Coefficient Std. Err. $t$-stat

$\mathrm{q} 2-\mathrm{q} 4$

$-0.629$

$1.418-0.440$

0.851

$\begin{array}{ll}0.781 & 1.090\end{array}$

0.106

0.5550 .190

q3-q4

1.652

$\begin{array}{ll}1.298 & 1.270\end{array}$

1.258

$\begin{array}{ll}0.554 & 2.270\end{array}$

0.747

$0.386 \quad 1.930$

Southern Residence at Age 14

0.781

$\begin{array}{ll}1.281 & 0.610\end{array}$

0.299

$0.452 \quad 0.660$

0.302

$\begin{array}{ll}0.390 & 0.770\end{array}$

Broken Home

1.158

$\begin{array}{lll}0.976 & -1.600 & -0.403\end{array}$

$\begin{array}{ll}0.467 & -0.860\end{array}$

0.332

$0.364 \quad 0.910$

Urban Residence at Age 14

Mother's Education

$-1.050$

$1.245 \quad 0.930$

$-0.370$

$0.605-0.610$

0.146

$0.401 \quad 0.360$

Father's Education

$-0.363$

$1.019-1.030$

$-0.054$

$0.489-0.110$

$-0.057$

$\begin{array}{ll}0.335 & -0.170\end{array}$

Constant

0.149

$\begin{array}{ll}0.203 & -1.790\end{array}$

$-0.061$

$0.122-0.490$

$-0.157$

$0.084-1.870$

5.242

$3.277 \quad 1.600$

$0.078-0.450$

$-0.022$

$\begin{array}{ll}0.060 & -0.370\end{array}$

Constant

Variable:

q1-q4

$\mathrm{q} 2-\mathrm{q} 4$

$\mathrm{q} 3-\mathrm{q} 4$

Southern Residence at Age 14

Broken Home

Urban Residence at Age 14

Mother's Education

Father's Education

1.847

$1.467 \quad 1.26$

2.776

$1.088 \quad 2.550$

Panel F - Type of School

Lowest AFQT Tertile Middle AFQT Tertile Highest AFQT Tertile

Constant

\begin{tabular}{cccccccccc}
\hline \multicolumn{1}{c}{ Coefficient } & Std. Err. & $t$-stat & Coefficient Std. Err. $t$-stat Coefficient Std. Err. $t$-stat \\
-0.040 & 0.126 & -0.320 & -0.009 & 0.081 & -0.110 & -0.110 & 0.076 & -1.440 \\
-0.219 & 0.112 & -1.950 & -0.045 & 0.066 & -0.680 & -0.117 & 0.061 & -1.920 \\
-0.270 & 0.107 & -2.520 & 0.036 & 0.056 & 0.650 & -0.020 & 0.056 & -0.350 \\
0.044 & 0.089 & 0.490 & -0.057 & 0.055 & -1.030 & 0.014 & 0.052 & 0.260 \\
0.103 & 0.104 & 0.990 & -0.012 & 0.073 & -0.170 & -0.019 & 0.065 & -0.290 \\
0.128 & 0.096 & 1.330 & -0.055 & 0.057 & -0.960 & -0.045 & 0.052 & -0.850 \\
-0.014 & 0.020 & -0.700 & 0.027 & 0.012 & 2.210 & 0.025 & 0.011 & 2.170 \\
-0.007 & 0.015 & -0.480 & 0.013 & 0.009 & 1.550 & 0.013 & 0.009 & 1.540 \\
0.963 & 0.301 & 3.200 & 0.298 & 0.157 & 1.900 & 0.340 & 0.147 & 2.320 \\
\hline
\end{tabular}


Table B-4

Coefficients for the Construction of the Family Background Index

Regression of College Enrollment on Southern and Urban Origin, BrokenHome, and Parental Education, White Males, NLSY79

\begin{tabular}{lcc}
\hline Variable: & Coefficient & Std. Err. \\
Southern Origin & 0.0266 & 0.0233 \\
Broken Home & -0.0544 & 0.0270 \\
Urban Origin & 0.0603 & 0.0235 \\
Mother's Education & 0.0310 & 0.0054 \\
Father's Education & 0.0400 & 0.0033 \\
AFQT & 0.0046 & 0.0006 \\
Constant & -0.6814 & 0.0538 \\
\hline \hline
\end{tabular}

